Universidade de São Paulo Instituto de Física

\title{
Propriedades magnéticas de filmes nanoestruturados de FeRh e FeRh/Fe
}

Gerson de Carli Proença de Almeida Pessotto

Orientador: Prof. Dr. Daniel Reinaldo Cornejo

Dissertação de mestrado apresentada ao Instituto de Física para a obtenção do título de Mestre em Ciências

Banca examinadora:

Prof. Dr. Daniel Reinaldo Cornejo (Orientador - IF - USP)

Prof. Dr. Sérgio Luiz Morelhão (IF - USP)

Prof. . Dr. a Fanny Berón (IFGW - UNICAMP) 
FICHA CATALOGRÁFICA

Preparada pelo Serviço de Biblioteca e Informação do Instituto de Física da Universidade de São Paulo

Pessotto, Gerson de Carli Proença de Almeida

Propriedades magnéticas de filmes nanoestruturados de FeRh e FeRh/Fe. São Paulo, 2014.

Dissertação (Mestrado) - Universidade de São Paulo. Instituto de Física. Depto. de Física dos Materiais e Mecânica.

Orientador: Prof. Dr. Daniel Reinaldo Cornejo

Área de Concentração: Física

Unitermos: 1. Magnetismo; 2. Física do estado sólido; 3. Materiais magnéticos; 4. Filmes finos.

USP/IF/SBI-055/2014 
Aos meus professores Gerson (pai), Celeste (mãe) e Karen (esposa)

Ao meu colega de classe Renan (irmão) 


\section{Agradecimentos}

Ao meu orientador, prof. Dr. Daniel Reinaldo Cornejo, por todo tempo dedicado sendo orientador, com seus ensinamentos, conversas e questionamentos. Por ter se tornado mais que um orientador, mas um amigo.

Aos meus pais, Gerson e Celeste, pelo apoio de uma vida inteira. Por serem meus espelhos e por mostrarem que a vida pode dar voltas, mas que sempre devo estar de cabeça erguida e seguir um passo de cada vez, pois saberei que sempre terei em quem me apoiar.

À minha esposa, Karen, pelo apoio dado diariamente e pelas horas de companhia que me fez no laboratório. Por ser minha inspiração diária.

Ao meu amigo Hardeep, por ser, em muitos momentos, um co-orientador, pelas conversas e ensinamentos, tanto acadêmicas como pessoais.

Ao meu amigo Karel, por todas as conversas, discussões e algumas conclusões.

Aos professores, Carmen, Luiz e Toninho, e aos colegas do LMM pelo acoIhimento que me deram no grupo e pela agradável convivência.

Aos técnicos do LMM, especialmente Renato e Sérgio, pela agradável companhia diária e pelos inúmeros cafés matinais, além de todas as aulas informais, nas quais transmitiram a experiência de anos de trabalho dentro de nossos laboratórios.

Ao laboratório de cristalografia do IF - USP, profㄹ. Márcia C. A. Fantini e prof. Sérgio L. Morelhão e os técnicos Antônio Carlos e Tarsis, por todas as medidas de XRD feitas em minhas amostras.

Ao pessoal do LAMFI pelas medidas de RBS feitas em minhas amostras e por todas as conversas e aulas informais sobre análise de dados.

À CNPq, CAPES e FAPESP, pelo apoio financeiro. 
O significado das crises consiste exatamente no fato de que indicam que é chegada a ocasião para renovar os instrumentos.

(Thomas S. Kufn) 


\section{Resumo}

As ligas de FeRh apresentam um comportamento não usual quando encontradas próximas da composição equiatômica, sendo observada uma transição de fase magnetoestrutural de primeira ordem, na qual o sistema passa de um estado antiferromagnético para um estado ferromagnético com a temperatura crítica próxima da temperatura ambiente. A temperatura crítica de transição é fortemente dependente da composição da liga, das técnicas de produção e dimensionalidade da amostra, além de fatores externos como pressão e campo magnético.

No presente trabalho foram depositados, via magnetron sputtering, filmes de FeRh (monocamadas) e FeRh/Fe (bicamadas) sobre substratos monocristalinos de $\mathrm{MgO}$ (001), sendo utilizado duas temperaturas de deposição diferentes: $798 \mathrm{~K}$ e 913 K. A estrutura cristalina dos filmes foi analisada através de técnicas de medidas de difração de raios $X$ (varredura $\theta-2 \theta$, varredura em $\phi$ e rocking curves) e as composições e espessuras dos filmes foram analisadas por medidas de RBS. A principal diferença morfológica encontrada entre as amostras foi uma melhor uniformidade na distribuição de orientações dos grãos cristalinos nos filmes depositados na temperatura mais elevada.

As propriedades magnéticas, medidas por meio de um VSM equipado com um criostato e um forno, evidenciaram diferenças entre as amostras depositadas nas diferentes temperaturas mencionadas, observando-se variações significativas nas temperaturas de transição de fase e diferentes larguras dos ciclos térmicos. Também foi observado, em todas as amostras, coexistência de fases antiferromagnética e ferromagnética na camada de FeRh, principalmente na região de baixas temperaturas. As amostras depositadas em $798 \mathrm{~K}$ foram mais favoráveis à formação da fase FeRh antiferromagnética e, no caso das bicamadas, também apresentaram um meIhor acoplamento entre as camadas de FeRh e Fe que as amostras depositadas em $913 \mathrm{~K}$, favorecendo um incremento do campo coercivo e da magnetização remanente relativa do sistema. 


\section{Abstract}

FeRh alloys, near the equiatomic composition, present an unusual magneto structural first-order phase transition in which the system changes from antiferromagnetic to ferromagnetic state at a critical temperature close to ambient temperature. The critical transition temperature is strongly dependent on the alloy composition, production techniques and dimensionality of the sample, as well as external factors such as pressure and magnetic field.

In the present work, FeRh (monolayers) and FeRh/Fe (bilayers) films were deposited on monocrystalline $\mathrm{MgO}$ (001) substrates, via magnetron sputtering, at two different deposition temperatures: $798 \mathrm{~K}$ and $913 \mathrm{~K}$. The crystalline structures of the films were analyzed by using different techniques of X-ray diffraction $(\theta-2 \theta$ scan, $\phi$ scan and rocking curves). The compositions and thicknesses of the films were analyzed by RBS measurements. The main morphological difference between the samples was a better uniformity in the distribution of crystalline grain orientations in the films deposited at higher temperature.

The magnetic properties, which were measured by a VSM equipped with a cryostat and an oven, revealed differences between the samples obtained at different temperatures. Significant variations in the critical phase transition temperatures and different widths of thermal cycles were observed. It was also observed, in all samples, coexistence of antiferromagnetic and ferromagnetic phases in the FeRh layer, mainly at low temperatures. The samples deposited at $798 \mathrm{~K}$ were more favorable to the formation of the antiferromagnetic FeRh phase. In addition, for the bilayers deposited at $798 \mathrm{~K}$, it was observed a better coupling between the FeRh and Fe layers in comparison to samples deposited at $913 \mathrm{~K}$, favoring an increase in the coercive field and the remanence magnetization. 


\section{Sumário}

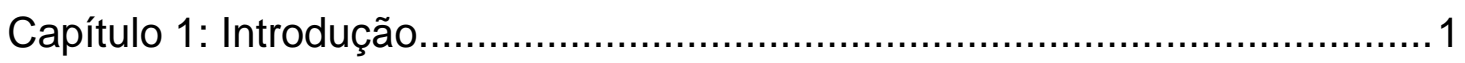

1.1 Ferromagnetismo e Antiferromagnetismo …………...........................

1.2 Transições de Fase de Primeira Ordem ................................................

1.3 Acoplamentos magnéticos entre materiais antiferromagnéticos e

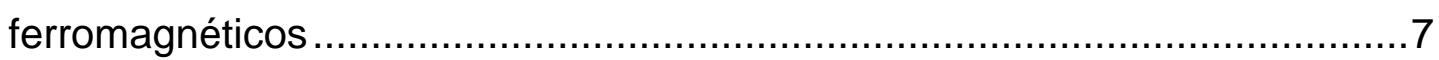

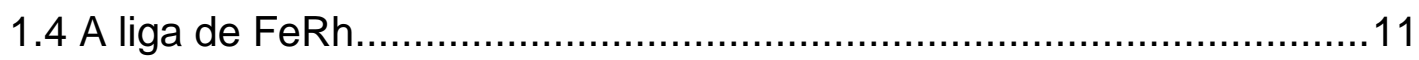

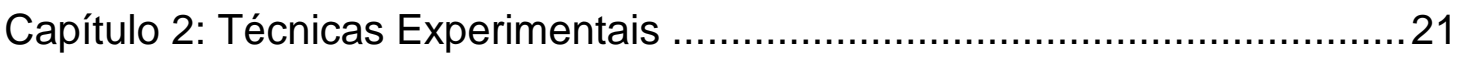

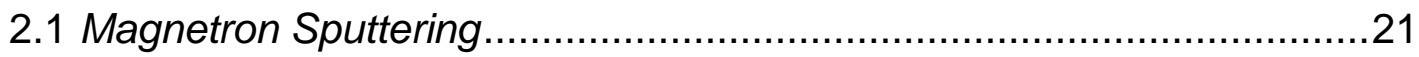

2.2 Espectroscopia de Retroespalhamento Rutherford..............................25

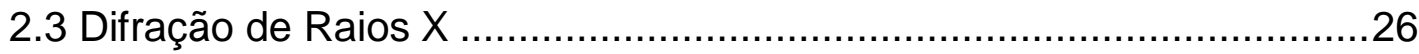

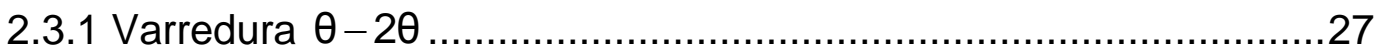

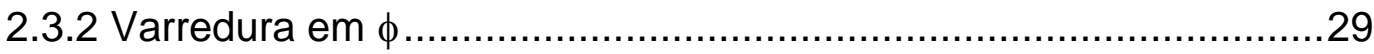

2.3.3 Rocking Curves ....................................................................

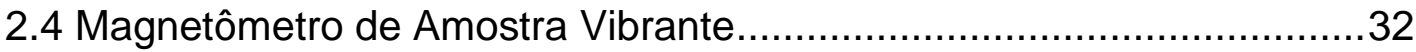

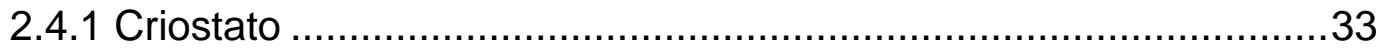

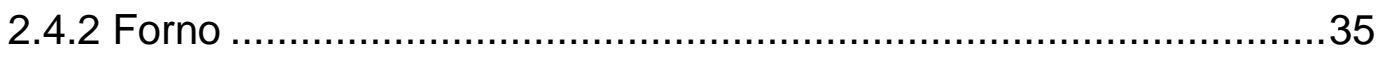

Capítulo 3: Produção e Caracterização Estrutural das Amostras ......................37

3.1 Obtenção das Amostras via Magnetron Sputtering ................................37

3.2 Resultados da Espectroscopia de Retroespalhamento Rutherford ........39

3.3 Resultados da Difração de Raios X.................................................. 41

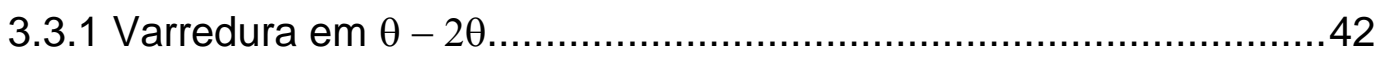

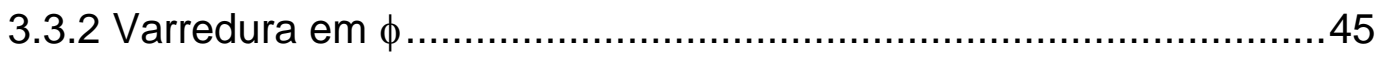

3.3.3 Resultados das Medidas do tipo Rocking Curves...........................47

3.3.4 Considerações sobre a microestrutura das amostras......................49

Capítulo 4: Caracterização Magnética das Amostras .....................................50 
4.1 Estudo dos Ciclos Térmicos das Amostras ......................................50

4.1.1 Amostras monocamadas .................................................52

4.1.2 Amostras bicamadas .......................................................... 56

4.1.3 Campo perpendicular ....................................................6 60

4.2 Análise dos Ciclos de Histerese das Amostras ................................61

4.2.1 Amostras Monocamadas de Fe .........................................62

4.2.2 Histereses em Função da Temperatura ....................................64

4.2.2.1 Amostras monocamadas................................................... 64

4.2.2.2 Amostras bicamadas ................................................... 80

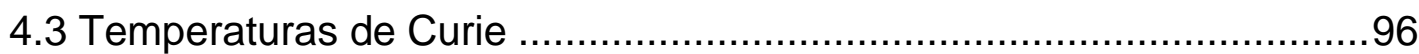

Capítulo 5: Discussões e Conclusões .......................................................98

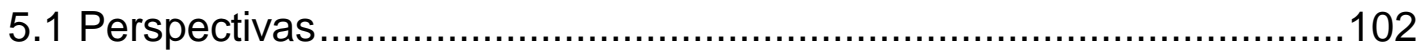




\section{Lista de Figuras}

Figura 1-1. Ordenamento ferromagnético dos momentos magnéticos. .3

Figura 1-2. Curva típica de uma medida de magnetização em função do campo magnético aplicado para um material ferromagnético. 3

Figura 1-3. Ordenamento antiferromagnético dos momentos magnéticos. ......4

Figura 1-4. (a) Descontinuidade da magnetização em função da temperatura. (b) Histerese térmica.

Figura 1-5. Diagramas de fase $\mathrm{H}$ vs $\mathrm{T}$ hipotéticos para as transições de fase de primeira ordem para um sólido magnético no (a) aquecimento e (b) resfriamento, sendo mostrada a região metaestável onde ocorre coexistência de fases. 6

Figura 1-6. Imagem representativa do deslocamento da histerese devido ao efeito de exchange-bias.

Figura 1-7. Rotação coerente da magnetização da camada ferromagnética devido à aplicação de um campo magnético $\mathrm{H}$.

Figura 1-8. Histereses feitas para um filme de $\mathrm{IrMn} / \mathrm{NiCu}$. No topo são apresentados histereses para diferentes temperaturas de tratamentos térmicos feitos no filme após a deposição. No meio e no último são apresentadas histereses de filmes que foram irradiados por $\mathrm{He}^{+}$e $\mathrm{Ge}^{+}$, respectivamente, com diferentes intensidades de feixe. Tirada de [11].

Figura 1-9. Diagrama de fases da liga binária de $\mathrm{Fe}_{1-x} \mathrm{Rh}_{\mathrm{x}}$ (Adaptado da ref. [17]). Em evidência, quadrado vermelho, se encontra a região de fase antiferromagnético da liga. 12

Figura 1-10. Histereses térmicas da magnetização com diferentes valores de campo magnético aplicados. Tirada de [20].

Figura 1-11. Comparação entre transições de fase magnética obtidas para liga $\mathrm{Fe}_{48} \mathrm{Rh}_{52}$ tipo bulk (linha tracejada) e para a liga $\mathrm{Fe}_{47} \mathrm{Rh}_{53}$ em forma de filme fino (linha contínua). Tirada de [21].

Figura 1-12. Transições de fase para a liga $\mathrm{Fe}_{47,8} \mathrm{Rh}_{52,2} \mathrm{em}$ forma de filme fino, sendo uma do filme com o substrato (círculos preenchidos) e do filme retirado do substrato (círculos vazios). Tirada de [20]. 
Figura 1-13. Histereses feitas ao longo da transição AFM $\rightarrow$ FM para um filme de $\mathrm{Fe}_{49} \mathrm{Rh}_{51}$ tratado a $973 \mathrm{~K}$. No gráfico interno é apresentada a magnetização em função da temperatura. Tirada de [31]. .16

Figura 1-14. Histereses feitas durante a transição AFM $\rightarrow$ FM para a liga $\mathrm{Fe}_{49} \mathrm{Rh}_{51}$ em forma de filme fino. Tirada de [24]...

Figura 1-15. Magnetização em função da temperatura feita a campo constante de $1 \mathrm{kOe}$ para a liga $\mathrm{Fe}_{48} \mathrm{Rh}_{52}$ em forma de filme fino. Tirada de [32]..... .18

Figura 1-16. Esquema dos momentos magnéticos dos átomos de Fe e Rh em uma célula unitária nas fases AFM e FM.

Figura 1-17. Histereses feitas para bicamadas Fe/FeRh-Ir com diferentes espessuras da camada de Fe (20 nm e $3 \mathrm{~nm})$. Tirada de [34]. 19

Figura 2-1. Esquema simplificado do confinamento do plasma num sistema do tipo magnetron sputtering. 22

Figura 2-2. Porta substrato utilizado para deposições via sputtering. .23

Figura 2-3. Visão geral do sistema de magnetron sputtering e detalhes dos instrumentos.

Figura 2-4. Ângulos de incidência e espalhamento na configuração de medida $\theta-2 \theta$. .28

Figura 2-5. Plano (211) em uma rede cúbica. Em (a) encontra-se o plano na célula unitária e em (b) os três principais átomos da rede que forma este plano......29

Figura 2-6. Rotação em $\alpha$ nos ângulos de incidência e espalhamento utilizados na varredura em $\phi$. 30

Figura 2-7. Ângulos de incidência e espalhamento na configuração Rocking Curve. 31

Figura 2-8. Montagem do VSM com o criostato, tanque de $\mathrm{Ni}_{2}$ e o transferidor. 34

Figura 2-9. Variação da temperatura ao longo do tempo para a medida de ZFC - FC, junto da variação de temperatura por minuto e a porcentagem do aquecedor utilizada.

Figura 2-10. Sinal magnético apresentada pela haste de quartzo mais a massa para fixação da amostra inseridos no forno. 36

Figura 3-1. Espectro de RBS experimental da amostra 1A (pontos vermelhos) e ajuste feito pelo programa SIMNRA (linha contínua). 
Figura 3-2. Imagem representativa da estrutura cristalina tipo $\mathrm{CsCl}$. .42

Figura 3-3. Difratograma de difração de raios $X$, na geometria $\theta-2 \theta$, para as amostras deste estudo: (a) Grupo 1 e (b) Grupo 2 43

Figura 3-4. Picos de espalhamento do plano (001) e seus respectivos valores de largura a meia altura (FWHM) dado em radianos. Em (a) amostras $1 \mathrm{~A}$ e $2 \mathrm{~A}$ (bicamadas) e em (b) amostras 1B e 2B (monocamadas). 45

Figura 3-5. Representação esquemática das células de FeRh e MgO; (a) Vista de cima (sem os átomos de O e Rh); (b) Vista lateral; (c) Vista dos três eixos. 46

Figura 3-6. Diagonal de um quadrado de meio parâmetro de rede. .46

Figura 3-7. Difratograma de raios $X$ para a amostra $2 A$ na varredura em $\phi . . .47$

Figura 3-8 Rocking curve do plano (002) para as amostras 1A e 2A. 48

Figura 4-1. Curvas ZFC - FC medidas para as amostras 1B e 2B com campo aplicado de (a) 100 Oe e (b) $10 \mathrm{kOe}$.

Figura 4-2. (a) Ciclo térmico observado para liga $\mathrm{Fe}_{0,955} \mathrm{Ni}_{0,045} \mathrm{Rh}$. No gráfico interno é dado evidência ao primeiro ciclo (ZFC - FCC) e a região reversível (FCC FCW) obtida após ao primeiro ciclo [48] (b) Ciclos térmicos observados para liga $\mathrm{Fe}_{47} \mathrm{Rh}_{53}$ feitos com diferentes valores de campo magnético aplicado. Tiradas de [49]. .53

Figura 4-3. Curvas ZFC - FC medidas para as amostras $1 \mathrm{~A}$ e $2 \mathrm{~A}$ com campo aplicado de (a) $100 \mathrm{Oe} \mathrm{e} \mathrm{(b)} 10 \mathrm{kOe}$. 59

Figura 4-4. Transições de fase magnética medidas para as amostras (a) monocamadas de FeRh e (b) bicamadas. As transições foram feitas a campo constante de $10 \mathrm{kOe}$ aplicado perpendicularmente ao plano do filme.

Figura 4-5. Curvas de histerese feitas em temperatura ambiente para as amostras (a) 1C e (b) 2C, ambas monocamadas de Fe. 63

Figura 4-6. Curvas de aquecimento e resfriamento para as amostras (a) 1B e (b) 2B, utilizadas como referência para a escolha das temperaturas a serem feitas as histereses. Aquecimento feito a campo nulo e resfriamento a $11 \mathrm{kOe}$.

Figura 4-7. Histereses feitas na fase AFM da amostra 1B. Medidas feitas em $80 \mathrm{~K}$. (a) Amostra virgem e (b) após primeiro ciclo térmico. .67

Figura 4-8. Histereses feitas na fase AFM da amostra 2B. Medidas feitas em 325 K. (a) Amostra virgem e (b) após primeiro ciclo térmico 68 
Figura 4-9. Amostra 1B: Histereses medidas na transição AFM $\rightarrow$ FM (aquecimento) e FM $\rightarrow$ AFM (resfriamento), sendo (a) e (b) baixas temperaturas, (c) e (d) temperaturas de transição e (e) e (f) altas temperaturas.

Figura 4-10. Amostra 1B: (a) Momentos magnéticos remanentes e (b) razão entre o momento magnético remanente e o momento magnético máximo. .73

Figura 4-11. Amostra 1B: (a) Campos coercivos e (b) campos de exchangebias. .74

Figura 4-12. Amostra 2B: Histereses medidas na transição AFM $\rightarrow$ FM (aquecimento) e FM $\rightarrow$ AFM (resfriamento), sendo (a) e (b) baixas temperaturas, (c) e (d) temperaturas de transição e (e) e (f) altas temperaturas. 76

Figura 4-13. Amostra 2B: (a) Momentos magnéticos remanentes e (b) razão entre o momento magnético remanente e o momento magnético máximo. .77

Figura 4-14. Amostra 2B: (a) Campos coercivos e (b) campos de exchangebias. .78

Figura 4-15. Histereses feitas na fase AFM da amostra 1A. Medidas feitas em 80 K. (a) Amostra virgem e (b) após primeiro ciclo térmico.

Figura 4-16. Histereses feitas na fase AFM da amostra 2A. Medidas feitas em 325 K. (a) Amostra virgem e (b) após primeiro ciclo térmico. 83

Figura 4-17. Curvas de aquecimento e resfriamento para as amostras (a) 1A e (b) $2 \mathrm{~A}$, utilizadas como referência para a escolha das temperaturas a serem feitas as histereses. Aquecimento feito a campo nulo e resfriamento a $11 \mathrm{kOe}$. .85

Figura 4-18. Amostra 1A: Histereses medidas na transição AFM $\rightarrow F M$ (aquecimento) e FM $\rightarrow$ AFM (resfriamento), sendo (a) e (b) baixas temperaturas, (c) e (d) temperaturas de transição e (e) e (f) altas temperaturas. .88

Figura 4-19. Amostra 1A: (a) Momentos magnéticos remanentes e (b) razão entre o momento magnético remanente e o momento magnético máximo. .89

Figura 4-20. Amostra 1A: (a) Campos coercivos e (b) campos de exchangebias.

Figura 4-21. Amostra 2A: Histereses medidas na transição AFM $\rightarrow F M$ (aquecimento) e FM $\rightarrow$ AFM (resfriamento), sendo (a) e (b) baixas temperaturas, (c) e (d) temperaturas de transição e (e) e (f) altas temperaturas.

Figura 4-22. Amostra 2A: (a) Momentos magnéticos remanentes e (b) razão entre o momento magnético remanente e o momento magnético máximo. 
Figura 4-23. Amostra 2A: (a) Campos coercivos e (b) campos de exchange-

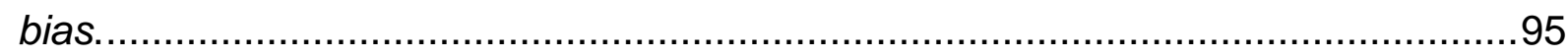

Figura 4-24. Gráfico de M vs T para a obtenção da Temperatura de Curie das

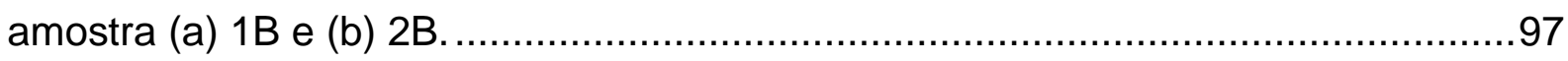




\section{Lista de Tabelas}

Tabela 3-1. Espessuras das camadas e composição da camada de FeRh para cada amostra.

Tabela 3-2. Parâmetros de rede calculados para as nossas amostras. Os valores para as amostras massivas são colocados para fins de comparação. 44

Tabela 3-3. Diâmetro médio dos grãos cristalinos do plano (001) da liga de FeRh.

Tabela 3-4. Largura mosaico dos planos (002) da camada de FeRh para as amostras $1 \mathrm{~A}$ e $2 \mathrm{~A}$. 48

Tabela 4-1. Temperaturas críticas de transição nas transições de fase AFM $\rightarrow$ $\mathrm{FM}$ e $\mathrm{FM} \rightarrow \mathrm{AFM}$ com suas respectivas larguras para as amostras 1B e $2 \mathrm{~B}$. .54

Tabela 4-2. Temperaturas críticas de transição nas transições $A F M \rightarrow F M$ e $\mathrm{FM} \rightarrow \mathrm{AFM}$ com suas respectivas larguras de transição. Ambas para as amostras $1 \mathrm{~A}$ e $2 \mathrm{~A}$. .58

Tabela 4-3. Temperaturas utilizadas para as medidas de momento magnético versus campo das amostras $1 \mathrm{~B}$ e $2 \mathrm{~B}$.

Tabela 4-4. Temperaturas utilizadas para as curvas de momento magnético versus campo das amostras $1 \mathrm{~A}$ e $2 \mathrm{~A}$. .86 


\section{Lista de Abreviações}

$\begin{array}{cl}\text { AFM } & \text { Antiferromagnético } \\ \text { bcc } & \text { Cúbica de Corpo Centrado } \\ \text { CPS } & \text { Contagens por Segundo } \\ \text { DC } & \text { Corrente Direta } \\ \text { FC } & \text { Field Cooling } \\ \text { FM } & \text { Ferromagnético } \\ \text { FWHM } & \text { Full Width at Half Maximum } \\ \text { GMR } & \text { Magnetorresistência Gigante } \\ \text { LAMFI } & \text { Laboratório de Análises de Materiais por Feixes lônicos } \\ \text { LMM } & \text { Laboratório de Materiais Magnéticos } \\ \text { PDF } & \text { Powder Diffraction File } \\ \text { PID } & \text { Proporcional, Integral e Derivativo } \\ \text { RBS } & \text { Espectroscopia de Retroespalhamento Rutherford } \\ \text { RF } & \text { Rádio Frequência } \\ \text { TAMR } & \text { Gravação Magnética Termicamente Assistida } \\ \text { TFPO } & \text { Transição de Fase de Primeira Ordem } \\ \text { VSM } & \text { Magnetômetro de Amostra Vibrante } \\ \text { XRD } & \text { Difração de Raios X } \\ \text { ZFC } & \text { Zero Field Cooling }\end{array}$




\section{Capítulo 1: Introdução}

No mundo contemporâneo palavras como inovação, sustentabilidade e globalização estão na moda, mas elas não estão apenas em nosso vocabulário, estando também à frente de desenvolvimentos tecnológicos, negociações internacionais e relações políticas. No mundo da ciência também não ficamos de fora de certo modismo e podemos dizer, por exemplo, que os substantivos "nanociência" e "nanotecnologia" estão entre estas palavras.

A capacidade de controlarmos a produção de dispositivos na escala nanométrica abriu um novo mundo para a ciência de materiais, surgindo fenômenos, muitas vezes, inesperados e surpreendentes. No caso do magnetismo a descoberta da magnetorresistência gigante (GMR) gerou o desenvolvimento das atuais cabeças de leitura e gravação dos discos rígidos, gerando um aumento enorme na quantidade de informação armazenada digitalmente, contribuindo diretamente para o avanço e popularização da tecnologia. Não podemos esquecer que esta descoberta foi feita simultaneamente pelos físicos Albert Fert e Peter Grünber, os quais foram premiados com o Nobel de Física no ano de 2007.

$\mathrm{Na}$ nanociência os materiais estudados podem ser apresentados basicamente em três grandes grupos de acordo com seus constituintes básicos: materiais formados por nanopartículas, materiais formados por nanofios e materiais na forma de filmes nanoestruturados. Em particular, do ponto de vista magnético, os resultados apresentados por estes grupos diferem, muitas vezes, entre eles e raramente apresentam resultados iguais ao material tipo bulk ${ }^{1}$, havendo, muitas vezes, uma necessidade de rever modelos e teorias, uma vez que a escala nanométrica representa uma região de transição entre fenômenos que se encontram nos domínios da física clássica e aqueles que se encontram nos domínios quânticos. Desta forma, as explicações teóricas dos fenômenos devem estar diretamente relacionadas com princípios físicos mais básicos, vindos do limite quântico.

Nesta perspectiva, o nosso estudo foi voltado para filmes finos nanoestruturados baseados na liga FeRh. Esta liga apresenta um comportamento inusual em suas

\footnotetext{
${ }^{1}$ Refere-se às amostras massivas.
} 
propriedades magnéticas, mudando de um estado antiferromagnético para um estado ferromagnético quando, por exemplo, aquecida, ocorrendo esta mudança próxima à temperatura ambiente. Porém este comportamento é fortemente dependente da composição, métodos de produção e da dimensionalidade da liga (filmes, amostra massiva, nanopartículas, etc.). Ciente destas dependências nosso estudo faz uma comparação entre o efeito de duas temperaturas diferentes de deposição e tratamento térmico nas características estruturais e nas propriedades magnéticas da liga de FeRh, quando esta se encontra próxima da composição equiatômica. Também foram estudados filmes finos compostos por uma camada de FeRh, sendo esta também depositada em duas temperaturas diferentes, e por uma camada de Fe, onde estudamos os efeitos do acoplamento entre as ambas as camadas.

\subsection{Ferromagnetismo e Antiferromagnetismo}

Os materiais ferromagnéticos (FM) podem apresentar uma magnetização não nula mesmo quando não estão inseridos num campo magnético. Esta qualidade permitiu o desenvolvimento de novas tecnologias e aplicações, sendo hoje amplamente utilizados, como, por exemplo, em motores elétricos e no armazenamento de dados digitais.

A magnetização resultante diferente de zero se dá devido aos momentos magnéticos, existentes no material, adotarem uma direção preferencial gerando uma magnetização resultante não nula. Quando o material se encontra em $T=0 \mathrm{~K}$, todos os momentos magnéticos encontram-se paralelos, ver Figura 1-1. Nesta condição a magnetização do material é máxima. Com o incremento da temperatura, os momentos magnéticos passam a adquirir energia térmica, gerando uma agitação dos mesmos e, consequentemente, uma diminuição da magnetização. Ao se continuar a incrementar a temperatura pode-se chegar numa temperatura crítica $T_{C}$ onde a magnetização é nula (sistema desmagnetizado), sendo $T_{C}$ chamada de temperatura de Curie $^{2}$.

\footnotetext{
${ }^{2}$ Pierre Curie
} 


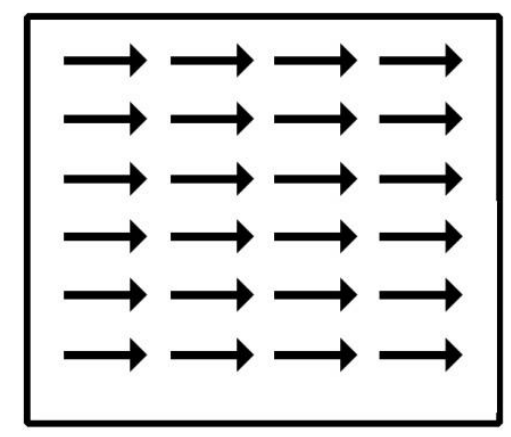

Figura 1-1. Ordenamento ferromagnético dos momentos magnéticos.

Ao medirmos a magnetização em função do campo magnético aplicado se obtém um ciclo característico, como o apresentado na Figura 1-2, sendo esta curva denominada histerese. Nela são nomeadas algumas regiões, sendo o campo necessário para desmagnetizar o material chamado de campo coercivo $\left(H_{c}\right)$, a magnetização resultante quando o campo aplicado é nulo é chamada de magnetização remanente $\left(M_{R}\right)$ e a magnetização máxima obtida de magnetização de saturação $\left(M_{S}\right)$.

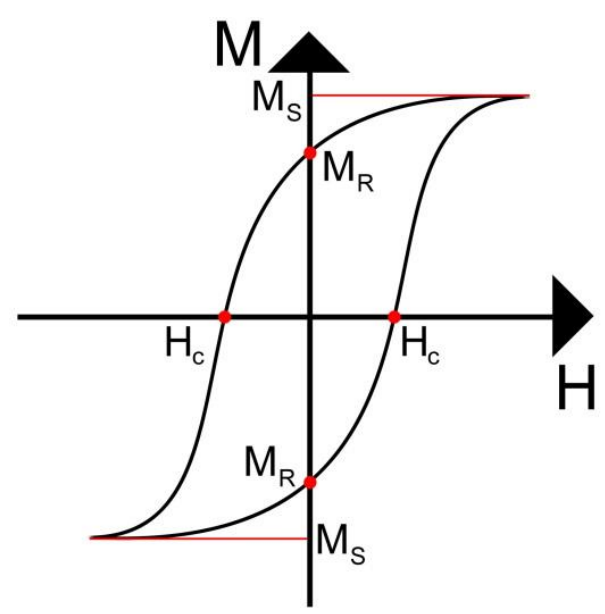

Figura 1-2. Curva típica de uma medida de magnetização em função do campo magnético aplicado para um material ferromagnético.

Os materiais antiferromagnéticos (AFM) apresentam um ordenamento que pode ser entendido como uma junção de dois ordenamentos ferromagnéticos, porém orientados em sentidos opostos. Tal junção pode ser observada na Figura 1-3, onde os momentos magnéticos de cor vermelha fazem parte de um ordenamento enquanto os de cor azul de outro. Da mesma forma que no ferromagnetismo, os momentos 
magnéticos encontram-se paralelos quando $\mathrm{T}=0 \mathrm{~K}$, ganhando energia térmica com o incremento da temperatura. Numa dada temperatura crítica $T_{N}$ os momentos magnéticos encontram-se totalmente desalinhados, sendo esta temperatura denominada temperatura de $\mathrm{Néel}^{3}$.

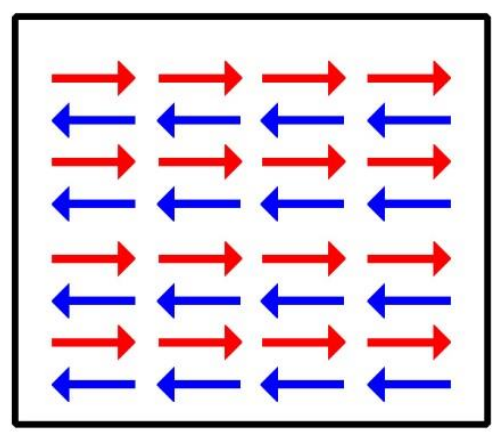

Figura 1-3. Ordenamento antiferromagnético dos momentos magnéticos.

\subsection{Transições de Fase de Primeira Ordem}

As transições de fase de primeira ordem (TFPO) são muito comuns na natureza, sendo um grande exemplo as transições de fase da água. Estas transições são caracterizadas por uma descontinuidade na primeira derivada da energia livre com relação à variação de algum parâmetro que cause a transição (ex.: pressão, temperatura, campo magnético, etc.). O calor latente está diretamente relacionado às TFPO, sendo o surgimento deste numa transição a confirmação de se tratar de uma TFPO.

Transições de fase de primeira ordem envolvendo somente fases sólidas são potencialmente interessantes para aplicações tecnológicas. Isto, sem dúvida, é um forte estímulo para desenvolver pesquisa teórica e experimental em materiais que apresentam TFPO. Em particular, sólidos magnéticos caracterizados por uma TFPO podem mostrar nesta transição mudanças de ordenamentos de spin, além da mu-

\footnotetext{
${ }^{3}$ Louis E. F. Néel
} 
dança estrutural, o que Ihes confere propriedades ainda mais atraentes. Este é, por exemplo, o caso da liga de FeRh e, em geral, as ligas de Heusler [1][2].

Os materiais magnéticos que possuem alguma TFPO apresentam duas características importantes. A primeira é a descontinuidade da magnetização (ver Figura 1-4 (a)), havendo uma mudança abrupta da mesma. A segunda é a presença de histerese térmica na região de temperaturas onde acontece a transição (ver Figura 1-4 (b)) [3]. Estas histereses podem ser explicadas pelo conceito de superaquecimento e sub-resfriamento, onde a amostra entra numa região metaestável com coexistência de fases [3].

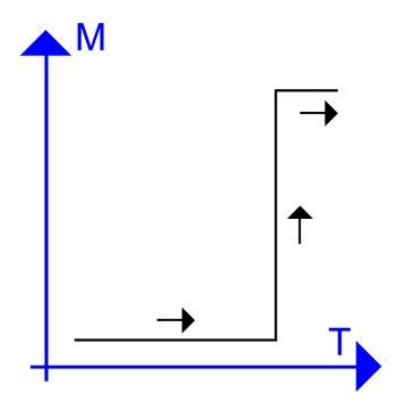

(a)

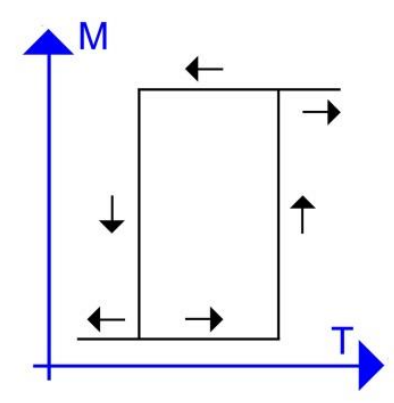

(b) térmica.

Figura 1-4. (a) Descontinuidade da magnetização em função da temperatura. (b) Histerese

O fenômeno de sub-resfriamento é bem conhecido em líquidos, sendo possível resfriar o sistema até uma temperatura abaixo da temperatura de fusão, onde o líquido entra numa região metaestável, chamada de estado sub-resfriado, o qual pode ser mantido apenas com flutuações infinitesimais da energia, sendo este estado limitado por uma segunda temperatura $T^{\star}$ menor que a temperatura de fusão. Estes estados metaestáveis também ocorrem no aquecimento, o que origina o estado superaquecido, o qual é análogo ao sub-resfriamento. Neste caso, uma fase metaestável superaquecida somente pode ser mantida até uma temperatura crítica $T^{* *}$. No caso de sólidos magnéticos é frequente observar que a temperatura crítica onde ocorre a TFPO pode ser alterada pela aplicação de campo magnético $\mathrm{H}$, o que deixa em evidência uma possível correlação entre os graus de liberdade da rede e os graus de liberdade de spin. Nestes casos, as regiões de metaestabilidade estão caracterizadas por temperaturas críticas $T^{*}$ e $T^{* *}$ dependentes do campo, como é mos- 
trado na Figura 1-5. Nesta figura mostra-se um hipotético diagrama de fases $\mathrm{H}$ vs $\mathrm{T}$ para um sólido magnético que experimenta uma TFPO [3].

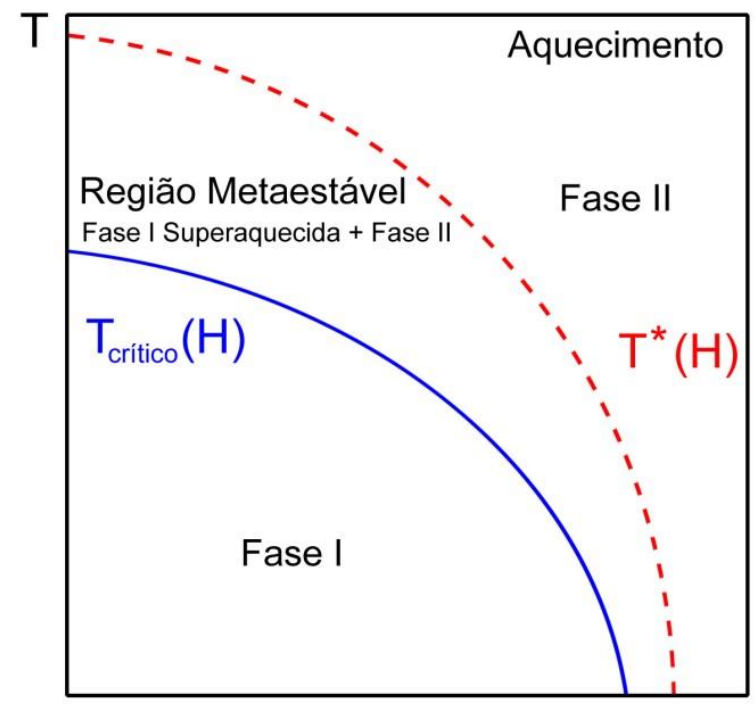

(a)

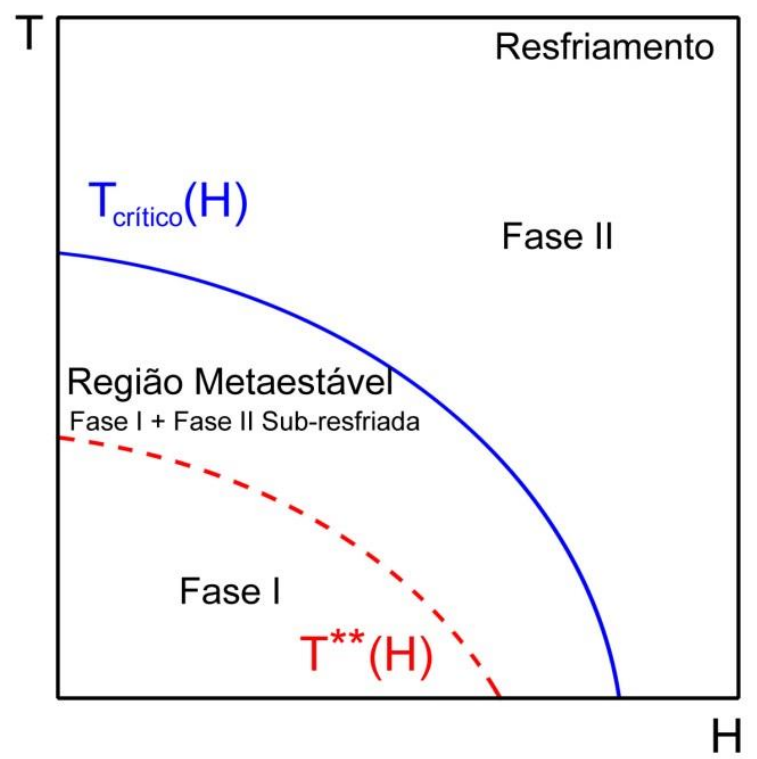

(b)

Figura 1-5. Diagramas de fase $\mathrm{H}$ vs $\mathrm{T}$ hipotéticos para as transições de fase de primeira ordem para um sólido magnético no (a) aquecimento e (b) resfriamento, sendo mostrada a região metaestável onde ocorre coexistência de fases.

No caso da liga de FeRh a transição de fase de primeira ordem ocorre simultaneamente na magnetização e na rede cristalina, sendo nomeada de magnetoestrutural. Para que tal transição ocorra é necessário que exista um acoplamento entre os graus de liberdade dos spins e da estrutura cristalina do sólido, levando a existência de um termo de acoplamento na energia livre do sistema, onde, neste caso, a energia livre de Gibbs $^{4}$ total $\mathrm{G}$ do sistema pode ser expressada como

$$
G_{\text {Total }}(T, H)=G_{\text {Spin }}(T, H)+G_{\text {Rede }}(T, H)+G_{\text {Spin-Rede }}(T, H)
$$

onde o termo $\mathrm{G}_{\text {Spin-Rede }}(\mathrm{T}, \mathrm{H})$ é o termo de acoplamento [4].

${ }^{4}$ Josiah Willard Gibbs 


\subsection{Acoplamentos magnéticos entre materiais antiferromagnéticos e ferro- magnéticos}

Materiais ferromagnéticos (FM) como o Fe exibem energia de troca intensas, porém costumam apresentar baixa anisotropia, sobretudo quando se tratam de fases cúbicas. Muitos materiais antiferromagnéticos (AFM), por outro lado, apresentam alta anisotropia e, consequentemente, grande estabilidade de orientação. Desta forma, numa heteroestrutura AFM/FM, o acoplamento de troca pode gerar um material com características FM, mas com maior estabilidade.

No ano de 1956, Meiklejohn e Bean, se depararam com um comportamento magnético inusual em partículas de Co (FM) recobertas por uma fina casca de $\mathrm{CoO}$ (AFM) [5]. O ciclo de histerese desta heteroestrutura se encontrava deslocado ao longo do eixo do campo magnético, como mostrado na Figura 1-6. Este fenômeno, posteriormente chamado de exchange-bias ou anisotropia unidirecional, resulta do acoplamento de troca entre os spins vizinhos na superfícies de contato entre os materiais AFM e FM. Neste caso, o ciclo de histerese passa a ter três valores de campo magnético importantes: os campos coercivos 1 e $2\left(\mathrm{H}_{\mathrm{c} 1}\right.$ e $\left.\mathrm{H}_{\mathrm{c} 2}\right)$ e o campo de exchange-bias $\left(\mathrm{H}_{\mathrm{EB}}\right)$, que é o valor de campo em que o centro da histerese encontrase deslocado.

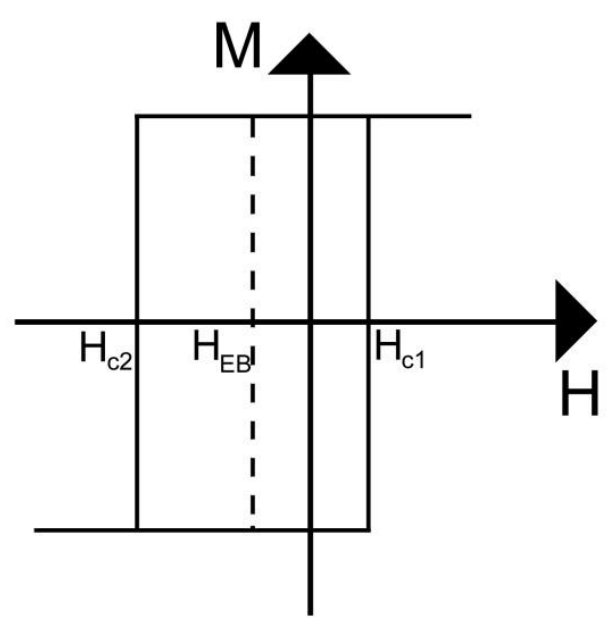

Figura 1-6. Imagem representativa do deslocamento da histerese devido ao efeito de exchange-bias. 
A compreensão detalhada do fenômeno de exchange-bias, assim como suas peculiaridades e a riqueza de fenômenos vinculados, motivou estudos que continuam até hoje [6][7]. Para ter uma ideia básica, mesmo que simplista, de como este fenômeno ocorre, vamos considerar que os materiais se encontram na forma de filmes finos, estando as camadas AFM e FM em contato através de uma interface plana. Vamos supor que inicialmente a temperatura da bicamada está acima da temperatura de Néel do AFM $\left(T_{N}\right)$, então é aplicado um campo magnético de intensidade suficiente para saturar a camada FM, e depois a bicamada é resfriada até uma temperatura de valor menor que $T_{N}$. Finalmente o campo é retirado. Desta forma a bicamada fica no estado magnético mostrado na Figura 1-7 (lado esquerdo), ou seja, a camada FM está em um estado remanente (muito próximo da saturação) e a outra camada apresenta um ordenamento AFM. Foi assumido que o acoplamento entre os spins vizinhos das camadas FM e AFM é ferromagnético. Depois deste passo, pode ser obtido um ciclo de histerese da bicamada. Para isso aplicamos um campo $\mathrm{H}$ desde um valor inicial máximo $\left(\mathrm{H}_{\max }\right)$ próximo àquele usado para saturar a camada FM e realizamos um ciclo entre $\pm H_{\max }$. Para um valor de $H$ dentro dessa faixa a energia por unidade de área do sistema pode ser aproximada como [8]

$$
\varepsilon=-H M_{s} t_{F M} \cos \theta-J \cos \theta+K \sin ^{2} \theta
$$

sendo $M_{s}$ a magnetização de saturação da camada $F M, t_{F M}$ é a espessura da camada FM, J é a constante de troca na interface AFM/FM, K é a constante de anisotropia uniaxial da camada FM e $\theta$ é o ângulo da magnetização da camada FM com relação ao eixo de anisotropia, ver Figura 1-7 (parte central).
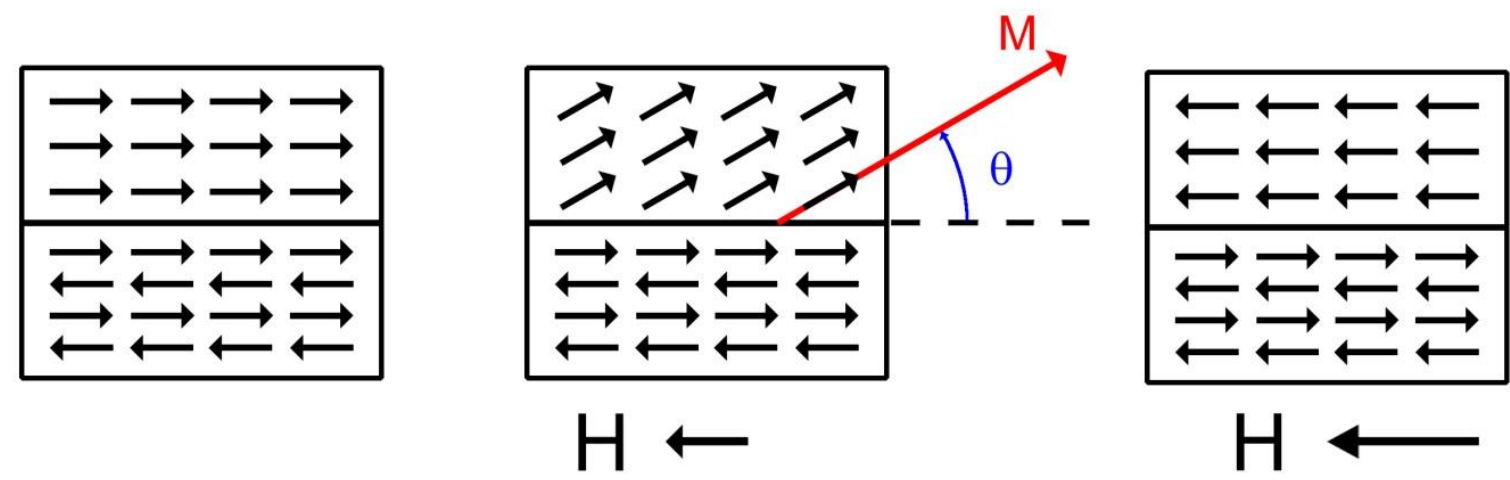

Figura 1-7. Rotação coerente da magnetização da camada ferromagnética devido à aplicação de um campo magnético $\mathrm{H}$. 
A energia apresenta dois ângulos de equilíbrio, $\theta=0$ e $\theta=\pi$, porém as energias diferem entre elas, sendo $\varepsilon(\theta=0)<\varepsilon(\theta=\pi)$, demonstrando a preferência de orientação da magnetização. Aplicando as condições de estabilidade para cada ângulo obtêm-se os respectivos campos coercivos

e

$$
H_{c 1}=-\frac{J+2 K}{M_{s} t_{F M}}
$$

$$
H_{c 2}=\frac{2 K-J}{M_{s} t_{F M}}
$$

O campo de exchange-bias pode ser definido como

$$
H_{E B}=\frac{H_{c 1}+H_{c 2}}{2}=-\frac{J}{M_{s} t_{F M}}
$$

sendo o mesmo proporcional a $\mathrm{t}_{\mathrm{FM}}^{-1}$. Desta forma, quanto maior a camada FM, menor será o efeito de deslocamento do ciclo histerese.

Já o campo coercivo, caso o ciclo de histerese não estivesse deslocado, pode ser dado por

$$
H_{c}=\frac{\left|H_{c 1}-H_{c 2}\right|}{2}=\frac{K}{M_{s} t_{F M}}
$$

sendo este também proporcional a $\mathrm{t}_{\mathrm{FM}}^{-1}$.

Comparando as equações 1.5 e 1.6 vemos que cada campo é dependente de uma constante diferente, sendo $\mathrm{H}_{\mathrm{EB}}$ proporcional a constante de troca entre spins AFM e FM vizinhos e $\mathrm{H}_{\mathrm{C}}$ proporcional a constante de anisotropia.

A aproximação utilizada acima, desenvolvida originalmente por Meiklejohn e Bean [9], permite uma fácil visualização do fenômeno, porém ela sobrestima o valor de campo $\mathrm{H}_{\mathrm{EB}}$ em duas ordens de grandeza aproximadamente. Num outro modelo um pouco mais detalhado, Mauri et al. [10], mostraram que valores mais próximos para $\mathrm{H}_{\mathrm{EB}}$ podem sem obtidos considerando a existência de uma parede de domínio na camada AFM durante a inversão da magnetização da camada FM. 
Existem vários modelos de exchange-bias mais elaborados e que explicam vários outros aspectos do fenômeno que não foram considerados aqui, mas a essência do efeito fica descrita com os já mencionados. Devemos ter em mente então que a presença de uma anisotropia unidirecional, produzida pelo acoplamento entre spins de estruturas com ordenamentos magnéticos diferentes, como são o AFM e o FM, se manifesta na heteroestrutura através de um deslocamento do ciclo de histerese, e de um incremento na coercividade em comparação ao apresentado pelo material FM isolado.

Um acoplamento via troca entre camadas AFM e FM que implica num aumento de $\mathrm{H}_{\mathrm{c}}$ sem que ocorra um deslocamento do ciclo de histerese com relação ao eixo do campo magnético aplicado, foi observado em amostras com $\mathrm{T}_{\mathrm{C}}<\mathrm{T}_{\mathrm{N}}$. Em trabalho recente, Sossmeier et al. apresentaram as propriedades de um filme de IrMn/NiCu o qual, quando devidamente tratado, apresenta este fenômeno [11][12]. Os tratamentos foram feitos termicamente ou por irradiação por íons de $\mathrm{He}^{+}$ou $\mathrm{Ge}^{+}$, sendo os resultados apresentados na Figura 1-8. Para os tratamentos térmicos e por irradiação por $\mathrm{He}^{+}$estes autores observaram incrementos de até duas vezes no valor de $\mathrm{H}_{\mathrm{c}}$, enquanto para a irradiação por $\mathrm{Ge}^{+}$observaram incrementos de até três vezes.

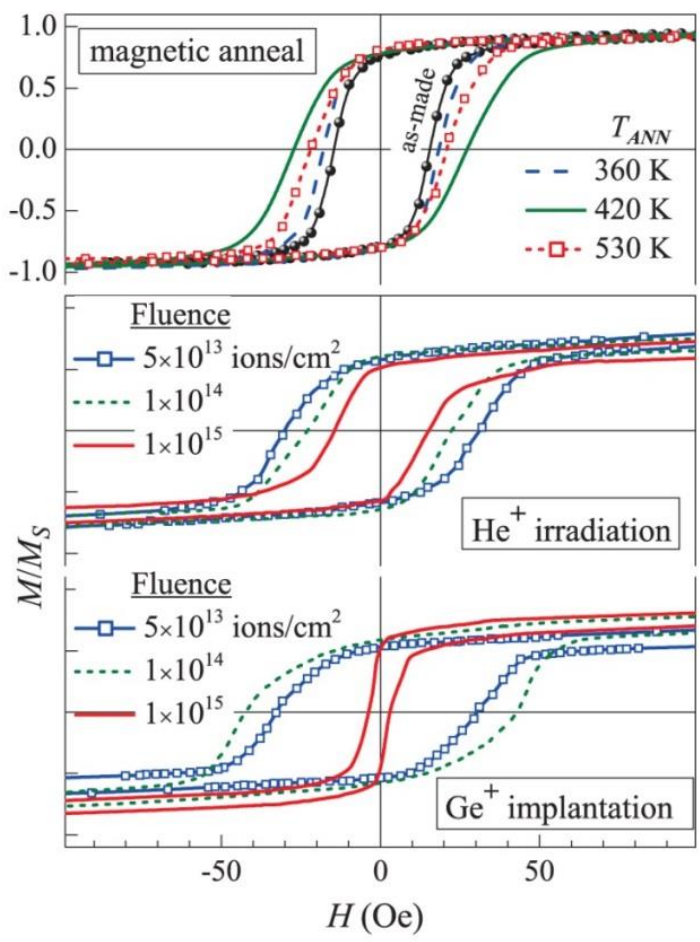

Figura 1-8. Histereses feitas para um filme de IrMn/NiCu. No topo são apresentados histereses para diferentes temperaturas de tratamentos térmicos feitos no filme após a deposição. No meio e no último são apresentadas histereses de filmes que foram irradiados por $\mathrm{He}^{+} \mathrm{e} \mathrm{Ge}^{+}$, respectivamente, com diferentes intensidades de feixe. Tirada de [11]. 
Os autores apresentaram três justificativas para o aumento do campo coercivo, sendo elas não exclusivas. Mudanças na estrutura cristalina foram descartadas como sendo uma das principais fontes de incremento de $\mathrm{H}_{\mathrm{c}}$, uma vez que não foram observadas mudanças significativas no espectro de raios $X$ entre a amostra sem tratamento e as demais. A primeira justificativa foi que os baixos valores de $M_{s}$ e $T_{c}$ do $\mathrm{NiCu}$ (a qual é uma liga ferromagnética fraca) não favorecem um eixo fácil a ser induzido tanto durante a deposição ou através de algum tratamento pós deposição, onde a forte anisotropia do IrMn e o fraco acoplamento de troca NiCu/IrMn não toleram uma reorientação dos spins da subcamada do IrMn adjacentes aos do $\mathrm{NiCu}$, mesmo quando este se encontra no estado de saturação. Um outro argumento foi com relação as variações dos tamanhos de grãos da camada AFM após os tratamentos, onde a interação na interface FM/AFM fica mais forte que o acoplamento dentro da camada FM, travando os spins adjacentes dentro de domínios com tamanhos menores que os da camada FM sozinha. O último argumento dado é com relação aos efeitos dos tratamentos pós deposição na superfície dos filmes, onde os mesmos aumentam a rugosidade na interface FM/AFM, podendo aumentar a área de contato e, consequentemente, influenciar no acoplamento das interfaces por causar uma dispersão local dos spins, resultando numa adição de anisotropias. Estas anisotropias promovem uma barreira de energia para o movimento das paredes de domínio, aumentando a coercividade.

\subsection{A liga de FeRh}

Em 1938 Fallot [13][14] relatou um comportamento incomum numa liga de FeRh, onde a mesma possuía uma transição de fase magnetoestrutural de primeira ordem, na qual o material passa de uma fase antiferromagnética (AFM) para uma fase ferromagnética (FM) quando atingida uma temperatura crítica próxima a temperatura ambiente. Porém, para existir esta transição, a composição da liga deve ser muito próxima aos $50 \%$ de $\mathrm{Rh}$, com uma variação máxima de aproximadamente $1 \%$ em torno deste valor, segundo se mostra no diagrama de fases do sistema $\mathrm{Fe}_{1-\mathrm{x}} \mathrm{Rh} \mathrm{h}_{\mathrm{x}}$ [15][16][17]. Neste, Figura 1-9, observamos que a liga possui uma estrutura B2 (fase 
bcc com estrutura tipo $\mathrm{CsCl}$ ) por uma longa extensão, apresentando um comportamento magnético FM com exceção de uma pequena região, em evidência no diagrama, na qual apresenta um comportamento AFM. A transição de fase magnética é acompanhada por uma expansão isotrópica da rede, caracterizado por um incremento de aproximadamente $0,3 \%$ no parâmetro de rede [18].

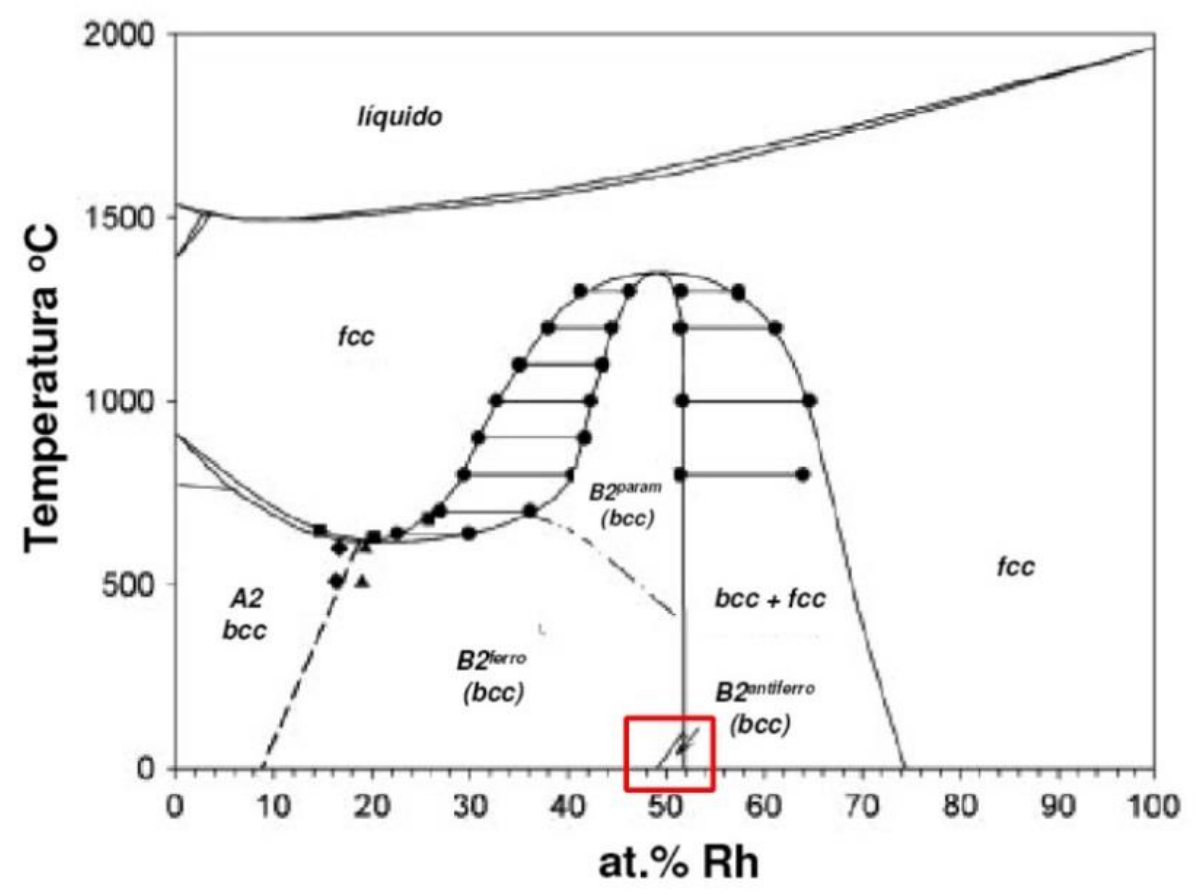

Figura 1-9. Diagrama de fases da liga binária de $\mathrm{Fe}_{1-\mathrm{x}} \mathrm{Rh}_{\mathrm{x}}$ (Adaptado da ref. [17]). Em evidência, quadrado vermelho, se encontra a região de fase antiferromagnético da liga.

A transição de fase magnética ocorre para uma temperatura crítica ( $T_{\text {AFM-FM }}$ ) próxima à temperatura $370 \mathrm{~K}$, sendo a mesma fortemente dependente de parâmetros termodinâmicos, principalmente a pressão, e de campo magnético aplicado. Um estudo da dependência de $T_{\text {AFM-FM }}$ com relação ao campo magnético aplicado é apresentado nos trabalhos de Kouvel [19] e Ohtani e Hatakeyama [20]. O estudo de Kouvel foi feito em amostras tipo bulk, apresentando um deslocamento de $-0,82$ $\circ / \mathrm{kG}$, enquanto o estudo de Ohtani foi feito em filmes finos, apresentando um deslocamento de $-1,0 \% \mathrm{kG}$ (ver Figura 1-10), sugerindo que as tensões entre o filme e o substrato favorecem a transição de fase. 


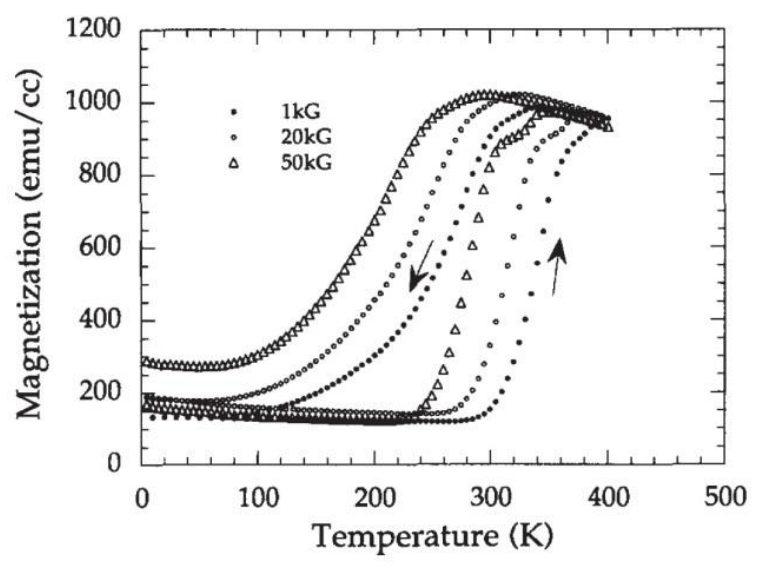

Figura 1-10. Histereses térmicas da magnetização com diferentes valores de campo magnético aplicados. Tirada de [20].

O primeiro trabalho publicado em filmes finos de FeRh foi realizado por Lommel [21]. Neste trabalho se reporta que os ciclos térmicos $M$ vs $T$ dos filmes apresentaram uma transição larga, maior que $200 \mathrm{~K}$, e incompleta, juntamente de uma grande histerese térmica, se opondo a transição abrupta apresentada pela amostra bulk, menor que $50 \mathrm{~K}$ (ver Figura 1-11) [22]. Outra característica apresentada foi a assimetria dos ramos do ciclo, correspondentes ao aquecimento (transição AFM $\rightarrow$ FM) e resfriamento (transição FM $\rightarrow$ AFM), sendo a segunda mais larga, o que não ocorre para as amostras bulk. Um estudo mais detalhado foi feito por Ohtani e Hatakeyama [23], onde foram produzidos filmes finos de ligas $\mathrm{Fe}_{1-x} \mathrm{Rh}_{\mathrm{x}}(0,28<\mathrm{x}<0,57)$ com espessuras da ordem de $200 \mathrm{~nm}$. Os filmes foram co-depositados em substratos de vidro a uma temperatura de $373 \mathrm{~K}$, posteriormente passaram por um tratamento térmico a $873 \mathrm{~K}$ numa atmosfera de $\mathrm{Ar}-\mathrm{H}_{2}$ por $4 \mathrm{~h}$. Os filmes apresentaram a estrutura tipo $\mathrm{CsCl}$ após passarem pelo tratamento térmico, mostrando uma estrutura similar à da amostra bulk. Os resultados magnéticos apresentaram um continuo decaimento na magnetização de 1800 para 200 emu/cc quando a concentração de Rh aumenta de 30 para $57 \%$ at, em contraste com as amostras bulk que apresentam uma pequena queda no valor de magnetização até cerca de $50 \%$ at. de Rh, quando cai subitamente à zero. As transições de fase AFM - FM apresentadas pelos filmes são mais largas que as correspondentes às amostras massivas, não sendo observadas transições para as ligas $\mathrm{Fe}_{1-\mathrm{x}} \mathrm{Rh}_{\mathrm{x}}$ com $\mathrm{x}<0,48$, da mesma forma que acontece com amostras massivas, embora tenha sido claramente observada uma transição para a composição $\mathrm{Fe}_{0,546} \mathrm{Rh}_{0,454}$. 


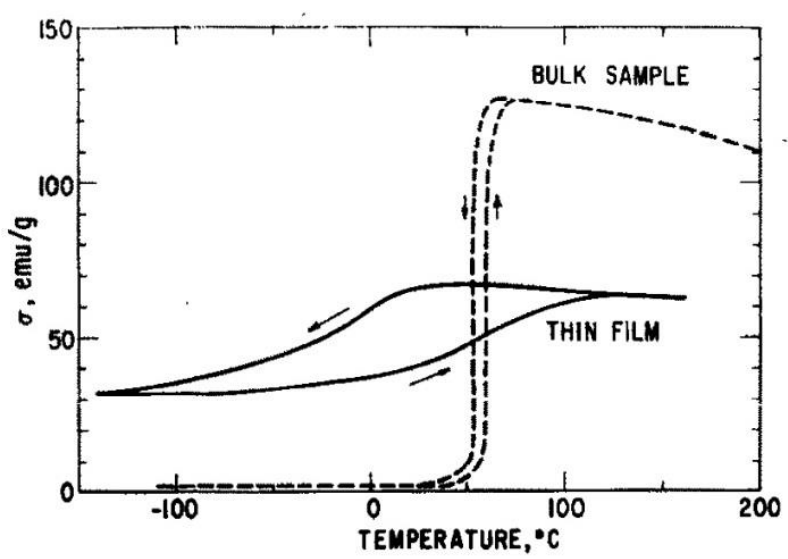

Figura 1-11. Comparação entre transições de fase magnética obtidas para liga $\mathrm{Fe}_{48} \mathrm{Rh}_{52}$ tipo bulk (linha tracejada) e para a liga $\mathrm{Fe}_{47} \mathrm{Rh}_{53}$ em forma de filme fino (linha contínua). Tirada de [21].

Depois de relatada a transição de fase AFM - FM em filmes de FeRh foram descritos na literatura trabalhos onde a obtenção destas ligas foi realizada por diferentes métodos, como sputtering [24], epitaxia por feixe molecular [25], evaporação por feixe de elétrons [26], fusão térmica [27] e síntese química [28]. Partículas finas monodispersas de várias composições de FeRh foram preparadas usando métodos químicos por Jia et al. [29].

As propriedades de materiais em forma de filmes finos, de um modo geral, são fortemente dependentes do substrato utilizado. No trabalho de Ohtani et al. [20] é feito um estudo da influência do substrato, onde, primeiramente, foram estudados filmes com substratos e, posteriormente, foram retirados do substrato, sendo submetidos, novamente, as mesmas medidas. Os filmes possuíam aproximadamente 200 $\mathrm{nm}$ de espessura e composição $\mathrm{Fe}_{0,478} \mathrm{Rh}_{0,522}$. A produção foi feita através de codeposição via sputtering sobre substratos de quartzo, sendo feito um tratamento térmico a $873 \mathrm{~K}$ por $4 \mathrm{~h}$. Foi observada uma diminuição da largura da faixa de temperaturas de transição juntamente de uma transição mais abrupta e um aumento de $50 \mathrm{~K}$ na temperatura crítica de transição para o filme sem substrato (ver Figura 1-12). Estes resultados foram explicados considerando as tensões existentes entre o filme e o substrato, as quais não favorecem a estabilidade das fases magnéticas nas regiões de metaestabilidade. 


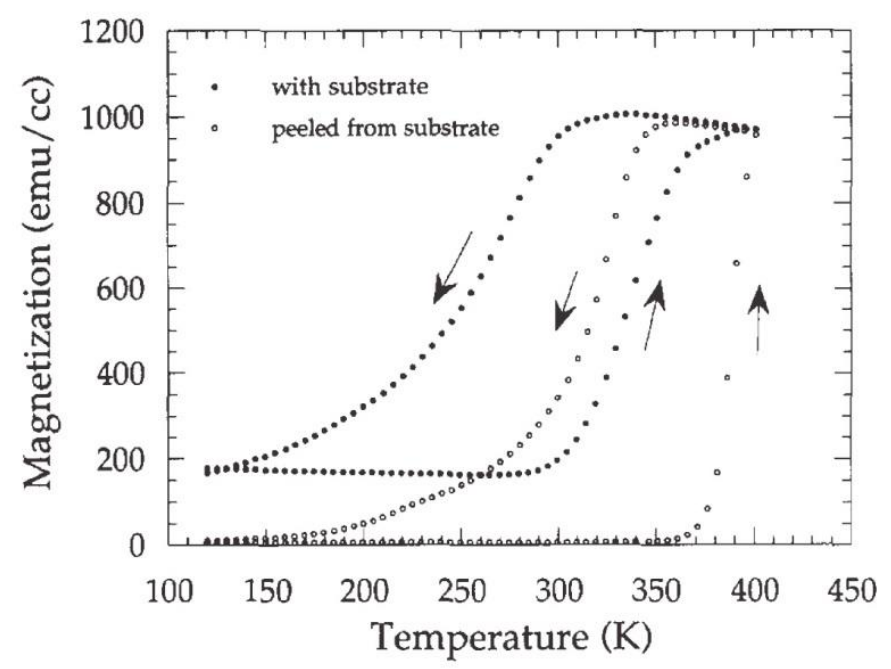

Figura 1-12. Transições de fase para a liga $\mathrm{Fe}_{47,8} \mathrm{Rh}_{52,2}$ em forma de filme fino, sendo uma do filme com o substrato (círculos preenchidos) e do filme retirado do substrato (círculos vazios). Tirada de [20].

As propriedades físicas do FeRh em forma de filmes finos são muito dependentes das condições de preparação. Entre os vários parâmetros importantes se encontra a temperatura à qual é realizado o tratamento térmico posterior à obtenção dos filmes. Nos trabalhos de Inoue et al. [30] e Cao et al [31], são feitas comparações entre as características magnéticas e estruturais de filmes finos de composição $\mathrm{Fe}_{49} \mathrm{Rh}_{51}$, depositados sobre substratos de $\mathrm{MgO}$ (001) e tratados termicamente em temperaturas diferentes. Os filmes foram produzidos via magnetron sputtering em temperatura ambiente, com aproximadamente $150 \mathrm{~nm}$ de espessura. Os filmes permaneceram sob tratamento térmico por $2 \mathrm{~h}$, sendo utilizadas temperaturas na faixa 473 - 973 K. A análise estrutural mostrou o surgimento da orientação cristalina (001) apenas para as amostras tratadas acima de $573 \mathrm{~K}$, juntamente de uma melhora na orientação cristalográfica relacionada diretamente com o aumento da temperatura de tratamento térmico, o que foi confirmado por medidas de difração de raios $\mathrm{X}$ do tipo rocking curves. Com relação aos resultados magnéticos os filmes tratados abaixo de $473 \mathrm{~K}$ demonstraram não ser ferromagnéticos, enquanto os tratados entre $573-673$ $\mathrm{K}$ apresentarem comportamento FM. A fase AFM apareceu, coexistente com a fase FM, em amostras tratadas acima de $693 \mathrm{~K}$. Apenas para tratamentos em temperaturas mais elevadas, acima de $793 \mathrm{~K}$, as amostras apresentaram fase única AFM. A temperatura crítica e a forma do ciclo térmico também demonstraram ser dependentes da temperatura do tratamento térmico, o que se manifestou através de uma tran- 
sição mais abrupta e em temperaturas maiores para as amostras tratadas a temperaturas mais elevadas. No trabalho de Cao et al. são apresentadas histereses obtidas ao longo do ramo da transição $\mathrm{AFM} \rightarrow \mathrm{FM}$, sendo as mesmas reproduzidas na Figura 1-13. Nesta figura se observa que os ciclos de histerese nas temperaturas limites do ramo (108 e $140^{\circ} \mathrm{C}$ ) são curvas simples, como os de um material FM normal, embora a magnetização de saturação para $108^{\circ} \mathrm{C}$ seja muito baixa em comparação com a de $140{ }^{\circ} \mathrm{C}$, o qual é razoável porque, naquela temperatura, predomina a fase AFM. No entanto, para as outras temperaturas, a magnetização mostra um incremento incomum para valores de campo na região de $10 \mathrm{kOe}$, o que gera áreas de histerese nas regiões onde se esperaria que a magnetização já estivesse saturada. A origem deste comportamento não é explicado, mas os autores sugerem que isto ocorre devido à combinação da anisotropia magnética fraca da fase AFM com a correspondente à fase $\mathrm{FM}$ mole. $\mathrm{O}$ incremento da magnetização de saturação com aumento da temperatura é explicado pelo incremento da quantidade de fase FM. Quanto ao comportamento do campo coercivo os autores não fazem nenhuma afirmação.

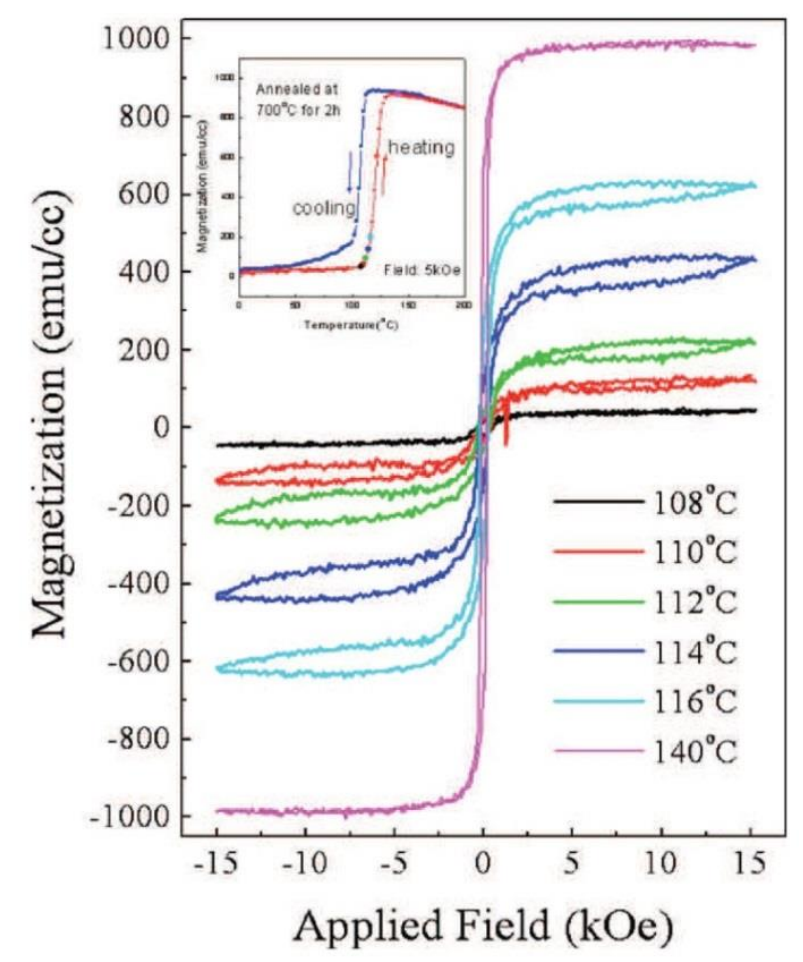

Figura 1-13. Histereses feitas ao longo da transição AFM $\rightarrow$ FM para um filme de $\mathrm{Fe}_{49} \mathrm{Rh}_{51}$ tratado a $973 \mathrm{~K}$. No gráfico interno é apresentada a magnetização em função da temperatura. Tirada de [31]. 
No trabalho de Maat et al. [24] para filmes finos de $\mathrm{Fe}_{49} \mathrm{Rh}_{51}$ com $110 \mathrm{~nm}$ de espessura depositados sobre $\mathrm{MgO}(001)$ e tratados termicamente a $1073 \mathrm{~K}$, os mesmos apresentam comportamentos similares ao apresentados por Cao et al. [31], porém, durante o aquecimento e na faixa de transição, a amostra apresenta uma região de reversibilidade no centro da histerese (ver Figura 1-14), sendo observado, da mesma forma que Cao, ciclos de histerese onde se imaginava a amostra estar saturada.

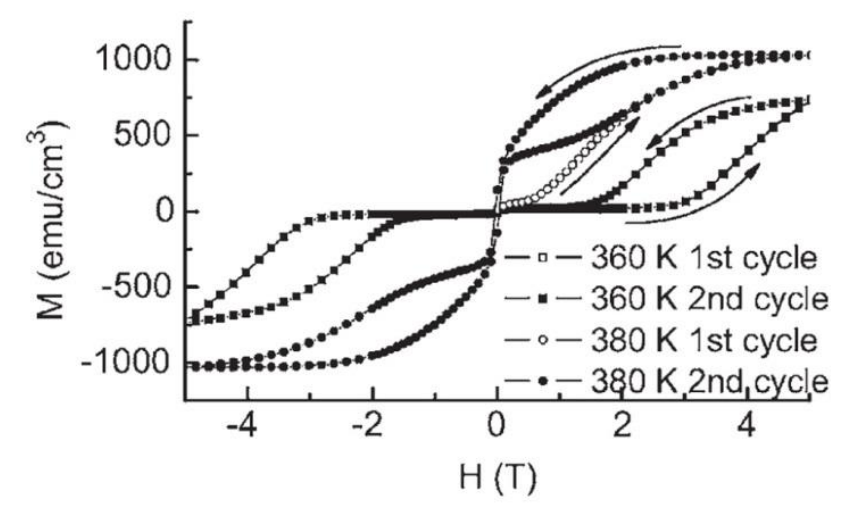

Figura 1-14. Histereses feitas durante a transição $A F M \rightarrow F M$ para a liga $\mathrm{Fe}_{49} \mathrm{Rh}_{51}$ em forma de filme fino. Tirada de [24].

Em um trabalho recente Loving et al. [32] mostraram que filmes muito finos de FeRh apresentam uma arquitetura de nanoilhas com estrutura cristalina do tipo $\mathrm{CsCl}$. Os filmes foram produzidos por deposição via magnetron sputtering sobre substratos de $\mathrm{MgO}$ (001), a uma temperatura de $873 \mathrm{~K}$, sendo feito, posteriormente, um tratamento térmico a $973 \mathrm{~K}$ por $1,5 \mathrm{~h}$ com o objetivo de se obter a estrutura $\mathrm{CsCl}$. A espessura nominal dos filmes foi de $10 \mathrm{~nm}$ e a composição $\mathrm{Fe}_{48} \mathrm{Rh}_{52}$. A observação das estruturas foi feita através de microscopia de força atômica e foi verificado que as ilhas apresentaram uma largura média de $\sim 100 \mathrm{~nm}$ e uma altura de $\sim 15 \mathrm{~nm}$. $\mathrm{O}$ filme apresentou uma faixa de temperaturas de transição AFM $\rightarrow$ FM menor que $100 \mathrm{~K}$ enquanto que a faixa de temperaturas da transição FM $\rightarrow$ AFM foi de $\sim 300 \mathrm{~K} \mathrm{e}$ ainda foi incompleta (ver Figura 1-15), o que sugere que as regiões FM permanecem remanescentes na fase AFM. 


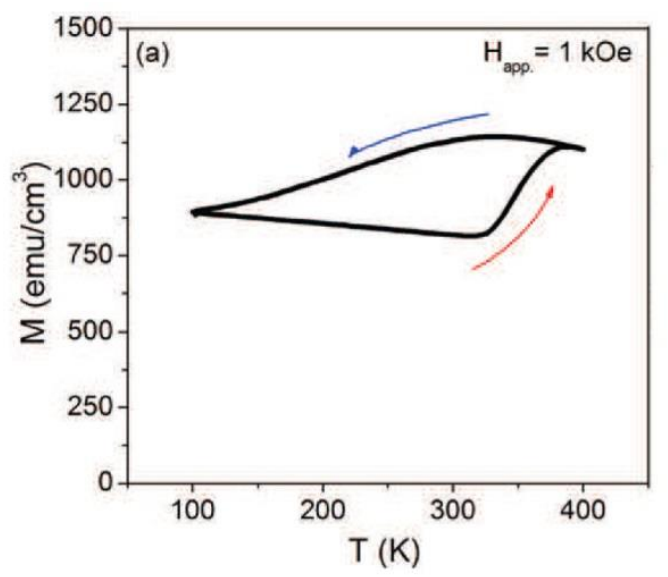

Figura 1-15. Magnetização em função da temperatura feita a campo constante de 1 kOe para a liga $\mathrm{Fe}_{48} \mathrm{Rh}_{52}$ em forma de filme fino. Tirada de [32].

Através de espectroscopia Mössbauer [15] e difração de nêutrons [33], Shirane et al. mediram os momentos magnéticos do Fe e do Rh nas fases FM e AFM. A fase FM apresenta uma estrutura colinear com momento magnético de $3,2 \mu_{\mathrm{B}}$ e $0,9 \mu_{\mathrm{B}}$ por átomo, para o $\mathrm{Fe}$ e o $\mathrm{Rh}$, respectivamente. Na fase AFM o Fe apresenta um momento magnético de $3,3 \mu_{\mathrm{B}}$ por átomo enquanto que o Rh não apresenta momento magnético. Um esquema dos momentos magnéticos por célula unitária para as fases AFM e FM encontra-se na Figura 1-16.

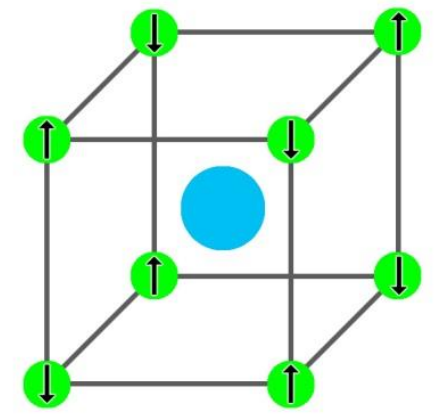

Estado AFM

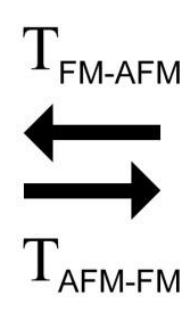

Figura 1-16. Esquema dos momentos magnéticos dos átomos de Fe e Rh em uma célula unitária nas fases AFM e FM.

Completada a transição de fase AFM $\rightarrow$ FM da liga de FeRh, se continua-se aumentando a temperatura, se observa que a magnetização diminui de acordo com o comportamento normal para um material ferromagnético, apresentando uma tran- 
sição de fase de segunda ordem para a fase paramagnética com uma temperatura de Curie $\left(\mathrm{T}_{\mathrm{C}}\right)$ igual a $675 \mathrm{~K}[22]$.

No trabalho de Kawagoe et al. [34] foi feito um estudo do comportamento magnético de bicamadas de Fe/FeRh-Ir (001), relacionando o campo coercivo, magnetização remanente e formato da curva de histerese com a espessura da camada de Fe e, consequentemente, o acoplamento entre as duas camadas quando a camada de FeRh se encontra na fase AFM (ver Figura 1-17). Para espessuras da camada de Fe acima de $14 \mathrm{~nm}\left(\mathrm{t}_{\mathrm{Fe}}>14 \mathrm{~nm}\right)$ as histereses de magnetização apresentam uma transição abrupta juntamente com um baixo campo coercivo, $\mathrm{H}_{\mathrm{c}}=83 \mathrm{Oe}$ para $t_{\mathrm{Fe}}=20 \mathrm{~nm}$. Para espessuras menores de $14 \mathrm{~nm}$ as histereses passam a ser arredondadas, com magnetização remanente consideravelmente menor ( $30 \%)$ que a magnetização de saturação, e apresentam um alto campo coercivo, $\mathrm{H}_{\mathrm{C}}=250 \mathrm{Oe}$ para $t_{\mathrm{Fe}}=5 \mathrm{~nm}$. Segundo os autores[34], a diminuição da magnetização remanente é um forte indício do acoplamento entre as camadas, já o fato da histerese passar a ser arredondada e o aumento do campo coercivo é uma consequência do fato de que muitos domínios pequenos estão envolvidos no processo de inversão da magnetização. O fato dos ciclos não mostrarem um deslocamento, mas sim um aumento do campo coercivo, sugere um acoplamento spin-flop entre os spins vizinhos das camadas AFM e FM.

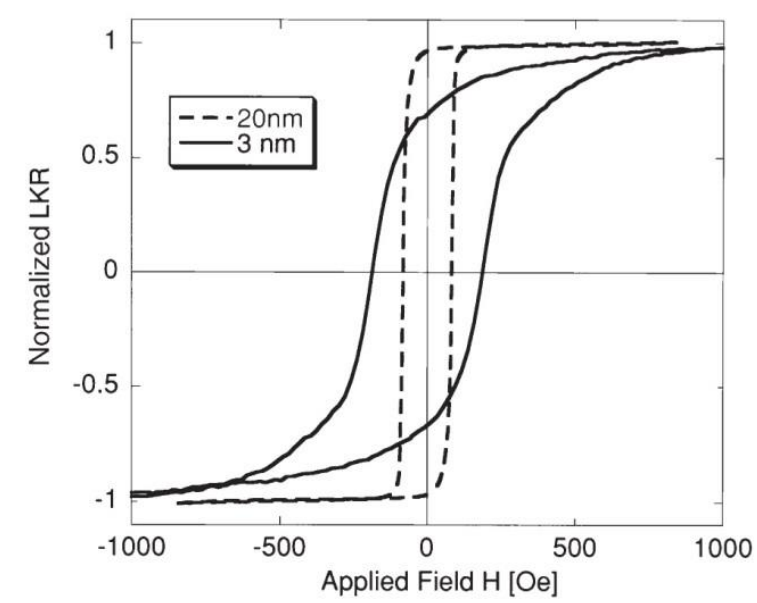

Figura 1-17. Histereses feitas para bicamadas Fe/FeRh-Ir com diferentes espessuras da camada de Fe (20 nm e $3 \mathrm{~nm})$. Tirada de [34]. 
Recentemente, foi sugerido que uma das potenciais aplicações da liga de FeRh está em dispositivos de gravação magnética termicamente assistida (TAMR), uma nova geração de sistemas de gravação magnética de alta densidade [35]. A ideia destes dispositivos é que as informações permanecem armazenadas em temperatura ambiente em um meio magnético termicamente estável de alta anisotropia magnetocristalina, porém a escrita da informação é feita em temperaturas maiores, onde a anisotropia é reduzida de forma a ser necessário a utilização de pequenos campos magnéticos [36]. 


\section{Capítulo 2: Técnicas Experimentais}

Neste capítulo iremos apresentar as técnicas experimentais utilizadas neste trabalho, onde partimos do método de deposição de filmes finos, isto é, deposições via magnetron sputtering, seguindo para as técnicas de caracterização morfológica e estrutural, espectroscopia de retroespalhamento Rutherford e difrações de raios $\mathrm{X}$, concluindo com a técnica de análise de propriedades magnéticas, magnetômetro de amostra vibrante.

\subsection{Magnetron Sputtering}

A técnica de sputtering é uma técnica de deposição física de filmes que consiste, basicamente, em retirar átomos de um determinado alvo por meio da colisão sobre ele de um feixe de átomos de um gás inerte, passar esses átomos retirados através de um plasma e depositá-los em um substrato. As limitações existentes na técnica, por exemplo, a tensão necessária para manter o plasma, que deveria ser muito alta, e a taxa de deposição que é muito baixa, levaram ao desenvolvimento do magnetron sputtering, onde o plasma passou a ser confinado através de imãs permanentes que geram um campo magnético paralelo ao alvo, logo acima do mesmo. Tal confinamento não produziu apenas um aumento eficaz da taxa de deposição, mas houve também uma diminuição na tensão aplicada, o que permitiu a utilização de pressões menores do gás inerte, além de uma melhora na reprodutibilidade das amostras [37]. Na Figura 2-1 segue um esquema simplificado do confinamento do plasma.

O magnetron sputtering utilizado neste trabalho, ver Figura 2-3, foi um sistema comercial modelo ATC 2000, fabricado pela empresa AJA International, localizado no Laboratório de Materiais Magnéticos do Instituto de Física da USP. Este sistema possui uma câmara de vácuo principal, onde todos os processos de deposição ocorrem, e uma câmara secundária, a qual permite a entrada e retirada das amostras produzidas sem alterarmos o vácuo da câmara principal. Uma bomba turbomo- 
lecular permite que a pressão na câmara principal chegue aos $\sim 10^{-7}$ Torr, o que é a chamada de pressão base. Durante os processos de deposição, os alvos são atingidos por um feixe de Ar, de alta pureza (99,9999\% - N60), o que ocasiona que se forme, dentro da câmara principal, uma atmosfera deste gás a qual é mantida, no nosso caso, a uma pressão de 5 mTorr, sendo esta controlada a partir do equilíbrio entre o gás que entra na câmara e o que é eliminado através das bombas. Para o controle de fluxo existe uma válvula gaveta entre a bomba turbomolecular e a câmara principal associada a um controlador eletrônico e um controlador de fluxo de massa no controle de entrada dos gases.

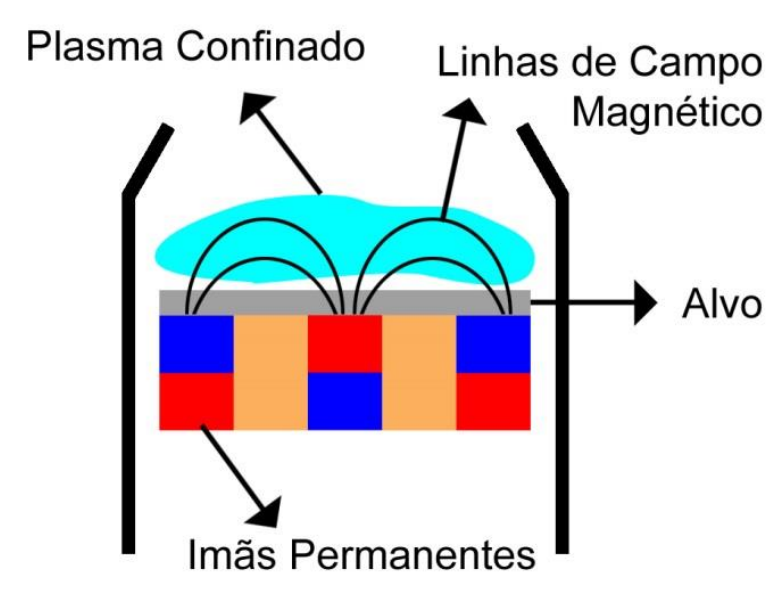
sputtering.

Figura 2-1. Esquema simplificado do confinamento do plasma num sistema do tipo magnetron

O sistema possui quatro canhões nos quais são colocados os alvos, o que permite fazermos deposições simultâneas (codeposições), ou ainda formar multicamadas. Os alvos são discos de duas polegadas de diâmetro e uns $3 \mathrm{~mm}$ de espessura compostos por elementos químicos simples ou ligas, sendo eles de alta pureza. Para a formação do plasma pode-se utilizar uma fonte de tensão contínua DC ou de pulsos de RF (rádio frequência). No nosso caso, como foram utilizados materiais metálicos, utilizamos a fonte DC. O bombardeamento do plasma no alvo resulta na retirada de átomos do mesmo, sendo estes átomos espalhados por toda a câmara principal e, inclusive, nos substratos. Como forma de direcionar os átomos retirados existe uma chaminé a qual reduz o espalhamento lateral, direcionando os átomos para o substrato. Para o controle das deposições existem, para cada canhão, os obturadores, que são utilizados para bloquear a passagem dos átomos retirados do 
alvo, sendo o controle deles feito através de um dispositivo mecânico controlado por ar comprimido. Devido ao aquecimento produzido pela corrente elétrica os canhões são resfriados a água.

Uma imagem do porta substrato utilizado se encontra na Figura 2-2. Na montagem foram utilizados três obturadores que permitiam a escolha das janelas, onde foram colocados os substratos, através das quais seria depositado o material em questão. Para evitarmos deposições preferenciais no substrato e efeitos de sombra (shadowing), o suporte do porta substrato é mantido girando durante a deposição. Caso seja necessário que as deposições sejam feitas em temperaturas acima da ambiente, o sistema está equipado com duas lâmpadas halógenas, protegidas por um refletor de alumínio, acopladas a um controlador de temperatura, sendo que com este sistema é possível atingirmos, no máximo, temperaturas de $923 \mathrm{~K}$.

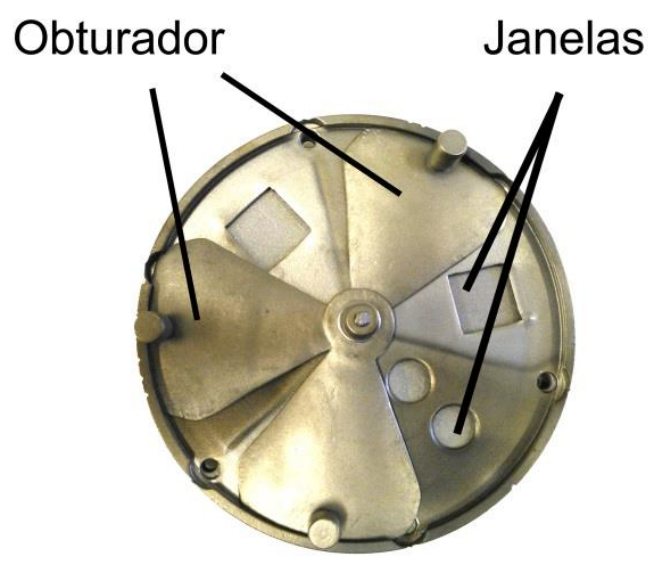

Figura 2-2. Porta substrato utilizado para deposições via sputtering.

As taxas de deposição dos filmes são influenciadas por diversos fatores, sendo os mais importantes a temperatura da câmara, o fluxo e a pressão do gás $\operatorname{Ar}$ e o sputtering yield. A temperatura da câmara, o fluxo e a pressão do gás estão diretamente ligadas ao livre caminho médio dos átomos dentro da câmera enquanto o sputtering yield é uma característica de cada material, sendo dependente da energia de ligação entre os átomos que compõem o alvo. O sputtering yield é definido como o número de átomos retirados do alvo por colisão com um íon incidente. 
Visão completa do sistema de magnetron sputtering
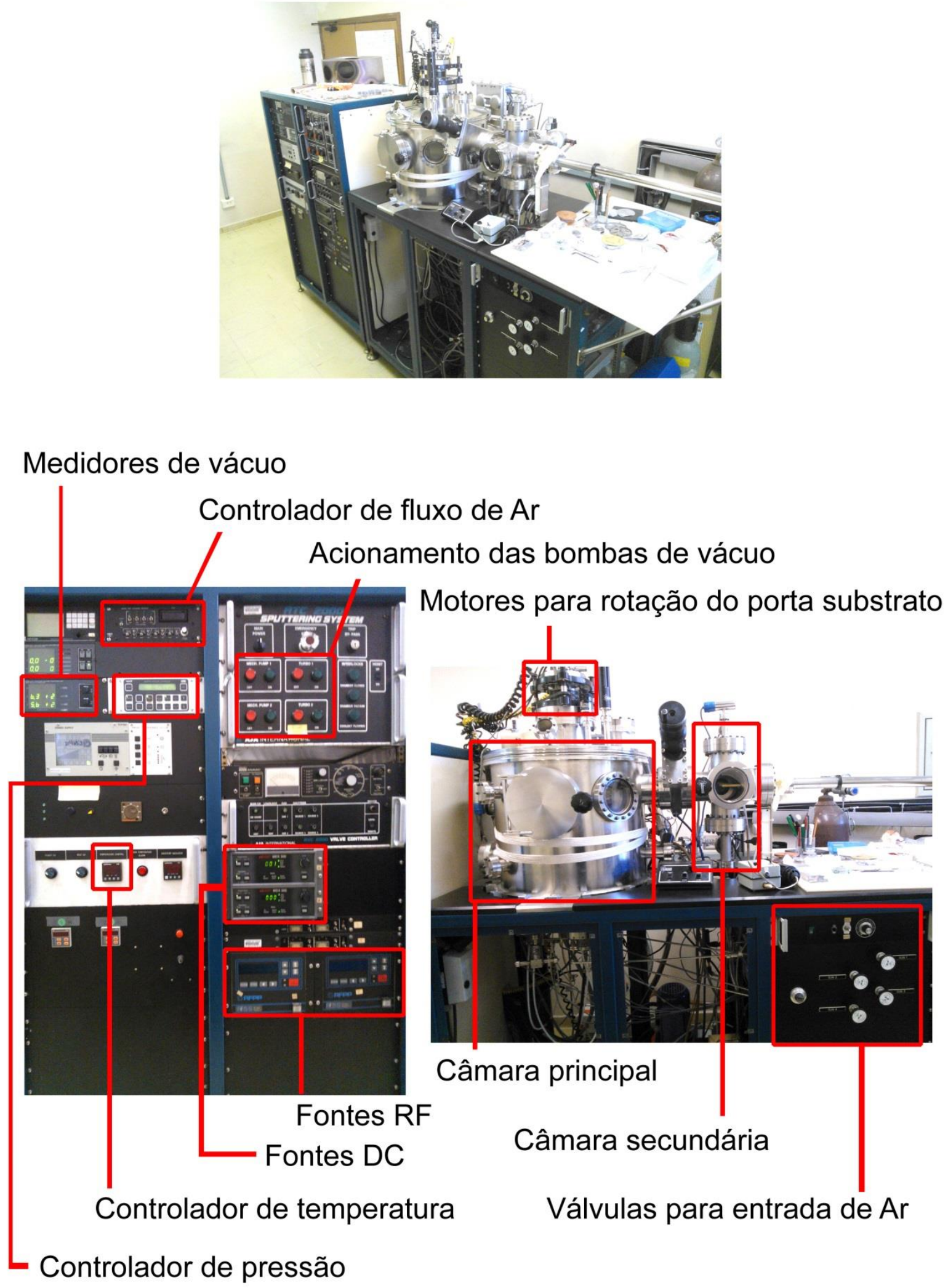

Figura 2-3. Visão geral do sistema de magnetron sputtering e detalhes dos instrumentos. 


\subsection{Espectroscopia de Retroespalhamento Rutherford}

Para as análises de composição e de espessura das camadas dos filmes foi utilizada a técnica de Espectroscopia de Retroespalhamento Rutherford (RBS - Rutherford Backscattering Spectometry). Esta técnica consiste em fazer incidir íons monoenergéticos sobre o filme, (em nosso caso foi utilizado $\mathrm{He}$ ), e medir por meio de detectores apropriados a intensidade e energia dos íons retroespalhados. Um fato importante, com relação ao RBS, é que este é um método não destrutivo.

Os ensaios de RBS das amostras deste trabalho foram feitas no Laboratório de Análises de Materiais por Feixes lônicos (LAMFI) localizado no Instituto de Física da USP. O acelerador é do tipo Pelletron-Tandem, modelo 5SDH, com stripper gasoso (Nitrogênio), construído pela NEC, National Electrostatic Corporation, dos $E U A^{5}$, podendo alcançar $1,7 \mathrm{MV}$ de tensão no terminal, sendo o mesmo equipado com uma estação de análise multiuso a qual permite a análise por espalhamentos elásticos (RBS) [38]. Na configuração em que se encontra, o acelerador pode fornecer feixes de prótons com energias entre 0,6 e 3,4 MeV e feixes de partículas alfa com energias entre 0,6 e 5,1 MeV. A corrente máxima de feixe alcançada é de 100 nA.

$\mathrm{Na}$ colisão os íons incidentes perdem energia para os átomos do alvo (amostra). A taxa com que esta energia é perdida depende da razão entre as massas do ín incidente e do átomo do alvo, o que permite a identificação do material do qual é constituído o alvo, uma vez que o íon incidente é conhecido. Com os átomos do alvo identificados é possível fazer um levantamento estatístico em relação ao número de partículas incidentes e refletidas, sendo a relação entre eles dada através da seção de choque de espalhamento, o que permite a identificação da densidade de átomos do material, sendo esta dada em átomos $/ \mathrm{cm}^{2}$. Ao incidir no alvo os íons podem não colidir logo ao entrar no material, mas sim após percorrerem certa distância. Durante o caminho percorrido os íons interagem com o meio perdendo energia, sendo esta perda proporcional à distância percorrida, o que permite a criação de uma escala referente à perda da energia do íon com a distância onde houve a colisão. No caso de uma primeira aproximação pode-se considerar apenas as interações com os elé-

\footnotetext{
${ }^{5}$ Informação retirada do site do LAMFI, ver ref. [38].
} 
trons do material, podendo ser descartada a colisão com os núcleos, uma vez que o tamanho reduzido dos mesmos implica numa pequena probabilidade de colisão comparada com a interação com os elétrons, desta forma os íons perdem energia dentro do material [39].

\subsection{Difração de Raios X}

A técnica de análises por difração de raios $X(X R D)$ é amplamente utilizada, uma vez que é uma técnica não danosa à amostra e muito poderosa, onde pode ser aplicada para medidas de estrutura cristalina, identificação de elementos, espessura de camadas (no caso de filmes), medidas de rugosidade, tamanho de grãos estruturais, defeitos, tensões, etc. Tal técnica consiste na interação de ondas eletromagnéticas com a matéria.

Quando um feixe de radiação eletromagnética de comprimento de onda $\lambda$ incide sobre um cristal as ondas serão espalhadas em todas as direções, havendo superposições construtivas e destrutivas, dependendo da direção de espalhamento. Para haver uma interferência construtiva as ondas espalhadas devem obedecer à lei de $B_{r a g g}{ }^{6}$ (eq. 2.1), a qual relaciona o ângulo $\theta$ de incidência e reflexão da onda, a distância interplanar d da rede cristalina e o comprimento de onda da radiação incidente, junto com a ordem $n$ da interferência.

$$
\mathrm{n} \lambda=2 \mathrm{~d} \sin \theta
$$

Para redes cúbicas, como as estudadas neste trabalho, a distância interplanar pode ser calculadas através da equação 2.2, onde a mesma utiliza os índices de Miller ${ }^{7}$ como identificação dos planos cristalográficos, sendo a o parâmetro de rede da célula unitária.

$$
\mathrm{d}_{\mathrm{hkl}}=\frac{\mathrm{a}}{\sqrt{\mathrm{h}^{2}+\mathrm{k}^{2}+\mathrm{l}^{2}}}
$$

\footnotetext{
${ }^{6}$ William Lawrence Bragg

${ }^{7}$ William Hallowes Miller
} 
Para as caracterizações estruturais de nossas amostras foram utilizadas três técnicas de difração de raios $X$ e dois instrumentos distintos. As técnicas que serão descritas nas seguintes subseções são varredura $\theta-2 \theta$, rocking curves e varredura em $\varphi$. Um dos instrumentos utilizados foi o difratômetro DR8 Advance, fabricado pela Bruker, o qual é equipado com uma fonte de $\mathrm{Cu}$, que gera uma radiação de comprimento de onda $\lambda_{\mathrm{Cu}_{\mathrm{k} a}}=1,5418 \AA$ e um filtro de $\mathrm{Ni}$, que elimina boa parte da componente $\lambda_{\mathrm{Cu}_{\mathrm{k \beta}}}$ da radiação. O segundo instrumento utilizado foi um equipamento home-made ${ }^{8}$ formado por uma fonte de $\mathrm{Cu}$ e um difratômetro comercial fabricado pela Huber. Neste último não foi utilizado filtro. Ambos os instrumentos estão localizados no Laboratório de Cristalografia do Instituto de Física da USP.

\subsubsection{Varredura $\theta-2 \theta$}

A primeira técnica a ser utilizada foi a varredura no arranjo $\theta-2 \theta$, sendo esta a única técnica a utilizar o instrumento da Bruker. A medida é feita de forma que o feixe incidente e o detector formam um ângulo $\theta$ com o plano do filme, porém posicionados de forma opostas, sendo a medida feita em função do ângulo $\theta$. Uma representação esquemática do posicionamento do feixe incidente e do detector com relação à amostra encontra-se na Figura 2-4. Por meio deste tipo de medida é possível identificar a estrutura cristalográfica e calcular os parâmetros de rede dos materiais envolvidos através das equações 2.1 e 2.2. Também é possível estimarmos o tamanho médio de grão através da fórmula de Scherrer (eq. 2.3). Em nossas medidas as amostras permanecem girando, em torno do eixo normal ao plano do filme, para detectarmos todas as orientações de grãos existentes, sendo dada, no mínimo, uma volta por ângulo medido. Os picos de difração dos espectros obtidos são comparados com os padrões de difração do banco de dados PDF (Powder Diffraction File), o

\footnotetext{
${ }^{8}$ Modelo não comercial.
} 
qual contém informações sobre uma enorme variedade de elementos e ligas policristalinas.

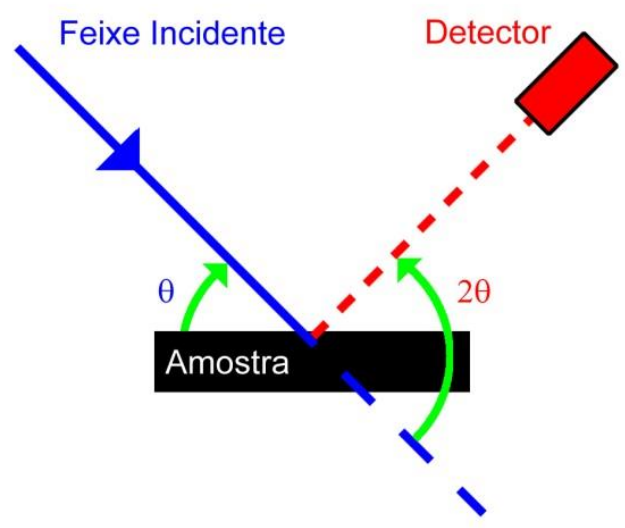

Figura 2-4. Ângulos de incidência e espalhamento na configuração de medida $\theta-2 \theta$.

Para o cálculo do diâmetro médio de grão $\left(D_{h k l}\right)$ perpendicular a um plano cristalográfico da rede, utiliza-se o comprimento de onda do raio $X$ utilizado nas medidas $(\lambda)$, uma constante adimensional $(K)$ relacionada ao fator de forma dos grãos, sendo a mesma igual a 0,9 com boa aproximação, a largura a meia altura ( $\left.\beta_{\mathrm{hkl}}\right)$ e o ângulo $\left(\theta_{\text {hkl }}\right)$ do pico referente ao plano escolhido, sendo estes parâmetros relacionado na equação 2.3.

$$
D_{h k l}=\frac{k \lambda}{\beta_{h k l} \cos \theta_{h k l}}
$$

Esta equação, chamada fórmula de Scherrer, costuma dar uma estimativa aproximada do tamanho médio de grão, e não é muito confiável para diâmetros maiores que, aproximadamente, $100-200 \mathrm{~nm}$, devido aos limites de resolução dos instrumentos utilizados, onde o aumento dos tamanhos de grãos implica em picos mais estreitos [41]. 


\subsubsection{Varredura em $\phi$}

A segunda técnica utilizada na caracterização estrutural das amostras foi a de varredura em $\phi$, onde a amostra gira em torno do eixo perpendicular ao plano do filme. Dentro da rede cristalina é possível identificar um conjunto de planos os quais não estão orientados de acordo a difratarem o feixe incidente quando feitas medidas na configuração $\theta-2 \theta$, porém são planos acessíveis através de mudanças no posicionamento do feixe incidente e do detector.

Na Figura 2-5 apresenta-se o plano (211) como exemplo, o qual foi utilizado nas medidas de nossas amostras. Em (a) encontra-se o plano na célula unitária cúbica, sendo apresentado em (b) os principais átomos da rede que constituem tal plano. Este plano possui uma simetria de $90^{\circ}$, o que implica numa medida em função do ângulo $\phi$, detectarmos quatro picos.

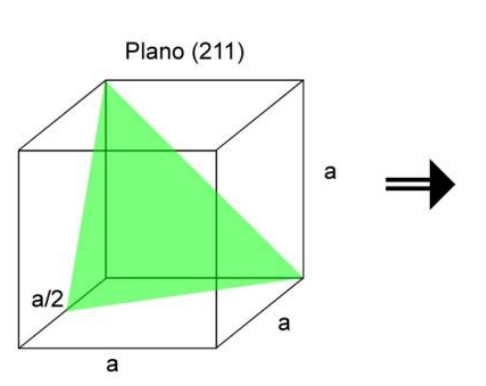

(a)

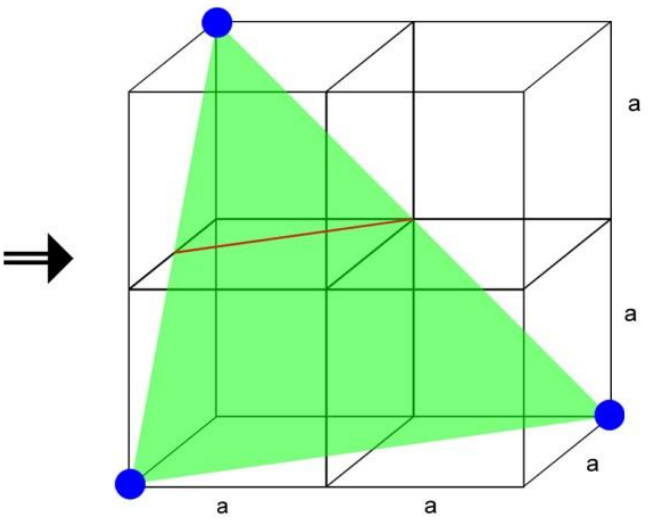

(b)

Figura 2-5. Plano (211) em uma rede cúbica. Em (a) encontra-se o plano na célula unitária e em (b) os três principais átomos da rede que forma este plano.

No caso de nossas amostras, que possuem uma célula unitária cúbica de corpo centrado, a identificação dos planos assimétricos se torna simples. Para tal, devemos, primeiramente, escolher um plano que não seja observado na medida $\theta-2 \theta$ (chamado de plano assimétrico), para isto utilizamos o banco de dados dos picos de espalhamento do material, e posicionar o feixe e o detector nos respectivos ângulos. Posteriormente rotacionamos a amostra de acordo a termos um ângulo de 
$\theta-\alpha$ entre o feixe e a amostra e um ângulo de $\theta+\alpha$ entre o detector e a amostra, sendo $\alpha$ o ângulo entre o plano assimétrico escolhido e um plano simétrico (existente na medida $\theta-2 \theta$ ) o qual iremos utilizar como referência, sendo para nós o plano (100). Ângulos entre planos podem ser encontrados na referência [40]. Na Figura 2-6 encontra-se um esquema de como o feixe e o detector são rotacionados.

Ao fazermos estas medidas para cada camada, seja ela substrato ou filmes depositados, quando comparados os espectros uns com os outros obtemos a informação de como ocorre o acoplamento estrutural entre as camadas, sendo este método eficiente para a verificação de epitaxia.

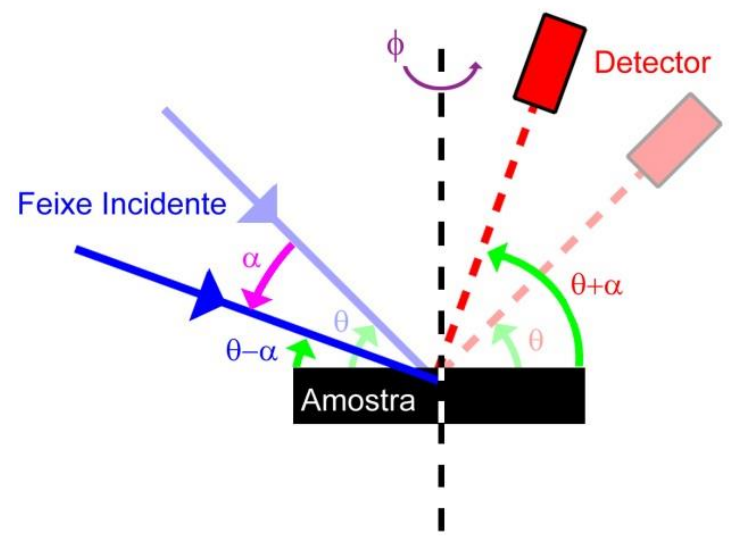

Figura 2-6. Rotação em $\alpha$ nos ângulos de incidência e espalhamento utilizados na varredura em $\phi$.

\subsubsection{Rocking Curves}

A última técnica utilizada foi a chamada Rocking Curve. Neste caso o ângulo entre o feixe incidente e o refletido permanece constante, como mostrado na Figura 2-7. Esta técnica permite analisar a uniformidade dos grãos cristalinos existentes na amostra onde os mesmos formam uma estrutura mosaica ao longo do filme. 


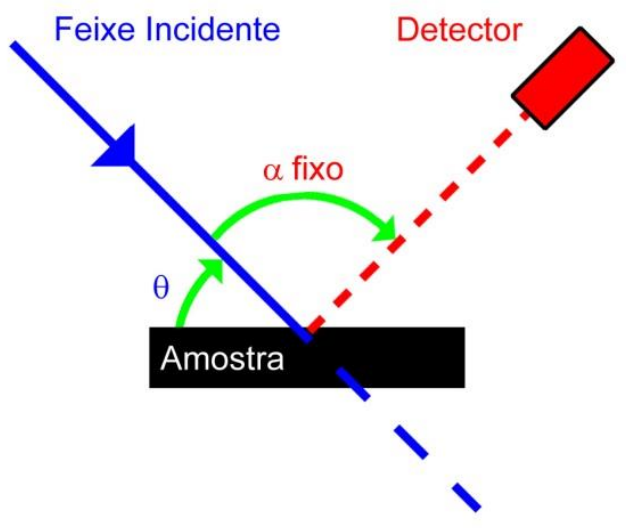

Figura 2-7. Ângulos de incidência e espalhamento na configuração Rocking Curve.

A medida rocking curve é feita de forma individual para cada pico obtido na varredura $\theta-2 \theta$. Nesta medida o feixe e o detector se encontram na posição de difração $\theta-2 \theta$ de um determinado plano escolhido, sendo varrido um ângulo $\theta+\gamma$. Para uma amostra ideal, com uma rede cristalina infinita, teríamos apenas um espaIhamento no ângulo $\theta$, porém, em uma amostra real, existe uma distribuição de orientações de planos em torno do valor de $\theta$. A distribuição encontrada é bem aproximada por uma função gaussiana, podendo ser analisada a partir da equação 2.4, sendo o desvio padrão $\eta$ denominado como a largura mosaico.

$$
f(\theta)=\frac{1}{\eta \sqrt{2 \pi}} e^{\frac{-\theta^{2}}{2 \eta^{2}}}
$$

Muitos trabalhos apresentam $\eta$ como sendo a largura à meia altura (FWHM full width at half maximum) da função gaussiana, para exemplo ver [42]. Tal fato ocorre devido FWHM ser dado pela eq. 2.5, implicando apenas num fator constante.

$$
\mathrm{FWHM}=2 \sqrt{2 \ln (2) \eta}
$$




\subsection{Magnetômetro de Amostra Vibrante}

No artigo publicado em 1956 [43], Foner descreve um método simples (e barato) para medidas de momentos magnéticos, que consiste em fazer uma amostra vibrar numa frequência bem definida, medindo a corrente induzida pela amostra em bobinas estrategicamente posicionadas, aplicando-se a lei de Faraday ${ }^{9}$. O sistema era composto, basicamente, por um alto falante, utilizado para vibrar a amostra, a qual estava fixada em uma haste, um par de bobinas ligadas em série, mas com orientações opostas, para a medida de momento magnético, e uma fonte de campo magnético. O funcionamento básico do nosso sistema de medida não se diferencia muito do apresentado por Foner. Nosso aparelho é um modelo comercial VSM 7404, produzido pela LakeShore, equipado com um criostato e um forno, localizado no Laboratório de Materiais Magnéticos (LMM) do Instituto de Física da USP. Todo o sistema de medidas e controle do VSM é feito via um programa, sendo apenas o alinhamento da amostra manual.

O VSM está equipado com uma fonte de alimentação de $2450 \mathrm{~W}$ com corrente / tensão máxima de saída de $\pm 70 \mathrm{~A} / \pm 35 \mathrm{~V}$. O conjunto de eletroímãs é constituído por duas bobinas com peças polares de 2 polegadas $(5,28 \mathrm{~cm})$ de diâmetro de face, possuindo gap de abertura variável, sendo permitido uma abertura um pouco maior que $11 \mathrm{~cm}$. A homogeneidade do campo é de $1 \mathrm{~cm}^{3} \pm 1 \%$. A medida de campo magnético é feita através de um gaussímetro equipado com um sensor Hall ${ }^{10}$, sendo a orientação do sensor perpendicular ao eixo do campo magnético aplicado, sendo a precisão da medida de $1 \%$. O controle do campo magnético é feito através de um programa, podendo ser controlado em dois modos: no modo corrente controla-se a corrente aplicada nos eletroímãs, gerando um campo magnético proporcional, e no modo campo controla-se o campo a partir das medidas do sensor Hall, onde o programa controla a corrente aplicada de acordo com a necessidade. Este último modo anula efeitos de possíveis magnetizações remanentes existentes nas peças polares, uma vez que o controle é feito em função do campo magnético total e não apenas

\footnotetext{
${ }^{9}$ Michael Faraday.

${ }^{10}$ Edwin Herbert Hall.
} 
daquele gerado pelos eletroímãs. O campo máximo obtido é de 21,7 kOe para um gap de abertura de $16 \mathrm{~mm}$.

A medida de momento magnético é feita através de quatro bobinas de 1,27 cm de diâmetro cada, dispostas duas a duas, sendo ligadas em série em cada par e de forma oposta entre os pares, sendo a amplificação do sinal feita através de um amplificador tipo lock in. Como padrão de calibração utiliza-se uma esfera de $\mathrm{Ni}$ com momento magnético conhecido em um dado campo magnético aplicado. Todas as vezes que o gap for alterado o sistema deve ser recalibrado, uma vez que as bobinas se movimentam junto das peças polares, medindo um sinal mais ou menos intenso de acordo com a distância da amostra. A incerteza apresentada na medida de momento magnética é menor do que $1 \%$. O alinhamento da amostra deve ser feito de modo a apresentar um momento magnético máximo nos eixos perpendiculares ao eixo do campo magnético aplicado e um momento mínimo no eixo paralelo ao do campo.

O head drive, sistema de vibração da amostra e local onde a haste é fixada, vibra numa frequência fixa de $82 \mathrm{~Hz}$. Tal sistema está equipado com um motor de passo, o que permite rotacionar a amostra, com uma precisão $<1^{\circ}$, de forma a termos diferentes ângulos de incidência do campo magnético. Para fixação das amostras são utilizadas hastes inteiriças ou com porta amostras na extremidade, sendo as hastes de fibra de vidro ou quartzo e os porta amostras de Kel-F, nome comercial, ou nitreto de boro. As hastes de fibra de vidro e os porta amostras de Kel-F possuem propriedades que permitem a utilização em temperaturas criogênicas. As hastes de quartzo e os porta amostras são utilizados em medidas de altas temperaturas.

\subsubsection{Criostato}

Para as medidas em baixas temperaturas o VSM possui um criostato, modelo comercial fabricado pela Janis, que trabalha com fluxo contínuo de líquido criogênico, podendo ser $\mathrm{He}$ ou $\mathrm{N}_{2}$, sendo o mesmo mantido através de um tanque externo e um transferidor equipado com uma válvula para controle de fluxo. Em nossas medidas foi utilizado apenas $\mathrm{N}_{2}$ como líquido criogênico. Na Figura 2-8 encontra-se a 
montagem completa do VSM com o criostato, tanque de $\mathrm{Ni}_{2}$ e o transferidor instalados.

A estabilização da temperatura é feita através do controlador PID (Proporcional, Integral e Derivativo), permitindo uma estabilidade de $\pm 0,2 \mathrm{~K}$ quando utilizado $\mathrm{N}_{2}$. A temperatura mínima de trabalho é dependente do líquido criogênico $(77 \mathrm{~K}$ para o $\mathrm{N}_{2}$ e 4,2 $\mathrm{K}$ para o $\mathrm{He}$ ) e a temperatura máxima é de $450 \mathrm{~K}$.

Para as medidas fixamos a amostra ao porta amostra com graxa de silicone, fita teflon e fita adesiva kapton. O excesso de itens para fazermos a fixação foi necessário por segurança, uma vez que nos testes de utilização do criostato, quando utilizamos apenas a graxa de silicone, recomendação do fabricante, a amostra caiu dentro do criostato após uma sequência de medidas em diversas temperaturas. Com o aumento da temperatura a graxa se torna menos viscosa e, acrescentando o fato da amostra estar vibrando, corre-se o risco da amostra se soltar durante a medida. $O$ sinal apresentado por este conjunto de itens foi diamagnético.
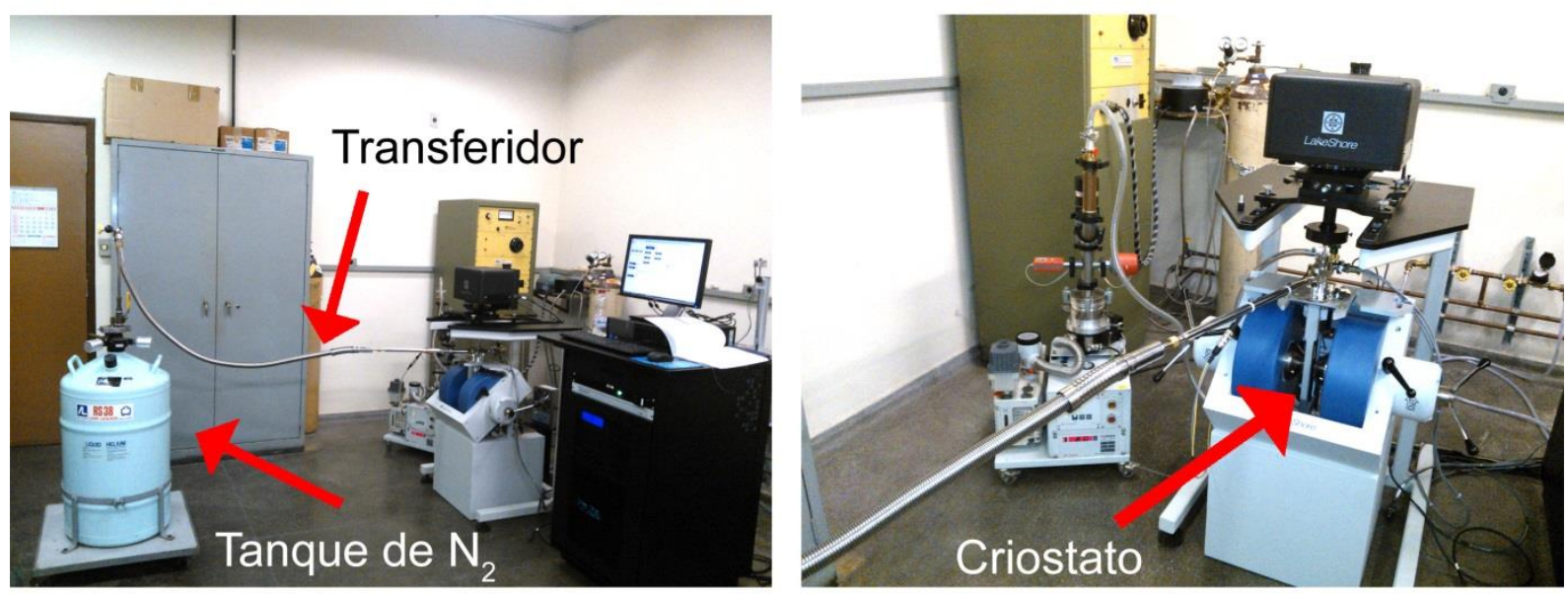

Figura 2-8. Montagem do VSM com o criostato, tanque de $\mathrm{Ni}_{2}$ e o transferidor.

Um recurso adicional existente é o de podermos gravar os valores de temperatura em função do tempo, onde podemos fazer uma análise da variação da temperatura durante a medida. Na Figura 2-9 encontra-se um exemplo da variação da temperatura ao longo do tempo de medida, junto da variação da porcentagem de aquecedor utilizada e a variação de temperatura por minuto. Pode-se observar uma linearidade no aquecimento e no resfriamento da amostra, com exceção de uma instabilidade ocorrida no resfriamento. 


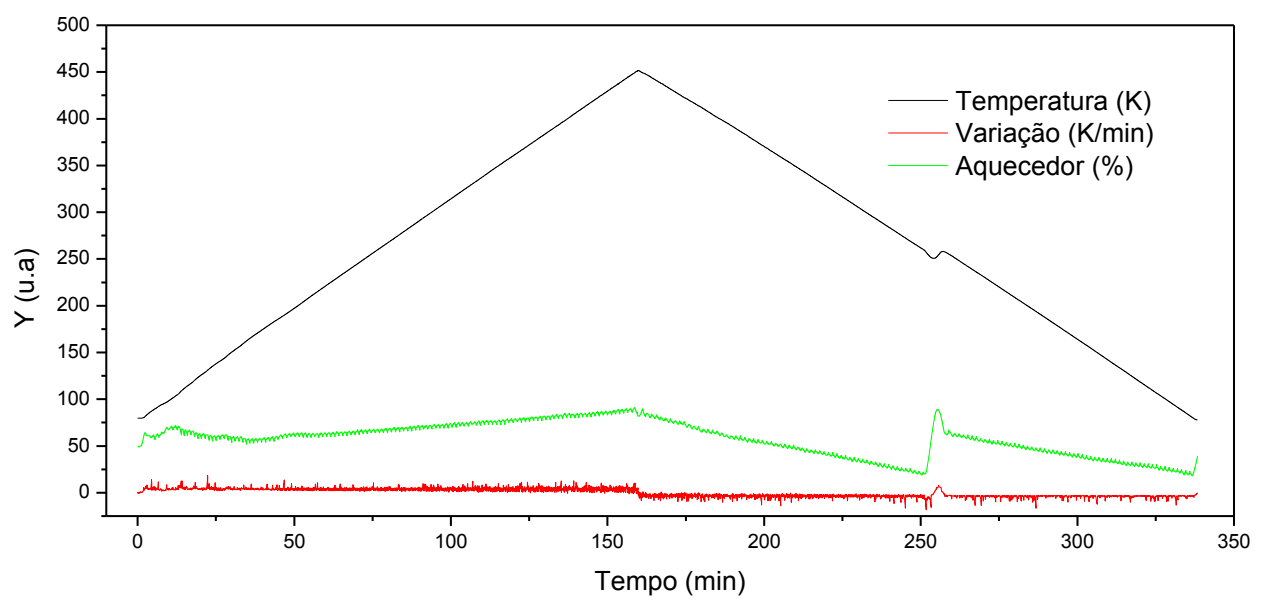

Figura 2-9. Variação da temperatura ao longo do tempo para a medida de ZFC - FC, junto da variação de temperatura por minuto e a porcentagem do aquecedor utilizada.

\subsubsection{Forno}

Para medidas acima da temperatura ambiente o VSM está equipado com um forno, modelo comercial da LakeShore, o qual permite medidas desde a temperatura ambiente até $1273 \mathrm{~K}$. O sistema trabalha linearmente em temperaturas acima de $373 \mathrm{~K}$. Para temperaturas abaixo de $373 \mathrm{~K}$ a variação da temperatura em função do tempo é linear apenas no aquecimento, enquanto no resfriamento torna-se cada vez mais lenta ao se aproximar da temperatura ambiente. A estabilização da temperatura, da mesma forma que no criostato, é feita através do controlador PID, permitindo uma estabilidade de $\pm 0,1 \mathrm{~K}$.

Para preservação das amostras e do aquecedor, evitando uma reação com o ar, é mantido um fluxo constante de gás Ar durante a medida. Da mesma forma que para o criostato existe o recurso de gravarmos a variação da temperatura em função do tempo.

Para a fixação da amostra utiliza-se uma massa cerâmica de óxido de alumínio, produzida pela Cotronics Corporation, sendo a mesma recomendada pela fabricante do VSM. A massa apresenta uma mudança estrutural no decorrer do aquecimento, onde em temperatura ambiente ela se encontra pastosa e enrijece com o aquecimento, alterando seu sinal magnético. Para evitarmos a mudança de sinal 
magnético da massa durante a medida é feito um rápido aquecimento prévio, suficiente para enrijecer a massa. O sinal magnético apresentado pela haste mais a massa enrijecida inseridos no forno encontra-se na Figura 2-10.

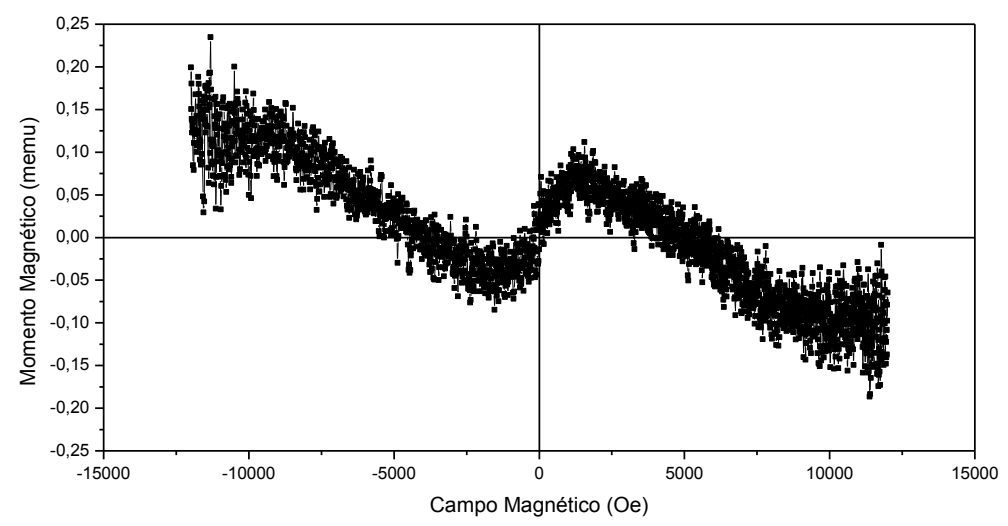

Figura 2-10. Sinal magnético apresentada pela haste de quartzo mais a massa para fixação da amostra inseridos no forno. 


\section{Capítulo 3: Produção e Caracterização Estrutural das Amostras}

Como apresentado na seção 1.3, o nosso interesse se encontra em estudar o comportamento magnético de filmes da liga FeRh com composição próxima a equiatômica. Em particular, buscava-se entender a influência da microestrutura do filme sobre a forma de curvas de magnetização $(\mathrm{M})$ versus temperatura $(\mathrm{T})$. Desta maneira, a obtenção das amostras foi feita através de deposições via magnetron sputtering. Foram criados dois grupos de amostras, diferenciados pela temperatura de deposição da camada de FeRh, onde cada grupo possuí amostras com três configurações diferentes, como será mostrado a seguir.

A caracterização das amostras foi feita inicialmente através de RBS, com o objetivo de se obter a espessura das camadas depositadas e, fundamentalmente, ter certeza que a estequiometria da camada de FeRh estivesse dentro da faixa de composições esperada. Posteriormente as características estruturais das diferentes amostras foram determinadas por difrações de raios $X$ nas configurações de varredura $\theta-2 \theta$, $\phi$ e rocking curve, sendo estas para a detecção dos planos simétricos, assimétricos e largura mosaico, respectivamente.

\subsection{Obtenção das Amostras via Magnetron Sputtering}

Para as deposições foram utilizados três alvos comerciais distintos de $\mathrm{Fe}, \mathrm{Rh}$ e Pt, sendo todos de alta pureza, 99,99\%. Os substratos utilizados foram monocristais de $\mathrm{MgO}$ (001), também comerciais, os quais foram cuidadosamente limpados antes das deposições. A utilização de substratos de $\mathrm{MgO}$ (001) se deu devido ser de conhecimento que a liga de FeRh que se forma com mais facilidade na fase $\mathrm{CsCl}$ quando depositada sobre este tipo de substrato. Também nesse caso resulta mais fácil obter amostras epitaxiais.

Feito vácuo na câmara principal do sputtering a pressão interna obtida foi da ordem de 2,5 $10^{-6}$ Torr. Injetou-se Ar mantendo-se a pressão interna em 5 mTorr com uma taxa de fluxo (flow rate) de $20 \mathrm{sccm}$. 
Por todo o período de deposição o porta substrato se manteve girando com o objetivo de se obter uma deposição uniforme ao longo do substrato, evitando-se aglomerações.

A camada de FeRh foi depositada por codeposição de Fe e Rh, sendo mantida uma potência de $50 \mathrm{~W}$ e $23 \mathrm{~W}$ para os alvos de Fe e Rh, respectivamente. Antes de se iniciar a deposição manteve-se o plasma aberto por 3 min para fazer uma "limpeza" dos alvos. A codeposição durou 53 min. Para as amostras do grupo 1 a deposição foi feita com o substrato na temperatura de $798 \mathrm{~K}$, sendo o mesmo mantido nesta temperatura durante, aproximadamente, 45 min antes da deposição. Depois de depositado esperou-se 2 min para iniciar o resfriamento. A escolha desta temperatura foi baseada em um trabalho recente de nosso grupo [44], onde foram feitas deposições em $773 \mathrm{~K}$, obtendo-se a formação da fase cristalina $\mathrm{CsCl}$ sem necessidade de tratamento térmico. Para as amostras do grupo 2 a deposição foi feita na temperatura de $913 \mathrm{~K}$, sendo realizado o mesmo processo que para o grupo 1 , mantendo a amostra na mencionada temperatura durante uma hora após a deposição, na própria câmara do magnetron sputtering. Neste caso escolhemos uma temperatura próxima à máxima permitida pelo sistema de aquecimento do sputtering, baseado nos trabalhos prévios que descrevem tratamentos térmicos apresentados na seção 1.3 .

Em algumas amostras foram depositadas uma camada de Fe com o intuito de estudar $\mathrm{o}$ acoplamento entre ambas as camadas. Para essas amostras a camada de Fe foi depositada na temperatura de $573 \mathrm{~K}$ para ambos os grupos, um valor suficientemente baixo para diminuir as chances de haver difusão do Fe dentro da camada de FeRh. O substrato foi mantido nesta temperatura por 40 min antes da deposição. A potência utilizada no alvo de Fe foi de $50 \mathrm{~W}$, com um tempo de deposição de 15 min. Após a deposição o sistema de aquecimento foi desligado, permitindo que as amostras resfriassem até a temperatura ambiente.

As amostras com camadas de Fe foram recobertas por uma fina camada de Pt apenas para proteção contra oxidação, sendo esta deposição realizada em temperatura ambiente. A potência utilizada no alvo de Pt foi de $50 \mathrm{~W}$ com um tempo de deposição de $5 \mathrm{~min}$. Previamente o plasma foi mantido aberto por 5 min para efetuar a "limpeza" do alvo. As amostras de FeRh não foram recobertas com Pt porque é 
conhecido que elas formam uma fina camada de óxido na superfície e que essa camada as protege eficientemente de posteriores oxidações.

Como o porta substrato possui janelas que podem ser fechadas sem a necessidade de abrir a câmara principal do sputtering é possível escolher em qual substrato a camada será depositada, desta forma foi possível produzirmos as três configurações de amostras com as mesmas condições de trabalho e tempos de deposição. As três configurações são dadas por:

$$
\begin{aligned}
& \text { A - Substrato / FeRh / Fe / Pt } \\
& \text { B - Substrato / FeRh } \\
& \text { C - Substrato / Fe / Pt }
\end{aligned}
$$

Desta forma, o nome das amostras foi dado pelo número do grupo quais pertencem acrescentado da letra respectiva referente a sua configuração (ex.: 1A Amostra do grupo 1 com a configuração A).

\subsection{Resultados da Espectroscopia de Retroespalhamento Rutherford}

A primeira caracterização feita nas amostras foi via RBS com o objetivo de verificar a estequiometria e a espessura das camadas depositadas. Tais resultados foram relevantes para darmos continuidade no estudo das mesmas, uma vez que o interesse estava centrado em amostras com composição, na camada de FeRh, próxima a equiatômica.

Os ajustes dos espectros experimentais foram realizados por meio dos programas SIMNRA [45] e Rump [46], sendo o último utilizado como referência e auxílio para os ajustes no primeiro.

Abaixo, na Figura 3-1, mostra-se, como exemplo, um gráfico com o espectro experimental da amostra $1 \mathrm{~A}$ e o ajuste obtido com o SIMNRA. Nele são identificados os picos correspondentes a cada elemento de nossa amostra, incluindo o substrato. 


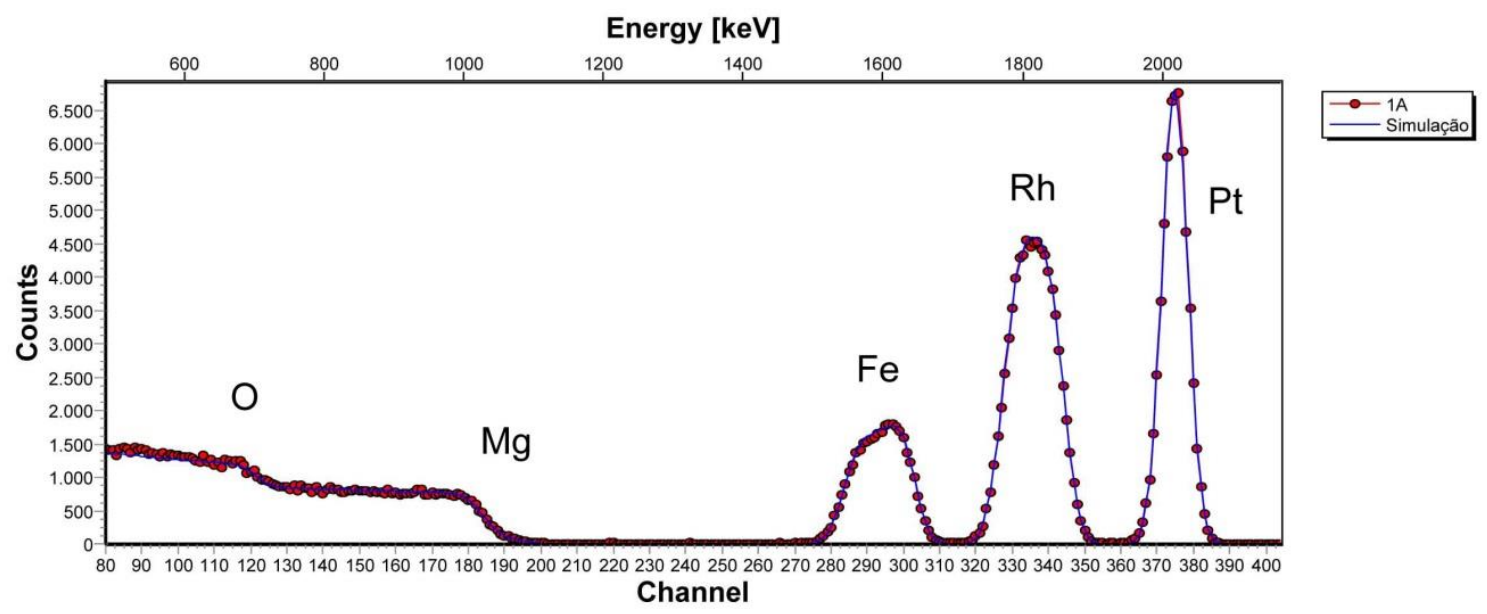

Figura 3-1. Espectro de RBS experimental da amostra 1A (pontos vermelhos) e ajuste feito pelo programa SIMNRA (linha contínua).

Como visto na Figura 3-1, os picos de espalhamento são isolados uns dos outros, tal fato permite a utilização da função thickness do Rump, onde a mesma faz uma integração numérica de um pico determinado, gerando um valor em átomos $/ \mathrm{cm}^{2}$. No caso das amostras na configuração B podemos obter, com um erro menor que 5\%, a composição da nossa camada.

Para o cálculo das espessuras (t) os programas utilizam um valor padrão para o parâmetro de rede de cada elemento, desta forma os primeiros resultados obtidos foram utilizados apenas como referência para darmos continuidade no ajuste. Posteriormente usamos os resultados de raios $X$ para determinar os correspondentes parâmetros de rede. Os cálculos são realizados por meio da seguinte equação:

$$
t=\frac{d a^{3}}{A}
$$

sendo $\mathrm{d}$ a densidade de área em átomos $/ \mathrm{cm}^{2}$ dada pelo programa, a é o parâmetro de rede do material e $A$ é a quantidade de átomos por célula unitária. Em nosso caso temos $A=2$ para FeRh e Fe e $A=2$ para Pt.

$\mathrm{Na}$ Tabela 3-1 mostram-se tanto as espessuras como as composições da camada de FeRh de cada amostra, assim como as espessuras das camadas de Fe e de Pt. 
Tabela 3-1. Espessuras das camadas e composição da camada de FeRh para cada amostra.

\begin{tabular}{c|cccc}
\hline & \multicolumn{3}{c|}{ Espessura $(\mathrm{nm})$} & Composição $(\mathrm{x})$ \\
\hline Amostra & $\mathrm{FeRh}$ & $\mathrm{Fe}$ & $\mathrm{Pt}$ & $\mathrm{Fe}_{1-\mathrm{x}} \mathrm{Rh}_{\mathrm{x}}$ \\
1A & $70(4)$ & $8,1(3)$ & $9,3(3)$ & $0,49(2)$ \\
1B & $73(4)$ & --- & --- & $0,49(2)$ \\
1C & --- & $7,1(3)$ & $8,8(3)$ & --- \\
2A & $68(3)$ & $8,3(3)$ & $9,3(3)$ & $0,50(2)$ \\
2B & $70(4)$ & --- & --- & $0,50(2)$ \\
2C & $1,8(1)$ & $7,6(3)$ & $8,1(2)$ & $0,66(3)$ \\
\hline
\end{tabular}

Observa-se que há uma fina camada de FeRh encontrada na amostra 2C (o que não foi previsto que acontecesse). Isto se explica porque houve, aparentemente, um fechamento incompleto da janela do porta substrato, o que permitiu a passagem de uma pequena quantidade de material no momento em que se estava depositando esta mesma camada nos demais substratos. Como as amostras $1 \mathrm{C}$ e $2 \mathrm{C}$ foram produzidas sob as mesmas condições, a amostra 2C não foi descartada, onde aproveitamos a camada de FeRh existente para compararmos um possível acoplamento entre esta camada e a camada de Fe. Para todas as amostras foi obtida a condição de composição próxima a equiatômica na camada de FeRh e condições similares de espessuras de camadas em todas as camadas da liga.

\subsection{Resultados da Difração de Raios X}

Como já mencionado, para caracterizações por difrações de raios $\mathrm{X}$ foram utilizados três técnicas de medidas diferentes. As primeiras medidas foram as varreduras $\theta-2 \theta$, o que permitiu identificar o ordenamento estrutural das camadas. Deu-se continuidade com as medidas na varredura em $\phi$, com as quais identificamos os planos assimétricos do filme e do substrato, identificando a epitaxia existente nos mesmos. Concluímos as medidas com as rocking curves, identificando a mosaicidade das amostras. 


\subsubsection{Varredura em $\theta-2 \theta$}

Devido à localização dos picos principais da liga de FeRh a varredura em $2 \theta$ foi feita de $20^{\circ}$ a $110^{\circ}$, sendo utilizado um passo de $0,05^{\circ}$ com um tempo de medida de $1 \mathrm{~s}$ por passo. Para evitar a perda de um pico de espalhamento devido a uma possível orientação preferencial do cristal, a amostra permaneceu girando em torno do eixo perpendicular a seu plano com uma velocidade de $60 \mathrm{rpm}$. Os resultados experimentais são mostrados na Figura 3-3 e confirmam a formação da estrutura $\mathrm{CsCl}$ (Figura 3-2), sugerindo que houve epitaxia entre a camada de FeRh e o substrato. Para as amostras 1A, 1B, 2A e 2B é possível identificar um pico, de pequena intensidade, referente ao plano (111), o qual pertence à estrutura $\gamma$ - Fe, sendo esta fase não ferromagnética.

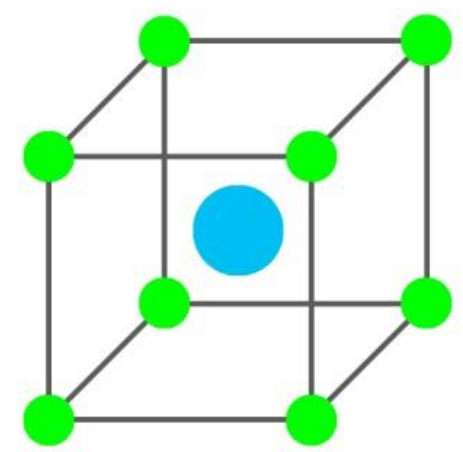

$\mathrm{Fe}$

$\mathrm{Rh}$

Figura 3-2. Imagem representativa da estrutura cristalina tipo $\mathrm{CsCl}$.

Todos os picos não indexados pertencem ao substrato. Para tal afirmação foi feito o espectro de difração do substrato nas mesmas condições das amostras e sobreposto ao espectro de cada uma. 

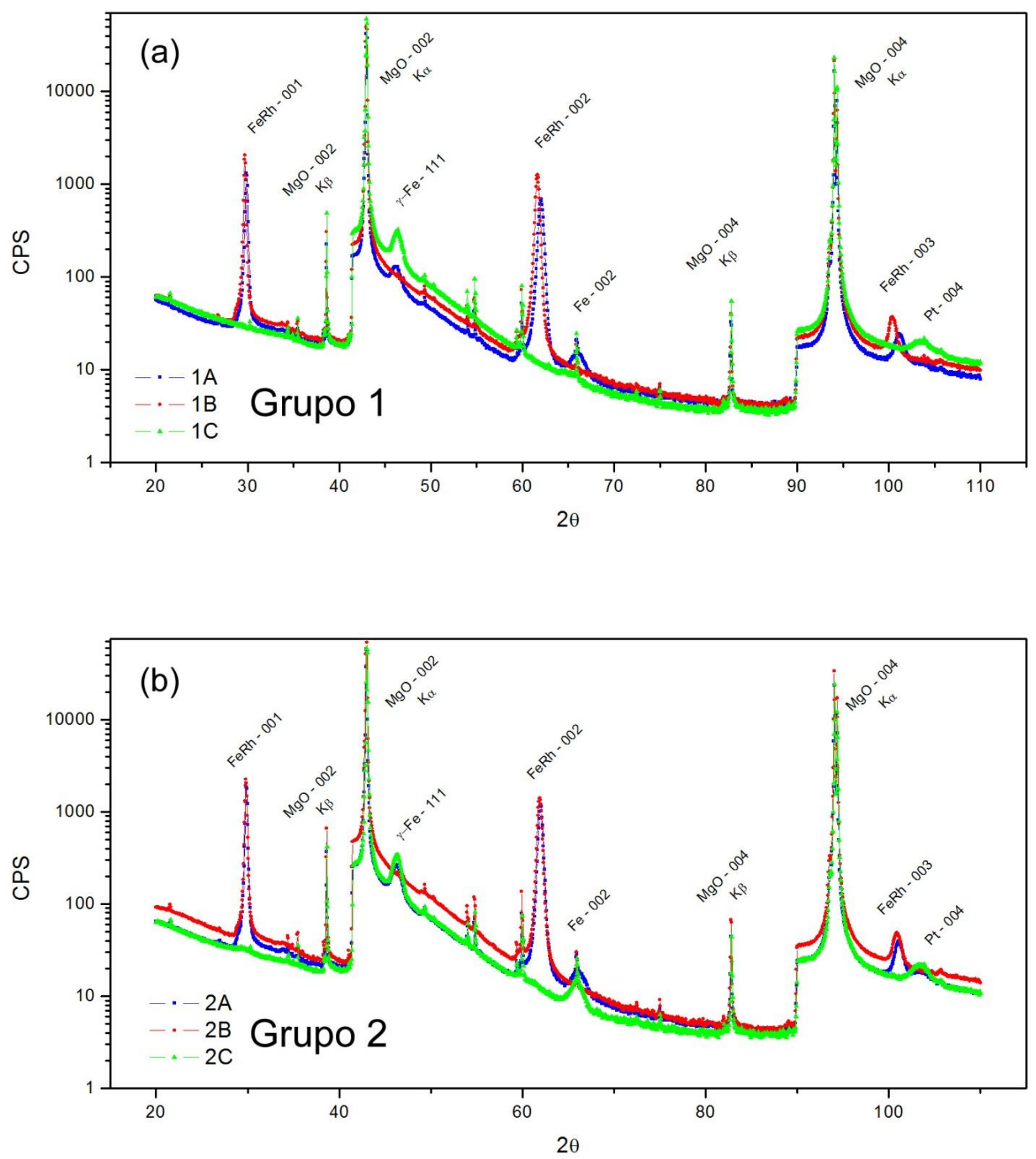

Figura 3-3. Difratograma de difração de raios $X$, na geometria $\theta-2 \theta$, para as amostras deste estudo: (a) Grupo 1 e (b) Grupo 2. 
A partir da identificação dos picos nos espectros de difração, os valores dos parâmetros de rede das fases envolvidas foram calculados e os resultados são mostrados na Tabela 3-2.

Tabela 3-2. Parâmetros de rede calculados para as nossas amostras. Os valores para as amostras massivas são colocados para fins de comparação.

\begin{tabular}{cccccccc}
\hline & \multicolumn{7}{c}{ Parâmetros de rede $(\AA)$} \\
Camadas & $1 \mathrm{~A}$ & $1 \mathrm{~B}$ & $1 \mathrm{C}$ & $2 \mathrm{~A}$ & $2 \mathrm{~B}$ & $2 \mathrm{C}$ & Bulk \\
\hline $\mathrm{MgO}$ & $4,21(9)$ & $4,21(9)$ & $4,21(9)$ & $4,21(9)$ & $4,21(9)$ & $4,21(9)$ & 4,212 \\
$\mathrm{FeRh}$ & $2,99(6)$ & $3,01(6)$ & --- & $3,00(6)$ & $3,00(6)$ & --- & 2,983 \\
$\mathrm{Fe}$ & $2,8(1)$ & --- & --- & $2,8(1)$ & --- & $2,8(1)$ & 2,867 \\
\hline
\end{tabular}

Para a camada de FeRh os valores dos parâmetros de rede são 0,5 - 0,9\% maiores que o parâmetro apresentado pela liga $\mathrm{Fe}_{50} \mathrm{Rh}_{50}(\mathrm{a}=2,983(7) \AA)$ tipo bulk [16], sugerindo, desta forma, a existência de tensões na interface filme / substrato, as quais favorecem o surgimento de uma estrutura policristalina nos filmes.

Utilizando a equação 2.3, foram calculados os diâmetros médios de grão para os planos cristalinos (001) da liga de FeRh. Os valores calculados podem ser encontrados na Tabela 3-3, sendo apresentados, na Figura 3-4, os picos de espalhamentos do plano (001) de cada amostra e seus respectivos valores de largura a meia altura (FWHM).

Tabela 3-3. Diâmetro médio dos grãos cristalinos do plano (001) da liga de FeRh.

\begin{tabular}{cc}
\hline Amostra & Diâmetro $(\mathrm{nm})$ \\
\hline 1A & $29(3)$ \\
1B & $35(4)$ \\
2A & $32(3)$ \\
2B & $33(3)$ \\
\hline
\end{tabular}

Os resultados da Tabela 3-3 sugerem que não houve grandes variações entre os tamanhos de grãos das diferentes amostras, mesmo havendo diferenças entre tratamentos térmicos. Durante o resfriamento, após a deposição e tratamento térmi- 
co, existem fortes tensões na interface substrato / filme devido aos diferentes coeficientes de dilatação térmica de cada material, o que favorece a formação de grãos no filme. Observando à proximidade entre os diâmetros médios de grão, sugere-se que estes estão fortemente relacionados ao resfriamento da amostra, o qual minimiza os efeitos do tratamento térmico.

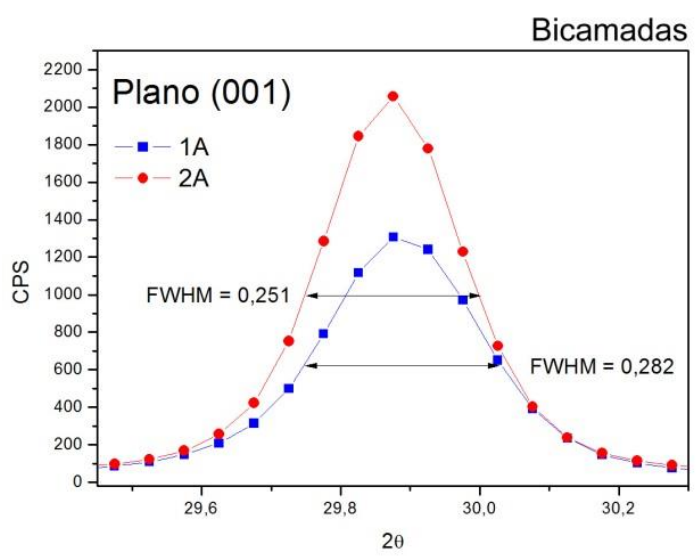

(a)

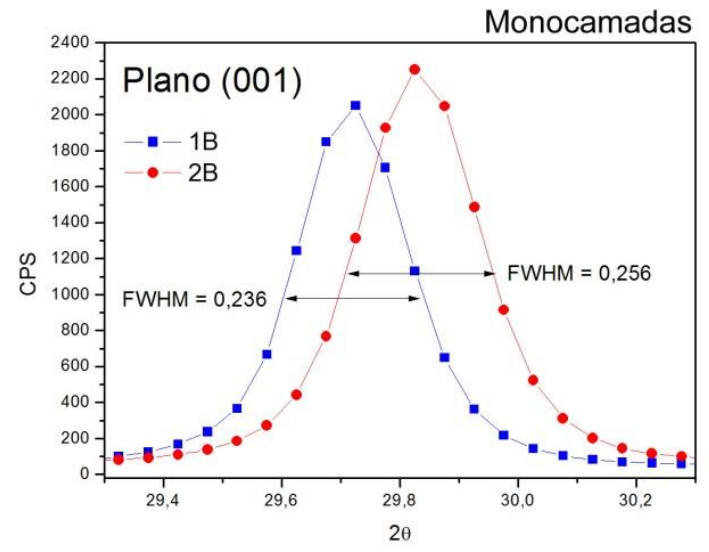

(b)

Figura 3-4. Picos de espalhamento do plano (001) e seus respectivos valores de largura a meia altura (FWHM) dado em radianos. Em (a) amostras 1A e 2A (bicamadas) e em (b) amostras 1B e 2B (monocamadas).

\subsubsection{Varredura em $\phi$}

Materiais como o $\mathrm{Fe}, \mathrm{Co}, \mathrm{Pt}$, entre outros, podem mostrar um crescimento epitaxial quando depositados via sputtering sobre $\mathrm{MgO}$. No caso do $\mathrm{Fe}$, quando crescidos na orientação bcc (cúbica de corpo centrado) sobre o substrato $\mathrm{MgO}$ (001) sofrem uma rotação de $45^{\circ}$ da célula unitária com relação à célula do substrato [42]. Considerando a proximidade dos parâmetros de rede e da estrutura cristalográfica do FeRh ( $\mathrm{CsCl}$ ) com o $\mathrm{Fe}(\mathrm{bcc})$, tem-se que a célula unitária do FeRh sofre a mesma rotação apresentada pelo $\mathrm{Fe}$, quando depositado em MgO (001). Uma representação de tal rotação encontra-se na Figura 3-5. 
(a)
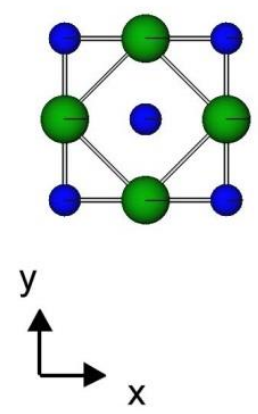

(b)

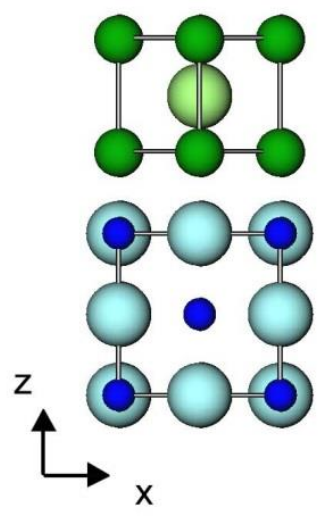

(c)

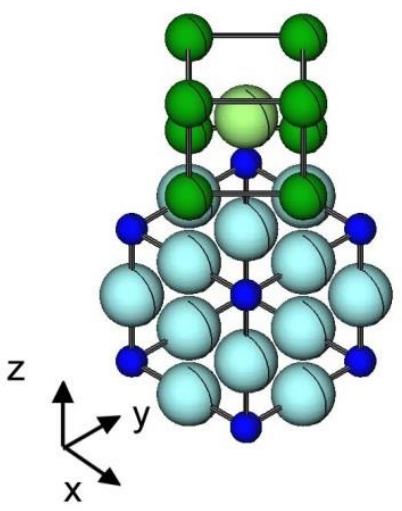

$\mathrm{Mg}$

$\mathrm{O}$

$\mathrm{Fe}$

$\mathrm{Rh}$

Figura 3-5. Representação esquemática das células de FeRh e MgO; (a) Vista de cima (sem os átomos de $\mathrm{O}$ e Rh); (b) Vista lateral; (c) Vista dos três eixos.

Calculando $(a / 2) \sqrt{2}$, sendo a o parâmetro de rede (ver Figura 3-6), para o substrato da amostra $1 A$ obtém-se $2,977 \AA$, o que é uma variação menor que $0,5 \%$ com relação ao parâmetro de rede do $\operatorname{FeRh}(2,99 \AA$ A ) da mesma amostra. Esta proximidade nas dimensões favorece a minimização de energia do sistema durante a deposição com a formação de estrutura $\mathrm{CsCl}$ rotacionada em $45^{\circ}$, em relação ao substrato.

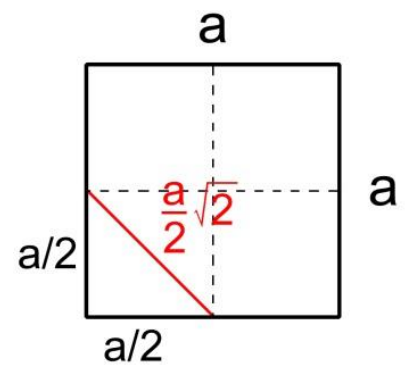

Figura 3-6. Diagonal de um quadrado de meio parâmetro de rede.

Em nossas medidas o plano assimétrico utilizado foi o (211), o qual forma um ângulo de $\alpha=35,3^{\circ}$ em relação ao plano (001). Desta forma, o posicionamento do feixe e do detector, primeiramente, foi da forma convencional $\theta-2 \theta$ para o plano (211), sendo $2 \theta=127,196^{\circ}$ para o $\mathrm{MgO}$ e $2 \theta=78,304^{\circ}$ para o FeRh. Uma vez posicionados estes instrumentos, eles foram reposicionados de modo a formarem um ângulo, com relação ao plano do filme, de $\theta-\alpha$ para o feixe e $\theta+\alpha$ para o detector 
(ver Figura 2-6). Posicionados o feixe e o detector, foi utilizado um passo de $0,1^{\circ} \mathrm{em}$ $\phi$, sendo o tempo de medida de 3 s para o substrato e 10 s para a camada de FeRh.

Como exemplo, na Figura 3-7 encontra-se o gráfico dos dados experimentais para a amostra 2B onde estão colocados os ângulos aproximados entre os picos do substrato e os picos da camada de FeRh.

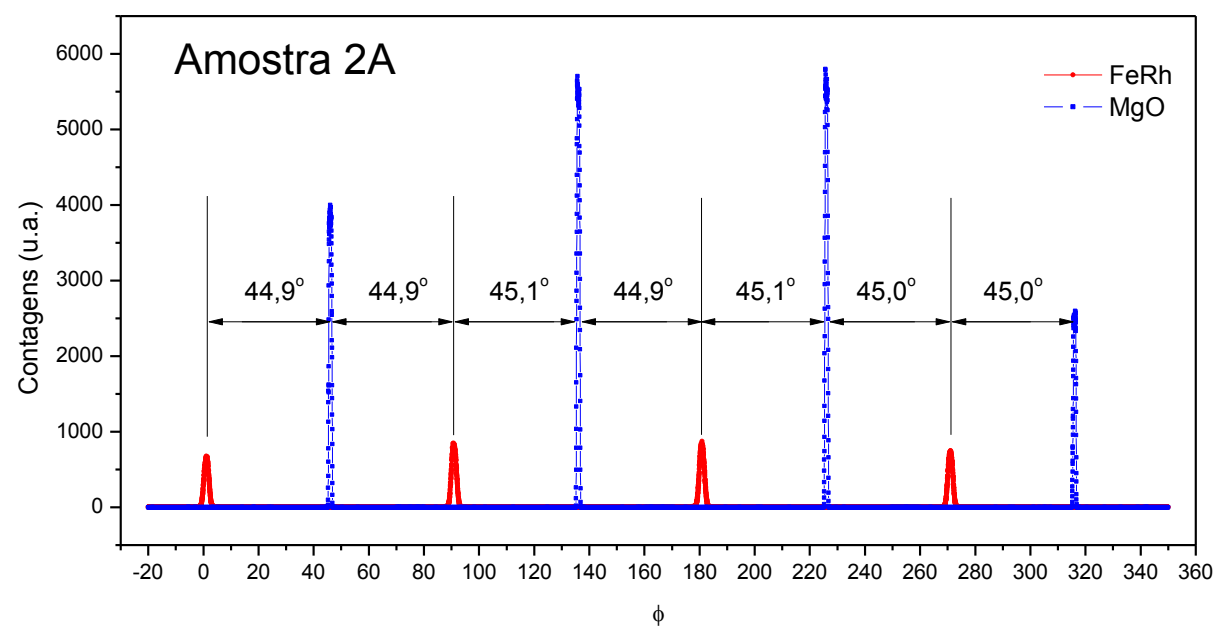

Figura 3-7. Difratograma de raios $\mathrm{X}$ para a amostra $2 \mathrm{~A}$ na varredura em $\phi$.

Para todas as amostras os ângulos obtidos foram equivalentes aos da amostra $2 \mathrm{~A}$, o que nos permitiu concluir que houve epitaxia entre o substrato e o filme depositado para todas as amostras produzidas.

\subsubsection{Resultados das Medidas do tipo Rocking Curves}

As medidas do tipo rocking curves foram feitas como uma tentativa de se encontrar possíveis diferenças estruturais nas amostras obtidas. As medidas foram feitas apenas para as amostras $1 \mathrm{~A}$ e $2 \mathrm{~A}$, sendo utilizado o plano (002) do FeRh. O ângulo $\phi$ permaneceu constante por toda a medida, sendo utilizado um passo de $0,02^{\circ}$ para o ângulo do feixe e um tempo de 2 s/passo. Na Figura 3-8 encontram-se as duas medidas realizadas. 


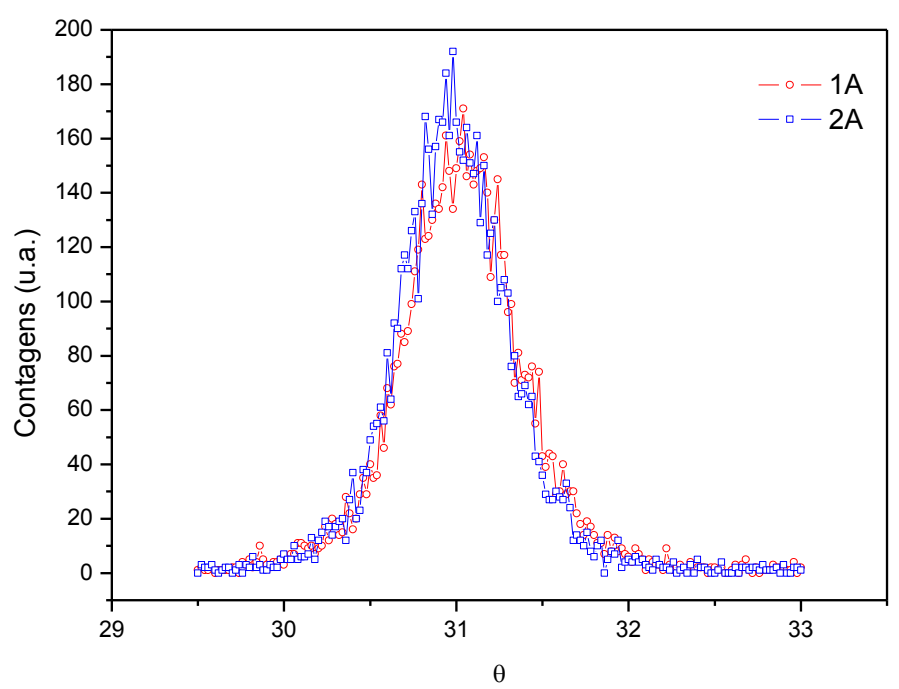

Figura 3-8 Rocking curve do plano (002) para as amostras $1 \mathrm{~A}$ e $2 \mathrm{~A}$.

A análise das medidas foi feita através da equação 2.5, onde foram calculadas as larguras mosaico $\eta$, sendo as mesmas apresentadas na Tabela 3-4. $2 \mathrm{~A}$.

Tabela 3-4. Largura mosaico dos planos (002) da camada de FeRh para as amostras 1A e

\begin{tabular}{cc}
\hline Amostra & $\eta\left(^{\circ}\right)$ \\
\hline $1 \mathrm{~A}$ & $0,346(5)$ \\
$2 \mathrm{~A}$ & $0,317(4)$ \\
\hline
\end{tabular}

Comparando os resultados concluímos que a amostra 2A possui uma maior uniformidade de grãos com relação à amostra 1A. Tal uniformidade pôde ser interpretada como uma melhor orientação dos grãos com relação a uma direção preferencial e não apenas pela amostra possuir maiores diâmetros de grãos e, consequentemente, menos grãos ao longo do filme. Essa maior uniformidade na orientação da amostra 2A é compatível com os resultados obtidos por Inoue [30], onde as amostras que passaram por tratamentos térmicos em temperaturas mais elevadas obtiveram uma melhor orientação cristalográfica. 


\subsubsection{Considerações sobre a microestrutura das amostras}

No presente trabalho foram preparados dois conjuntos de filmes de FeRh e FeRh/Fe, depositados sobre substratos de MgO (100). Os dois grupos se diferenciam na temperatura à qual se encontrava o substrato no momento da deposição, embora em ambos os casos foram usadas temperaturas altas o suficiente, de maneira a se obter a estrutura cristalina $\mathrm{CsCl}$ da fase $\mathrm{FeRh}$. A diferença de temperatura do substrato entre os dois grupos de amostras foi de $\sim 140 \mathrm{~K}$, e o uso das diversas técnicas de raios $X$ utilizadas para caracterizar as amostras visavam encontrar diferenças entre as microestruturas das camadas de FeRh em ambos grupos. Como se mostra na Figura 3-4 a comparação entre os espectros de raios $X$ na configuração $\theta-2 \theta$ das amostras 1B e 2B não mostra diferenças significativas quanto à posição dos picos de difração, o que é compatível com termos a mesma estrutura e praticamente a mesma composição da fase FeRh. As diferenças no diâmetro médio de grão (ver Tabela 3-3), também foram muito pequenas, de maneira que a diferença de temperaturas nos tratamentos não levaram a variações significativas deste parâmetro.

A medida feita em ângulos assimétricos simplesmente confirmou a existência de epitaxia entre filme e substrato para todas as amostras.

A última técnica utilizada, rocking curve, retorna a distribuição média de grãos referentes a um determinado plano de espalhamento. Como apresentada na seção 1.3, amostras com tratamentos térmicos feitos em temperaturas mais altas apresentam uma melhor uniformidade na distribuição de orientação dos grãos. Esta diferença na distribuição foi observada em nossas amostras, tornando-se este o único parâmetro em que podemos distinguir nossas amostras quando comparadas suas estruturas cristalinas.

Assim, podemos concluir que as diferenças estruturais entre as amostras do grupo 1 e as do grupo 2 são grãos com melhor uniformidade de distribuição de orientação para as do segundo grupo, ou seja, aquelas amostras que foram crescidas com uma temperatura maior do substrato. 


\section{Capítulo 4: Caracterização Magnética das Amostras}

Devido ao interesse em estudar a mudança de fase magnetoestrutural de primeira ordem apresentada pelas ligas de FeRh, as primeiras medidas feitas nas amostras foram as de momento magnético em função da temperatura, onde as amostras foram resfriadas e aquecidas sob campo constante. Isto permitu identificar as temperaturas de transição de cada amostra, ou, mais precisamente, as regiões de temperaturas de transição.

Posteriormente foram feitas medidas de momento magnético em função do campo magnético aplicado em diversas temperaturas, com o objetivo de se criar um perfil magnético ao longo da região de temperaturas de transições. Esta etapa foi dividida em duas, sendo a primeira feita com as mesmas amostras utilizadas para as medidas de momento magnético em função da temperatura e a segunda etapa feita com amostras virgens.

Os filmes monocamadas de Fe também foram submetidos a medidas de momento magnético em função de campo magnético aplicado, mas apenas em temperatura ambiente, e simplesmente com o objetivo de se ter uma referência para as intensidades de campos coercivos e para verificar um possível deslocamento das histereses com relação ao eixo campo.

\subsection{Estudo dos Ciclos Térmicos das Amostras}

Uma forma de estudar a transição de fase AFM - FM nas ligas de FeRh é usar as curvas conhecidas como Zero Field Cooling (ZFC) e Field Cooling (FC). O procedimento experimental consiste em resfriar a amostra até uma dada temperatura sem campo magnético aplicado, partindo da temperatura ambiente. Depois aplicase um campo e se aquece a amostra novamente enquanto a magnetização é medida em função da temperatura, esta curva $\mathrm{M}(\mathrm{T})$ é a chamada curva ZFC. Atingida a temperatura máxima escolhida, a amostra é resfriada novamente, mas mantendo 0 campo aplicado, e a nova curva M (T) gerada é a chamada curva FC. O conjunto 
formado por uma curva ZFC e a correspondente curva FC com retorno à temperatura inicial formam um ciclo térmico.

As primeiras medidas ZFC - FC consistiram em resfriar a amostra até $80 \mathrm{~K}$, a campo zero, aplicar um pequeno campo, de $100 \mathrm{Oe}$, que foi mantido constante por toda a transição, aquecer a amostra até, no máximo, $450 \mathrm{~K}$ e resfriar novamente até $80 \mathrm{~K}$. O objetivo de aplicar um pequeno campo foi o de favorecer uma direção para alinhar o momento magnético da amostra durante a transição.

Este procedimento foi efetuado para as amostras de configurações A (bicamadas) e B (monocamadas) virgens, com o objetivo de verificar a existência da transição de fase magnética e identificar possíveis diferenças entre as amostras com diferentes tratamentos térmicos na produção, além do efeito de acoplamento entre a camada de Fe e a camada de FeRh.

Efetuada as medidas mencionadas anteriormente as mesmas foram reproduzidas, com as mesmas amostras, mas com um campo aplicado de $10 \mathrm{kOe}$. O objetivo destas medidas foi de verificar a existência de um deslocamento na temperatura de transição da amostra, como tem sido relatado em vários trabalhos [20][24][47].

Como num filme há uma grande dificuldade na identificação da quantidade de material existente na amostra, todos os resultados serão apresentados em função do momento magnético (emu) e não em função da magnetização $\left(\mathrm{emu} / \mathrm{cm}^{3}\right)$. Tentativas de estimarmos o volume de material depositado foram feitas, porém os resultados apresentaram magnetizações consideravelmente acima das magnetizações apresentadas por amostras tipo bulk.

A velocidade de aquecimento e resfriamento durante as medidas ZFC e FC foi de $3 \mathrm{~K} / \mathrm{min}$, sendo que a oscilação de temperatura permitida para cada ponto foi $\pm 2 \mathrm{~K}$, para o qual foi necessária uma estabilização de $30 \mathrm{~s}$ para cada ponto medido. O objetivo desta variação de temperatura ser grande com um tempo de estabilização curto foi de permitir uma evolução linear da temperatura. Os pontos foram adquiridos a cada $3 \mathrm{~K}$.

A seguir vamos comparar, principalmente, resultados de amostras com iguais configurações. Nomeamos a temperatura crítica da transição AFM $\rightarrow$ FM (a qual se da no aquecimento) como $T_{A F M}$ - FM $e$ a transição inversa (que se verifica durante 0 resfriamento) como $T_{F M}$ - AFM, sendo elas definidas como a temperatura em que temos o máximo da derivada do momento magnético com relação à temperatura 
$(\operatorname{MAX}(\partial \mathrm{m} / \partial \mathrm{T}))$. A faixa de temperatura onde ocorre a transição, isto é, a variação de temperatura entre o início e o fim da transição, foi definida como $\Delta T_{A}$ no aquecimento e $\Delta T_{R}$ no resfriamento.

\subsubsection{Amostras monocamadas}
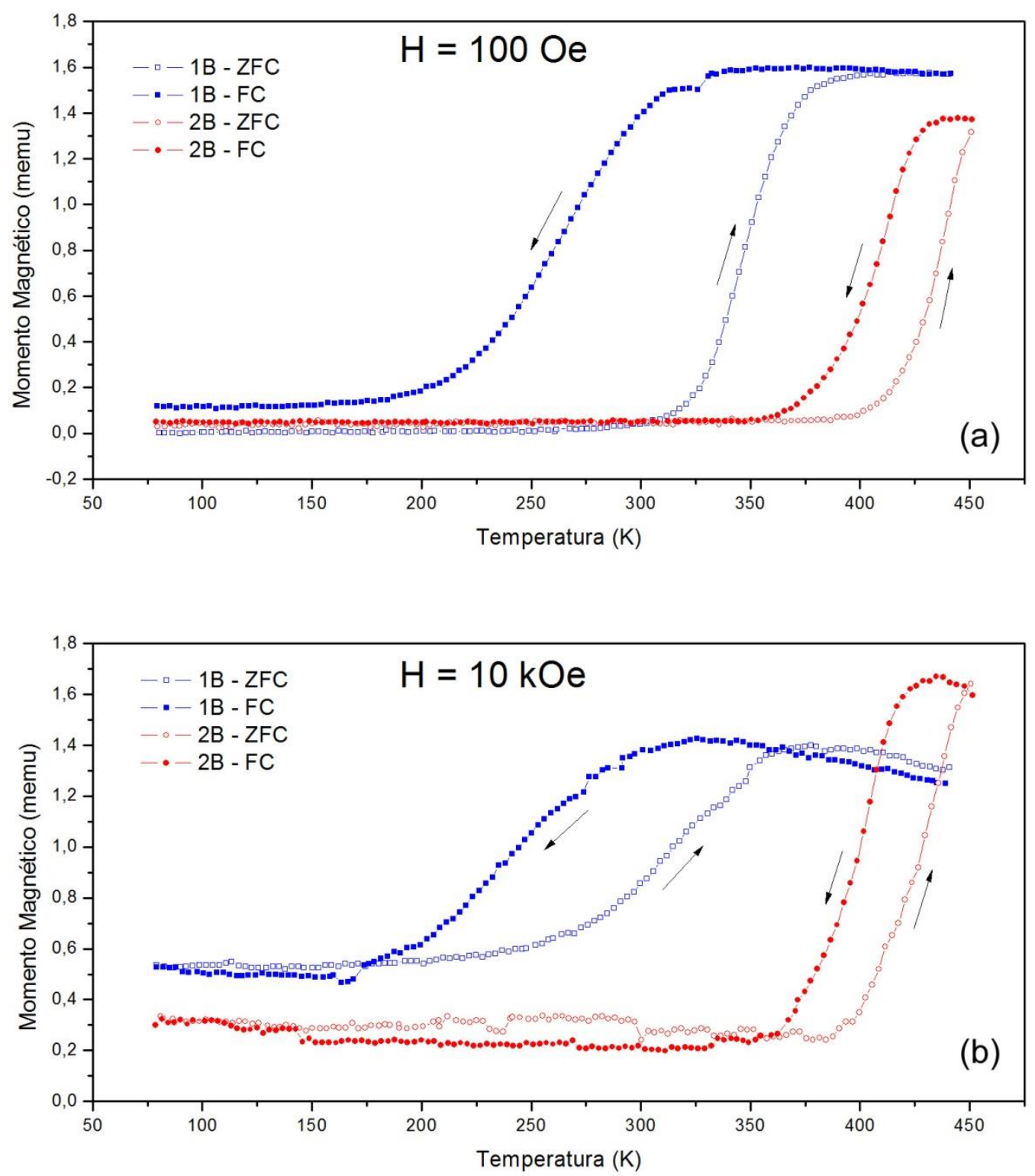

Figura 4-1. Curvas ZFC - FC medidas para as amostras 1B e 2B com campo aplicado de (a) 100 Oe e (b) 10 kOe. 
Na Figura 4-1 (a) encontram-se as transições AFM $\rightarrow$ FM e FM $\rightarrow$ AFM para as amostras $1 \mathrm{~B}$ e $2 \mathrm{~B}$ medidas com um campo de 100 Oe aplicado ao longo do plano do filme. A amostra 1B apresentou no aquecimento o início da transição em $260 \mathrm{~K}$ com $\mathrm{T}_{\mathrm{AFM}-\mathrm{FM}}=347 \mathrm{~K}$ e $\Delta \mathrm{T}_{\mathrm{A}} \cong 160 \mathrm{~K}$. No resfriamento o início da transição inversa ocorreu em $\sim 290 \mathrm{~K}$ com $\mathrm{T}_{\mathrm{FM}}-\mathrm{AFM}=263 \mathrm{~K}$ e $\Delta \mathrm{T}_{\mathrm{R}} \cong 160 \mathrm{~K}$, porém a magnetização final da curva FC foi diferente da inicial da ZFC, o que sugere que o sistema apresentou uma transição incompleta da fase FM para a fase AFM, havendo coexistência de fases numa região que, a principio, deveria ser monofásica. O momento magnético inicial da amostra foi $\mathrm{m}_{\mathrm{o}} \cong 6 \mu \mathrm{emu}$ e o final $\mathrm{m}_{\mathrm{f}} \cong 166 \mu$ emu. Este tipo de comportamento já foi observado por outros autores (ver Figura 4-2) no primeiro ciclo térmico de amostras virgens [48][49]. Este comportamento sugere que na região de baixas temperaturas ( $80 \mathrm{~K}$ ) os grãos de FeRh do filme se encontram na fase AFM, mas uma pequena fração deles está na fase FM. Após o ciclo térmico ter sido completado, os momentos magnéticos destes grãos FM estão preferentemente orientados na direção do campo, o que confere à amostra uma magnetização maior do que o valor inicial. Também é possível que nem todos os grãos que realizam a transição AFM $\rightarrow$ FM completem a transição inversa, ficando eles em estados metaestáveis e contribuindo para o incremento da magnetização da amostra em baixas temperaturas.

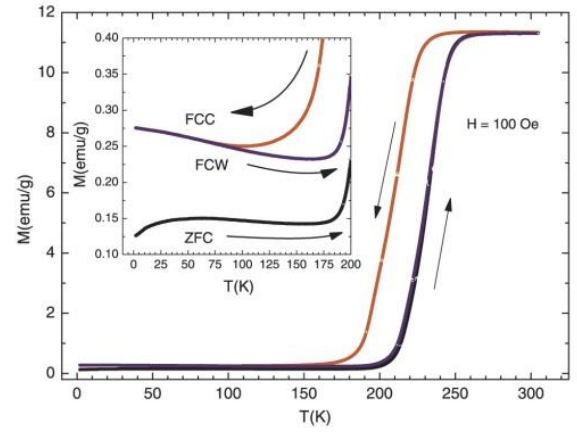

(a)

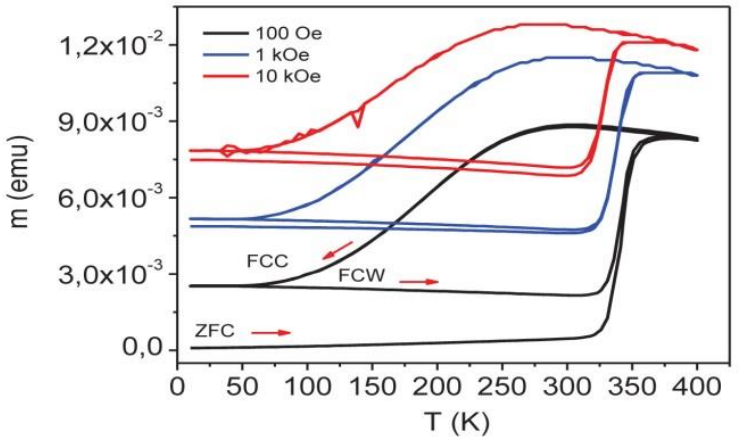

(b)

Figura 4-2. (a) Ciclo térmico observado para liga $\mathrm{Fe}_{0,955} \mathrm{Ni}_{0,045} \mathrm{Rh}$. No gráfico interno é dado evidência ao primeiro ciclo (ZFC - FCC) e a região reversível ( $F C C$ - FCW) obtida após ao primeiro ciclo [48] (b) Ciclos térmicos observados para liga $\mathrm{Fe}_{47} \mathrm{Rh}_{53}$ feitos com diferentes valores de campo magnético aplicado. Tiradas de [49]. 
A amostra 2B, por outro lado, apresentou no aquecimento o início da transição em $\sim 380 \mathrm{~K}$ com $\mathrm{T}_{\mathrm{AFM}-\mathrm{FM}}=473 \mathrm{~K}$. Como estávamos limitados a uma temperatura máxima de aquecimento do criostato, não foi possível observar uma transição completa para a fase FM da amostra, mas ajustando uma curva na derivada do momento com relação à temperatura e identificando o zero da mesma é possível estimar que o fim da transição ocorreria em um valor próximo aos $\sim 490 \mathrm{~K}$, obtendo-se $\Delta T_{A} \cong 110 \mathrm{~K}$. No resfriamento o início da transição se deu em $\sim 445 \mathrm{~K}$ com $T_{F M}-A F M=$ $414 \mathrm{~K}$ e $\Delta T_{\mathrm{R}} \cong 105 \mathrm{~K}$. A amostra apresentou uma transição de fase completa no resfriamento, sendo o momento magnético inicial e final $\mathrm{m}_{\mathrm{o}}=\mathrm{m}_{\mathrm{f}} \cong 44 \mu \mathrm{emu}$. Na Tabela 4-1 são apresentados os valores das temperaturas críticas e das faixas de temperaturas de cada transição e a largura do ciclo térmico, definida como $\Delta \mathrm{T}_{\text {ciclo }}=\mathrm{T}_{\mathrm{AFM}-\mathrm{FM}}$

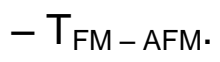

Tabela 4-1. Temperaturas críticas de transição nas transições de fase AFM $\rightarrow$ FM e FM $\rightarrow$ AFM com suas respectivas larguras para as amostras 1B e 2B.

\begin{tabular}{c|ccccc}
\hline & & $1 \mathrm{~B}$ & & & $2 \mathrm{~B}$ \\
& $100 \mathrm{Oe}$ & $10 \mathrm{kOe}$ & $100 \mathrm{Oe}$ & $10 \mathrm{kOe}$ \\
\hline $\mathrm{T}_{\text {AFM - FM }}$ & 347 & 314 & 437 & 429 \\
$\Delta \mathrm{T}_{\mathrm{A}}$ & 160 & 180 & 110 (estimado) & 105 \\
$\mathrm{~T}_{\mathrm{FM}-\text { AFM }}$ & 263 & 243 & 414 & 397 \\
$\Delta \mathrm{T}_{\mathrm{R}}$ & 160 & 160 & 105 & 90 \\
$\Delta \mathrm{T}_{\text {ciclo }}$ & 84 & 71 & 23 & 32 \\
\hline
\end{tabular}

Comparando os ciclos térmicos das duas amostras vemos que no caso da amostra 2B tivemos um ciclo muito mais estreito, o que fica evidente observando as larguras $\Delta \mathrm{T}_{\text {ciclo. }}$. Isto indica maior uniformidade na distribuição de temperaturas críticas da segunda amostra em relação à primeira. Da análise das curvas ZFC surge que a temperatura crítica de transição $T_{A F M}$ - FM da amostra 2B é aproximadamente $90 \mathrm{~K}$ maior que a da amostra $1 \mathrm{~B}$. Ambas as amostras apresentaram faixas de temperaturas de transições mais largas que amostras bulk [22] e filmes finos tratados termicamente em temperaturas similares [30] com composições semelhantes. Quanto às curvas $\mathrm{FC}$ as amostras apresentaram comportamentos distintos tanto com relação a $\Delta T_{R}$ e $T_{F M}$ - AFM, onde a amostra $1 \mathrm{~B}$ apresentou uma largura de transição 
maior que a amostra 2B em aproximadamente $55 \mathrm{~K}$, e uma variação de $151 \mathrm{~K}$ na temperatura crítica de transição. Comparando as faixas de temperaturas de transição vemos que $\Delta T_{R}>\Delta T_{A}$ para ambas as amostras, o que sugere que a fase $F M$ sub-resfriada é mais estável do que a fase AFM superaquecida.

Uma vez medidas as primeiras transições de fase nas amostras virgens, as mesmas amostras foram submetidas a um novo ciclo térmico, porém, desta vez, o campo magnético aplicado foi de $10 \mathrm{kOe}$, também ao longo do plano do filme. Os resultados experimentais para as duas amostras encontram-se na Figura 4-1 (b).

Durante o aquecimento a amostra 1B apresentou o início da transição no aquecimento em $\sim 200 \mathrm{~K}$ com $\mathrm{T}_{\mathrm{AFM}-\mathrm{FM}}=314 \mathrm{~K}$ e $\Delta \mathrm{T}_{\mathrm{A}} \cong 180 \mathrm{~K}$. No resfriamento 0 início da transição ocorreu em $\sim 325 \mathrm{~K}$ com $\mathrm{T}_{\mathrm{FM}-\mathrm{AFM}}=243 \mathrm{~K}$ e $\Delta \mathrm{T}_{\mathrm{R}} \cong 160 \mathrm{~K}$. A largura do ciclo térmico foi de $71 \mathrm{~K}$ e o filme experimentou uma transição de fase completa tanto no aquecimento como no resfriamento, apresentando um momento magnético inicial e final com valores muito próximos $m_{0}=m_{f} \cong 515 \mu$ emu. Observa-se que este valor é aproximadamente 4,4 vezes o valor final do momento do primeiro ciclo

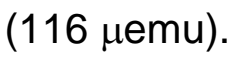

Para a amostra 2B o início da transição ocorreu em $\sim 380 \mathrm{~K} \mathrm{com} \mathrm{T}_{\mathrm{AFM}}-\mathrm{FM}=$ 429 K. Da mesma forma que a primeira transição medida (Figura 4-1 (a)) esta amostra não teve uma transição de fase completa e, utilizando o mesmo procedimento que anteriormente, obtivemos que a temperatura estimada para o fim da transição seria em $\sim 490 \mathrm{~K}$, sendo $\Delta \mathrm{T}_{\mathrm{A}} \cong 110 \mathrm{~K}$. No resfriamento o início da transição foi em $\sim 435 \mathrm{~K}$ com $\mathrm{T}_{\mathrm{FM}}-\mathrm{AFM}=397 \mathrm{~K}$ e $\Delta \mathrm{T}_{\mathrm{R}} \cong 90 \mathrm{~K}$, apresentando uma transição de fase completa e momento magnético inicial e final $\mathrm{m}_{\mathrm{o}}=\mathrm{m}_{\mathrm{f}} \cong 311 \mu \mathrm{emu}$. A largura do ciclo térmico foi, neste caso, de $32 \mathrm{~K}$.

Para ambas as amostras o sinal medido foi mais ruidoso do que o correspondente ao primeiro ciclo a campo de 100 Oe. Durante o aquecimento, nas temperaturas abaixo do início da transição (fase AFM), ambas as amostras apresentaram um momento maior do que o obtido no final do ciclo inicial (Figura 4-1 (a)), tal fato era esperado para a amostra 1B, uma vez que a mesma apresentou uma transição de fase incompleta, havendo presença de fase FM em baixa temperatura. Já para a amostra 2B, poderia ter sido esperado que ela mostrasse, no segundo ciclo, um momento magnético inicial próximo ao da primeira medida, porém, como vemos na Figura 4-1 (b), ela apresentou um momento magnético quase sete vezes maior. 
Um fato intrigante é que o momento magnético máximo atingido pela amostra 1B, sob a ação do campo de 100 Oe, é quase $10 \%$ maior do que o máximo atingido no ciclo térmico, feito com campo de $10 \mathrm{kOe}$. Nada equivalente foi observado na amostra 2B. Inclusive, é observado que no começo do resfriamento do segundo ciclo térmico da amostra $1 \mathrm{~B}$, a magnetização relaxa até um valor menor ao atingido no final do aquecimento. Esta viscosidade mostra que o sistema, mesmo se encontrando a uma temperatura alta o suficiente para a transição AFM $\rightarrow$ FM ter terminado, ainda está em um estado metaestável. Isto não foi totalmente verificado na amostra 2B (embora se observe um indicio de viscosidade no ponto de maior temperatura) uma vez que não foi possível ultrapassar os $450 \mathrm{~K}$ nesse experimento. Não temos elementos suficientes para explicar a queda no momento magnético máximo da amostra 1B para o campo de $10 \mathrm{kOe}$, mas as medidas sugerem que nessa amostra (a qual é a que tem um pouco mais de desordem na orientação dos grãos), o alto valor do campo aplicado dificultou a transição de fase AFM $\rightarrow$ FM de alguns grãos de FeRh.

Como esperado, nas duas amostras foi observado que as temperaturas de transição se deslocam para valores menores com o incremento da intensidade do campo aplicado, assim como é observado tanto em amostras bulk [19] como em filmes finos [23]. Isto mostra que o campo magnético aplicado favorece a transição de fase AFM $\rightarrow$ FM, já que através do termo de energia Zeeman, permite que seja suficiente fornecer menos energia térmica para que se produza a transição, e ainda confere mais estabilidade à fase FM, o que diminui a temperatura da transição inversa $\mathrm{FM} \rightarrow \mathrm{AFM}$.

\subsubsection{Amostras bicamadas}

Uma vez concluídas as medidas de transição de fase das amostras monocamadas o estudo se estendeu para as amostras bicamadas (1A e 2A) com o objetivo de estudarmos possíveis efeitos de acoplamento entre as camadas de FeRh e Fe.

Para definir um critério de comparação, as amostras $1 \mathrm{~A}$ e 2A foram submetidas aos mesmos ciclos térmicos que as amostras $1 \mathrm{~B}$ e $2 \mathrm{~B}$, sendo utilizados os 
mesmos parâmetros e procedimentos experimentais. Assim as primeiras curvas ZFC - FC foram feitas com um campo de 100 Oe aplicado ao longo do plano do filme. $\mathrm{Na}$ Figura 4-3 (a) encontram-se as curvas para as amostras 1A e 2A virgens. A amostra $1 \mathrm{~A}$ apresentou um momento magnético inicial negativo sendo $\mathrm{m}_{\mathrm{o}}=-180 \mu \mathrm{emu}$. Como a amostra é isotrópica no plano não houve uma preocupação com a orientação da amostra no porta amostra, com exceção do plano do filme, desta forma o momento poderia ter se tornado positivo apenas com uma rotação em $180^{\circ}$ da amostra. Por outro lado, é perfeitamente possível que uma amostra epitaxial preparada via magnetron sputtering tenha algum momento magnético diferente de zero em alguma direção do plano após o processo de preparação, sendo que isto se origina pela geometria do campo magnético dos próprios imãs do sistema de sputtering. Durante o aquecimento o início da transição ocorreu em $\sim 315 \mathrm{~K} \mathrm{com} \mathrm{T}_{\mathrm{AFM}}$ - FM $=378 \mathrm{~K}$. Até os $450 \mathrm{~K}$ a transição da amostra não se completou e, devido ao formato da curva de transição, não foi possível estimarmos a temperatura em que ocorreria o fim da transição. No resfriamento o início da transição foi em $\sim 420 \mathrm{~K} \mathrm{com} T_{F M}-A F M=331 \mathrm{~K} \mathrm{e}$ $\Delta T_{\mathrm{R}} \cong 160 \mathrm{~K}$. Devido à presença da camada de Fe não é possível saber se a transição inversa se completou ou não, já que após o ciclo a amostra ficou com um momento final $m_{f}=356 \mu \mathrm{emu}$, o qual deve estar formado pela magnetização da camada de $\mathrm{Fe}$ depois do processo $\mathrm{FC}$, mas também pode existir uma componente FM da liga de $\mathrm{FeRh}$ que não completou a transformação inversa. A largura deste ciclo foi de $47 \mathrm{~K}$. Da mesma forma que a amostra $1 \mathrm{~A}$, a amostra $2 \mathrm{~A}$ apresentou um momento magnético inicial negativo $m_{0}=-58 \mu \mathrm{emu}$, o início da transição foi em $\sim 400 \mathrm{~K}$ com $\mathrm{T}_{\mathrm{AFM}-\mathrm{FM}}=436 \mathrm{~K}$. A transição foi incompleta, porém foi possível estimar o fim da transição, sendo em $\sim 470 \mathrm{~K}$, desta forma $\Delta \mathrm{T}_{\mathrm{A}} \cong 70 \mathrm{~K}$. No resfriamento o início da transição foi em $\sim 430 \mathrm{~K} \mathrm{com} \mathrm{T}_{\mathrm{FM}}$ - AFM $=404 \mathrm{~K}$ e $\Delta \mathrm{T}_{\mathrm{R}} \cong 70 \mathrm{~K}$. O momento magnético final desta amostra foi $m_{f}=190 \mu$ emu e a largura do ciclo ficou em $32 \mathrm{~K}$. Na Tabela 4-2 são reapresentados os valores das temperaturas críticas e das faixas de temperaturas de transição e das larguras dos ciclos térmicos. 
Tabela 4-2. Temperaturas críticas de transição nas transições $A F M \rightarrow F M$ e FM $\rightarrow$ AFM com suas respectivas larguras de transição. Ambas para as amostras $1 \mathrm{~A}$ e $2 \mathrm{~A}$.

\begin{tabular}{c|cc|cc}
\hline & \multicolumn{2}{|c|}{$1 \mathrm{~A}$} & \multicolumn{2}{c}{$2 \mathrm{~A}$} \\
\hline $\mathrm{T}_{\text {AFM }-\mathrm{FM}}$ & $100 \mathrm{Oe}$ & $10 \mathrm{kOe}$ & $100 \mathrm{Oe}$ & $10 \mathrm{ke}$ \\
$\Delta \mathrm{T}_{\mathrm{A}}$ & 378 & 356 & 436 & 424 \\
$\mathrm{~T}_{\mathrm{FM}}-\mathrm{AFM}$ & --- & 135 & 70 & 65 \\
$\Delta \mathrm{T}_{\mathrm{R}}$ & 331 & 323 & 404 & 397 \\
$\Delta \mathrm{T}_{\text {ciclo }}$ & 160 & 180 & 70 & 70 \\
\hline
\end{tabular}

Fazendo uma comparação entre as amostras preparadas com e sem camada de $\mathrm{Fe}$, observa-se que a amostra $1 \mathrm{~A}$ apresentou um deslocamento para temperaturas maiores nas temperaturas críticas de transição de fase, em comparação com a amostra 1B, tendo um deslocamento de $31 \mathrm{~K}$ em $\mathrm{T}_{\mathrm{AFM} \text { - FM }}$ e de $68 \mathrm{~K}$ em $\mathrm{T}_{\mathrm{FM}}$ - AFM. Este aumento nas temperaturas críticas sugere que $\mathrm{o}$ acoplamento entre as camadas de FeRh e Fe confere estabilidade à fase AFM na liga. Também se observou uma significativa diminuição na largura do ciclo térmico, que passou de $84 \mathrm{~K}$ na amostra $2 \mathrm{~A}$ para $47 \mathrm{~K}$ na amostra $1 \mathrm{~A}$. No caso da amostra $2 \mathrm{~A}$, não se observou uma variação significativa na temperatura de transição $A F M \rightarrow F M$, mas sim uma diminuição de $10 \mathrm{~K}$ na temperatura de transição $T_{F M}$ - AFM, em comparação com aquela da amostra 2B. Em relação ao momento magnético neste ciclo térmico se observou que o momento magnético começou num valor próximo de zero, mas também negativo $\mathrm{m}_{\mathrm{o}}=-58 \mu \mathrm{emu}$, e terminou em $\mathrm{m}_{\mathrm{f}}=190 \mu \mathrm{emu}$. Novamente, este valor final deve ser resultante entre a componente da magnetização da camada de Fe e uma possível componente gerada por grãos de FeRh que ainda permanecem na fase FM.

Seguindo os passos das amostras $1 \mathrm{~B}$ e $2 \mathrm{~B}$, as amostras $1 \mathrm{~A}$ e $2 \mathrm{~A}$ foram submetidas à um novo ciclo térmico, mas agora com o campo magnético aplicado de 10 $\mathrm{kOe}$. Da mesma forma que ocorrido para as amostras 1B e 2B, as curvas apresentaram um sinal mais ruidoso do que as curvas medidas com campo de $100 \mathrm{Oe}$. As curvas medidas para as amostras 1A e 2A encontram-se na Figura 4-3 (b). 

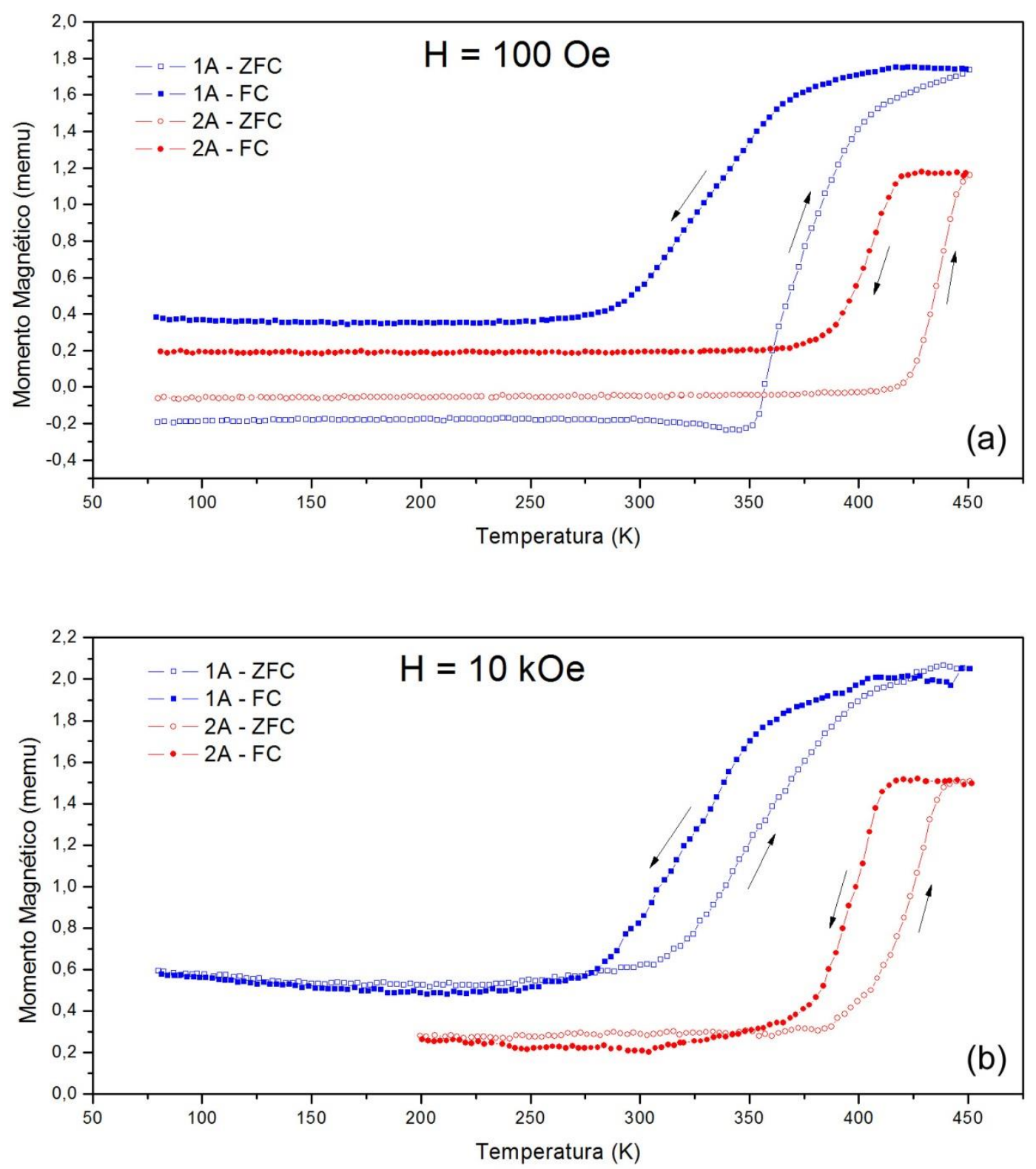

Figura 4-3. Curvas ZFC - FC medidas para as amostras 1A e 2A com campo aplicado de (a) $100 \mathrm{Oe} \mathrm{e} \mathrm{(b)} 10 \mathrm{kOe}$.

$\mathrm{Na}$ amostra 1A o início da transição, no aquecimento, ocorreu em 305 K, com $T_{A F M}-F M=356 \mathrm{~K}$ e $\Delta T_{A} \cong 135 \mathrm{~K}$. Já no resfriamento, a transição inversa começou em $\sim 420 \mathrm{~K}$, com $T_{F M}-A F M=323 \mathrm{~K}$ e $\Delta T_{R} \cong 180 \mathrm{~K}$. Neste caso o momento magnético apresentado pela amostra no início e no fim do ciclo foi $m_{0}=m_{f}=526 \mu e m u$, o que sugere que a transformação FM $\rightarrow$ AFM foi completa. Também foi observado que a largura destes ciclos foi bastante menor que aquele obtido para o campo apli- 
cado de 100 Oe. A amostra $2 \mathrm{~A}$ apresentou o início da transição no aquecimento em $\sim 380 \mathrm{~K}$, com $\mathrm{T}_{\mathrm{AFM}-\mathrm{FM}}=424 \mathrm{~K} \mathrm{e} \Delta \mathrm{T}_{\mathrm{A}} \cong 65 \mathrm{~K}$, apresentando uma transição completa. No resfriamento, o início da transição inversa foi observado em $\sim 420 \mathrm{~K}$, com $T_{F M}$ AFM $=397 \mathrm{~K} \mathrm{e} \Delta \mathrm{T}_{\mathrm{R}} \cong 70 \mathrm{~K}$. A transição também foi completa, onde o momento magnético inicial e final foi $m_{o}=m_{f}=257 \mu$ emu. Ambas as amostras apresentaram os mesmos comportamentos com relação às amostras 1B e 2B onde, devido o campo magnético mais intenso, as temperaturas críticas de transição sofreram um deslocamento para temperaturas menores.

\subsubsection{Campo perpendicular}

Finalmente, em relação aos ciclos térmicos cada amostra foi submetida a uma nova medida sob a ação de um campo de $10 \mathrm{kOe}$ aplicado na direção perpendicular ao plano do filme. Na Figura 4-4 mostram-se estes ciclo térmicos, sendo em (a) as transições para as amostras monocamadas, tipo B, e em (b) as medidas para as amostras bicamadas, tipo $A$.

O comportamento magnético de todas as amostras for similar ao comportamento mostrado quando o campo estava aplicado no plano do filme. Devido as amostras do grupo 2 não apresentarem transição de fase magnética completa AFM $\rightarrow \mathrm{FM}$ até os $450 \mathrm{~K}$ não podemos obter conclusões quanto ao momento magnético de saturação na região onde amostra se encontra na fase FM, porém para a amostras do grupo 1 foi observada uma diminuição da magnetização, sendo para a amostra 1B o momento de saturação, para o campo aplicado paralelo ao plano, de $\mathrm{m}_{\mathrm{s}}^{\|} \cong 1,40$ memu e o momento de saturação, para o campo aplicado perpendicular ao plano, de $\mathrm{m}_{\mathrm{s}}^{\perp} \cong 1,0$ memu, enquanto para a amostra $1 \mathrm{~A}$ os momentos foram $\mathrm{m}_{\mathrm{s}}^{\|} \cong 2,00$ memu e $\mathrm{m}_{\mathrm{s}}^{\perp} \cong 1,33$ memu. Esta diminuição no momento de saturação está de acordo com o fato que a magnetização (tanto da camada de FeRh quanto da camada de $\mathrm{Fe}$ ) tende a ficar paralela ao plano do filme e, por tanto, há um campo desmagnetizante mais intenso perpendicular ao plano do filme do que o apresentado paralelo ao plano. 

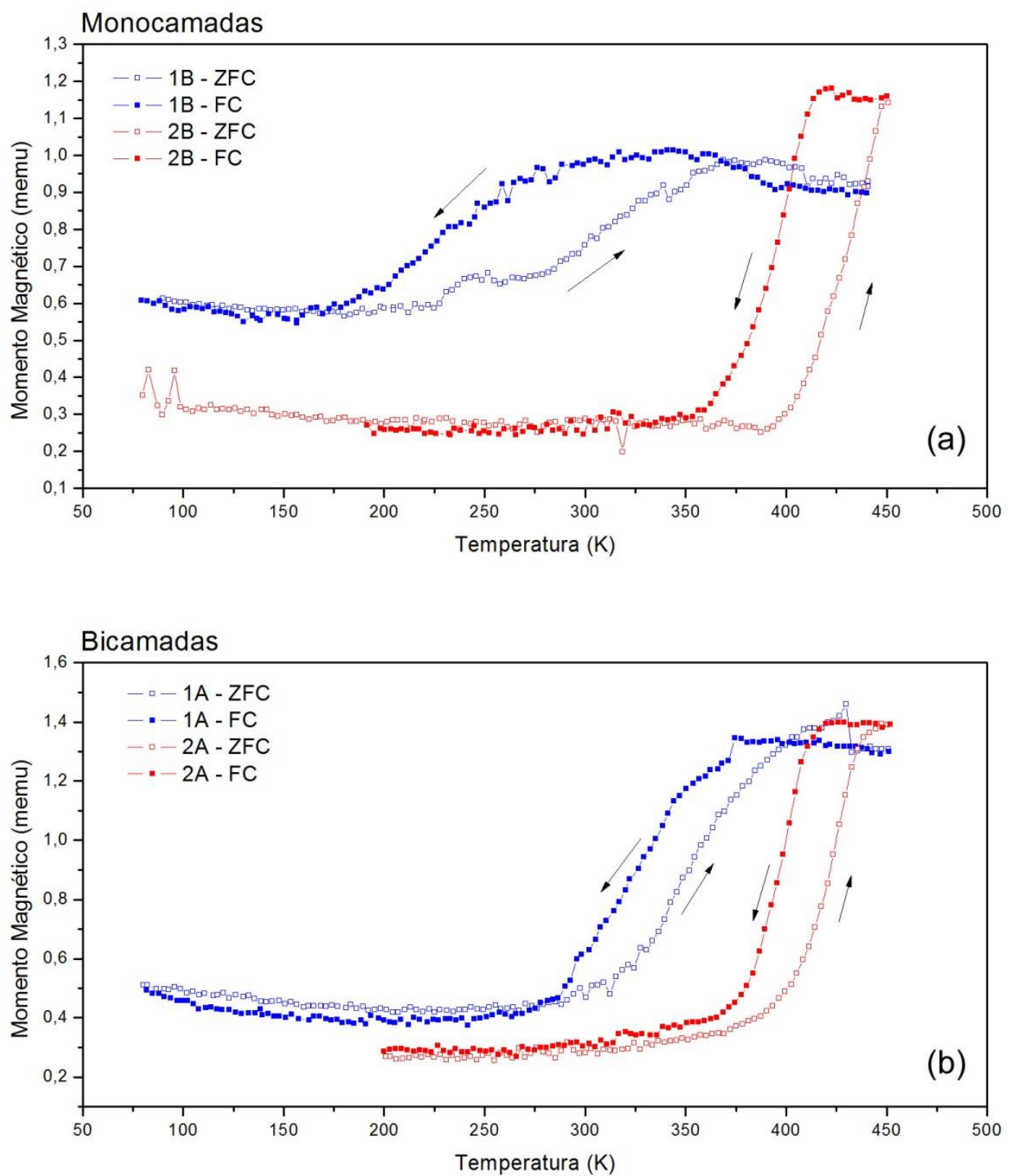

Figura 4-4. Transições de fase magnética medidas para as amostras (a) monocamadas de FeRh e (b) bicamadas. As transições foram feitas a campo constante de $10 \mathrm{kOe}$ aplicado perpendicularmente ao plano do filme.

\subsection{Análise dos Ciclos de Histerese das Amostras}

Visando construir um perfil magnético para cada amostra, foram realizadas medidas de vários ciclos de histereses tanto na transformação AFM $\rightarrow$ FM quanto na 
transformação inversa, para cada amostra. As temperaturas de cada ciclo foram escolhidas de maneira a ter informação nos extremos da faixa de temperaturas usadas, e principalmente na região da transição correspondente.

Foi adotado como padrão para as medidas de curvas de histerese uma velocidade de variação de campo magnético de 400 Oe/min, sendo cada ciclo medido na modalidade ponto a ponto, com uma sensitividade de 4 memu, sendo a constante de tempo de hardware e a média de constante de tempo do software de $1 \mathrm{~s}$.

\subsubsection{Amostras Monocamadas de Fe}

Para termos uma referência do quanto à camada de Fe contribui no momento magnético total apresentado pelas amostras bicamadas e se há um deslocamento do zero da histerese dado pelo VSM, primeiramente foram feitas medidas de histerese para as amostras $1 \mathrm{C}$ e $2 \mathrm{C}$, monocamadas de $\mathrm{Fe}$, em temperatura ambiente com o campo magnético aplicado no plano do filme. Na Figura 4-5 encontram-se as curvas de histerese das amostras $1 \mathrm{C}$ (a) e 2C (b). A amostra 1C apresentou $m_{R}(+)=$ 0,25 memu e $m_{R}(-)=-0,25$ memu juntamente de $H_{C}=19,15$ Oe, enquanto a amostra $2 \mathrm{C}$ apresentou $m_{R}(+)=0,27$ memu e $m_{R}(-)=-0,27$ memu, juntamente de $H_{C}=46,3$ Oe. Ambas as amostras apresentaram um deslocamento no eixo do campo de -5 Oe. Posteriormente, foi verificado que este deslocamento aparecia também em outras amostras (que não estão relacionadas com este trabalho) e, desta maneira, foi verificado que este deslocamento tratava-se de um erro sistemático, provavelmente vinculado à eletrônica do VSM. Desconsiderando então o mencionado deslocamento, pôde-se observar uma chamativa diferença entre os ciclos de histerese das amostras 1C e 2C. Ambas as amostras possuem uma camada de Fe de aproximadamente $8 \mathrm{~nm}$ de espessura, sendo crescidas em condições idênticas. Porém, enquanto a amostra $1 \mathrm{C}$ apresentou um ciclo de histereses bastante retangular e com uma coercividade de aproximadamente 19 Oe, a amostra 2C mostrou um ciclo de histerese compatível com a presença de duas fases e uma coercividade de uns 46 Oe. Isto mostra que a fina camada de FeRh (Tabela 3-1) presente na amostra $2 \mathrm{C}$ se acoplou à camada de Fe e conferiu maior coercividade ao conjunto. 


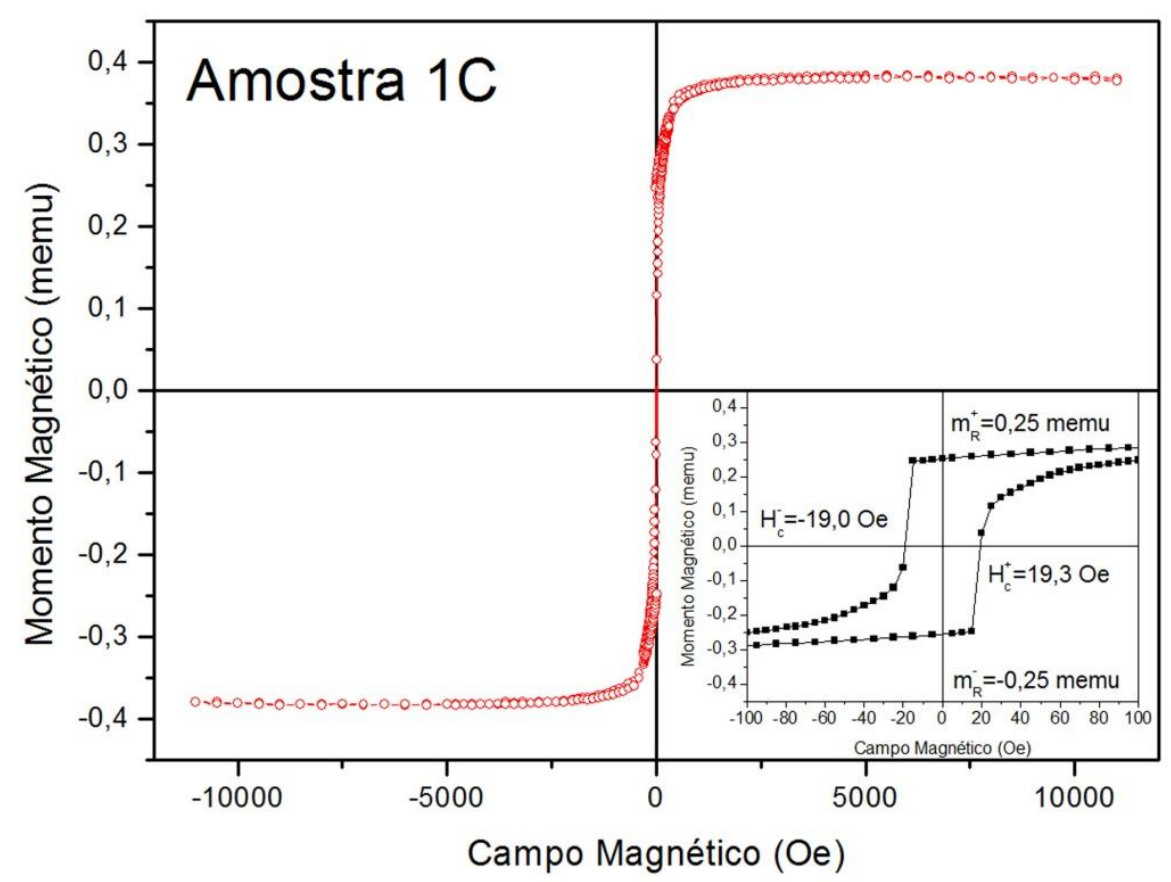

(a)

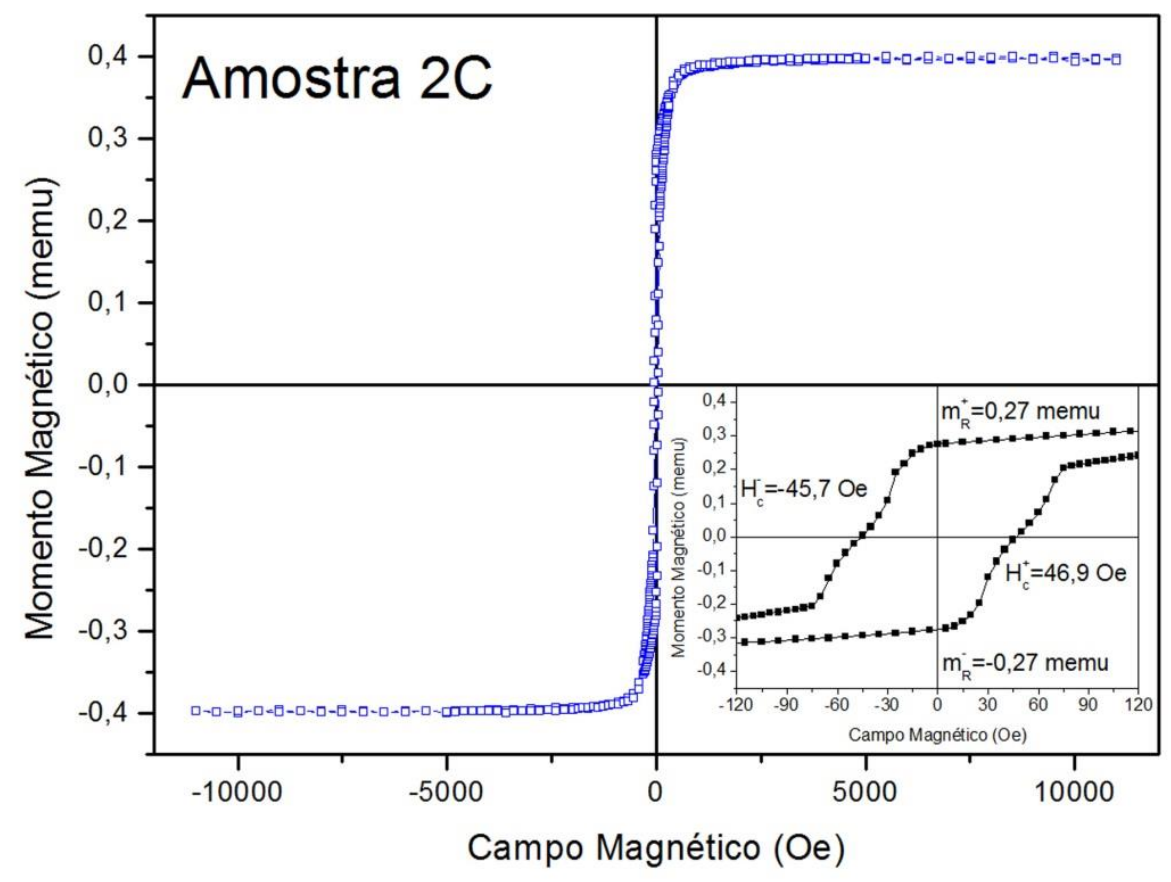

(b)

Figura 4-5. Curvas de histerese feitas em temperatura ambiente para as amostras (a) $1 \mathrm{C} \mathrm{e} \mathrm{(b)}$ 2C, ambas monocamadas de Fe. 


\subsubsection{Histereses em Função da Temperatura}

Como foi mencionado, para cada amostra foram medidos vários ciclos de histerese, em diferentes temperaturas, tanto no ramo de aquecimento, quanto no ramo de resfriamento. Como parâmetro de escolha das temperaturas em que faríamos as medidas de histerese, optamos por realiza-las no maior ciclo térmico possível, o que garante que, nas regiões das transições, o sistema se encontra nas condições de máxima metaestabilidade. Assim, o ramo de aquecimento (transição $A F M \rightarrow F M$ ) foi realizado em campo nulo e o ramo de resfriamento (transição FM $\rightarrow$ AFM) com o máximo campo aplicado que o sistema permite, uma vez que a aplicação de campo magnético durante o aquecimento e no resfriamento desloca a transição de fase para temperaturas mais baixas.

Primeiramente iremos apresentar e analisar os resultados obtidos para as amostras monocamadas, 1B e 2B, sendo apresentado, posteriormente, o conjunto correspondente às amostras bicamadas, $1 \mathrm{~A}$ e $2 \mathrm{~A}$. Deve-se esclarecer, de início, que as medidas nas amostras do grupo 1 ( $1 \mathrm{~A}$ e $1 \mathrm{~B}$ ) foram realizadas com o criostato, enquanto que as do grupo 2 ( $2 \mathrm{~A}$ e $2 \mathrm{~B}$ ), por ser necessário atingir temperaturas maiores, tiveram que ser realizadas no forno.

\subsubsection{Amostras monocamadas}

A Figura 4-6 mostra as curvas de aquecimento (em campo nulo) e resfriamento (com campo aplicado de $11 \mathrm{kOe}$ ) para as amostras 1B (a) e 2B (b), respectivamente. Estas curvas foram utilizadas como referências para a escolha das temperaturas em que se iriam fazer as medidas de ciclos de histerese ao longo das transições de fase. Observamos que estes ciclos térmicos não são fechados, havendo uma diferença entre as magnetizações inicial e final na temperatura mínima e também na temperatura máxima. 

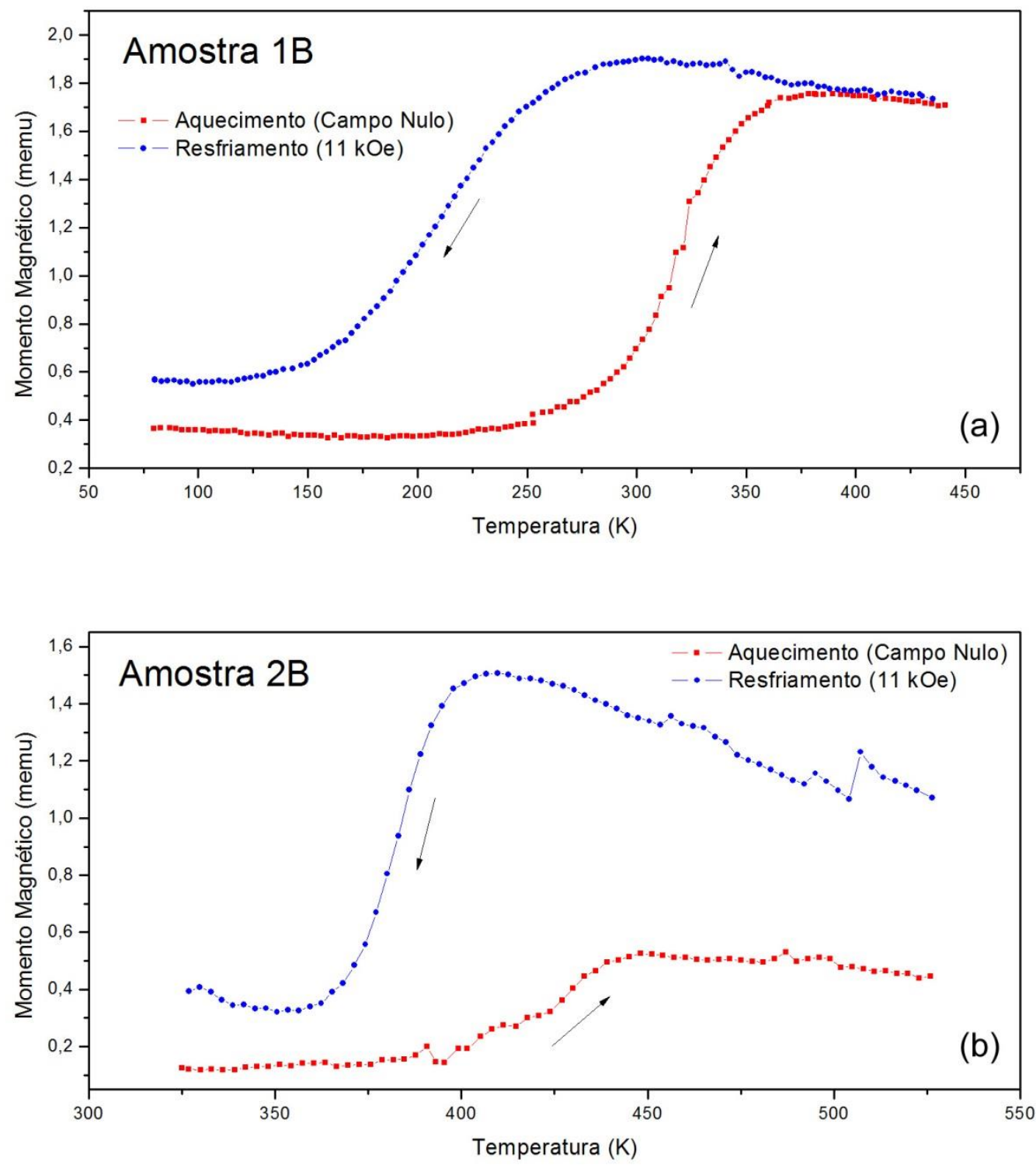

Figura 4-6. Curvas de aquecimento e resfriamento para as amostras (a) 1B e (b) 2B, utilizadas como referência para a escolha das temperaturas a serem feitas as histereses. Aquecimento feito a campo nulo e resfriamento a $11 \mathrm{kOe}$.

Para ambas as amostras, no ponto inicial da curva de aquecimento, prévio a este procedimento, foi medido um ciclo de histerese com a amostra ainda virgem, e essa medida foi repetida depois de realizado o ciclo térmico. Estes ciclos foram medidos a $80 \mathrm{~K}$ para a amostra 1B e em $325 \mathrm{~K}$ para a amostra 2B. Os resultados são apresentados nas Figura 4-7 e Figura 4-8, respectivamente. Para a amostra 1B não se observam diferenças significativas entre os ciclos de histerese no início e no fim do ciclo térmico: tanto as magnetizações máximas e as remanentes são muito pró- 
ximas, e somente se observa um pequeno incremento de aproximadamente $2 \%$ na coercividade da amostra quando medida após o ciclo térmico. A forma da curva de desmagnetização, mostrada como detalhe dentro dos mencionados gráficos, é compatível com uma amostra que apresenta duas fases magnéticas, a primeira delas desmagnetizando em campos da ordem dos 200 Oe, e a segunda com coercividade próxima aos 500 Oe. Na Figura 4-8 mostram-se os ciclos de histerese da amostra 2B no início e no fim do corresponde ciclo térmico. Novamente, ambos os ciclos são muito similares, com pouca variação de magnetização máxima, remanência e coercividade, porém a forma geral destes ciclos é bastante complexa. Em primeiro lugar, durante a curva de desmagnetização, os ciclos mostram uma pequena remagnetização quando o campo magnético é de aproximadamente $20 \mathrm{Oe}$, o que foi observado em ambos os ramos do ciclo nas duas medidas realizadas. Depois, o sistema se desmagnetiza com uma coercividade de aproximadamente $90 \mathrm{Oe}$. Outro fato curioso é que a magnetização atinge um máximo para campos da ordem de $1500 \mathrm{Oe}$, depois a magnetização diminui até campos de intensidade aproximada aos $2500 \mathrm{Oe}$, e logo se observa um pequeno incremento, em uma região onde os ramos ascendente e descendente do ciclo de histerese se encontram separados. Devemos lembrar que estas medidas (tanto para esta amostra quanto para a amostra 1B) foram realizadas a uma temperatura onde a fase magnética predominante era a AFM. Mas em ambos os casos, foi observada uma histerese compatível com uma componente FM presente na amostra. Assim, entendemos que estes ciclos foram produzidos pela presença de uma pequena quantidade de fase FM, presente na região de fase predominante AFM, e que essa fase FM estava em uma condição metaestável. No caso da amostra 1B, a medida foi realizada em uma temperatura suficientemente afastada da temperatura crítica de transição AFM $\rightarrow$ FM, de forma que os ciclos obtidos foram mais estáveis. No entanto, para a amostra $2 \mathrm{~B}$, a medida foi realizada em $325 \mathrm{~K}$, uma temperatura relativamente próxima do começo da região de transição AFM $\rightarrow$ FM (ver o painel (b) da Figura 4-6), o qual pode ter influenciado na forma do ciclo de histerese, conferindo-Ihe mais complexidade. 


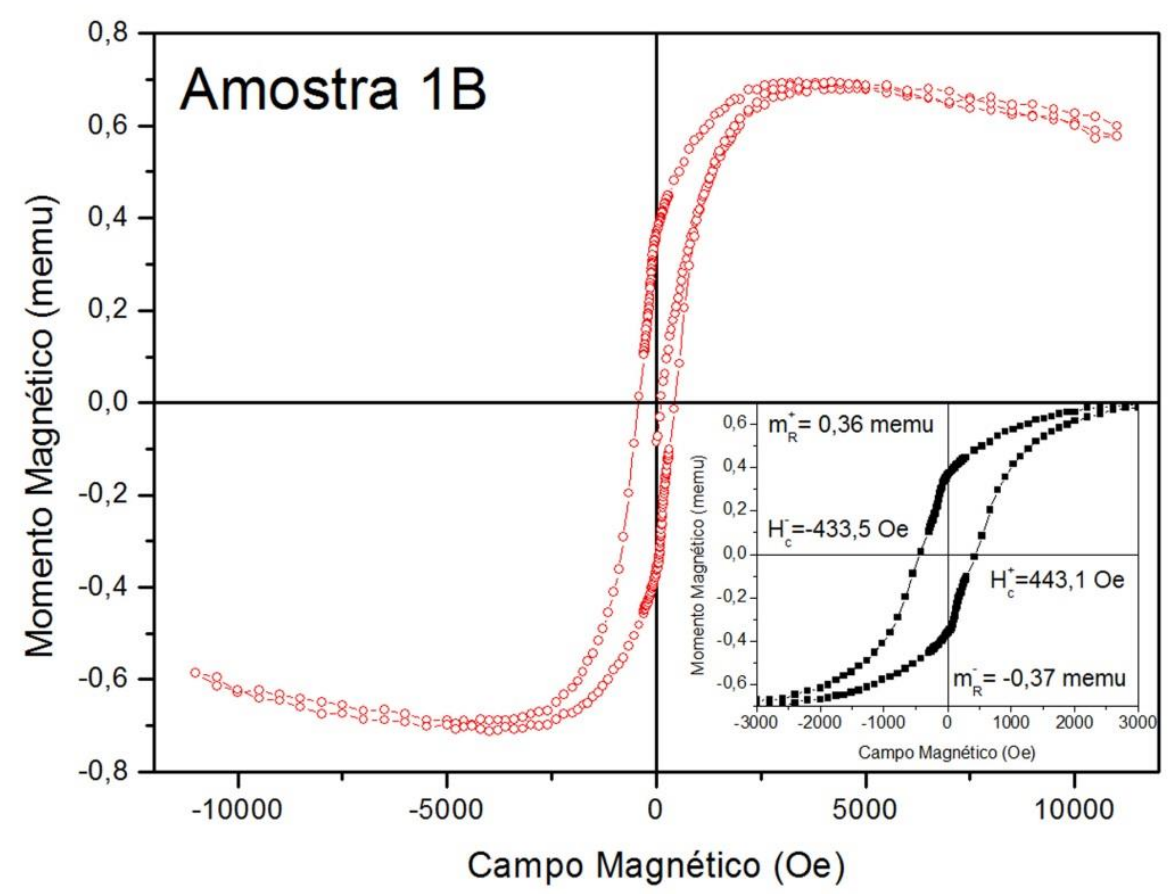

(a)

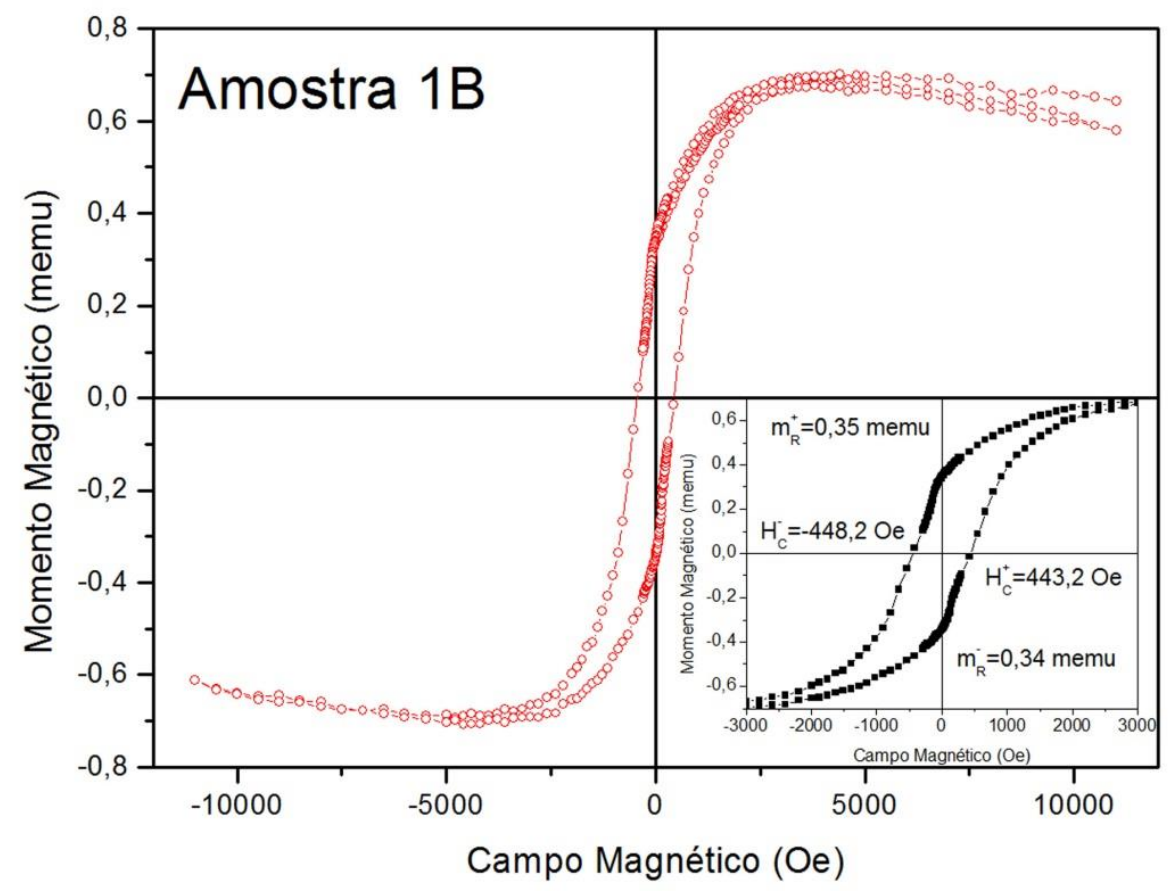

(b)

Figura 4-7. Histereses feitas na fase AFM da amostra 1B. Medidas feitas em 80 K. (a) Amostra virgem e (b) após primeiro ciclo térmico. 


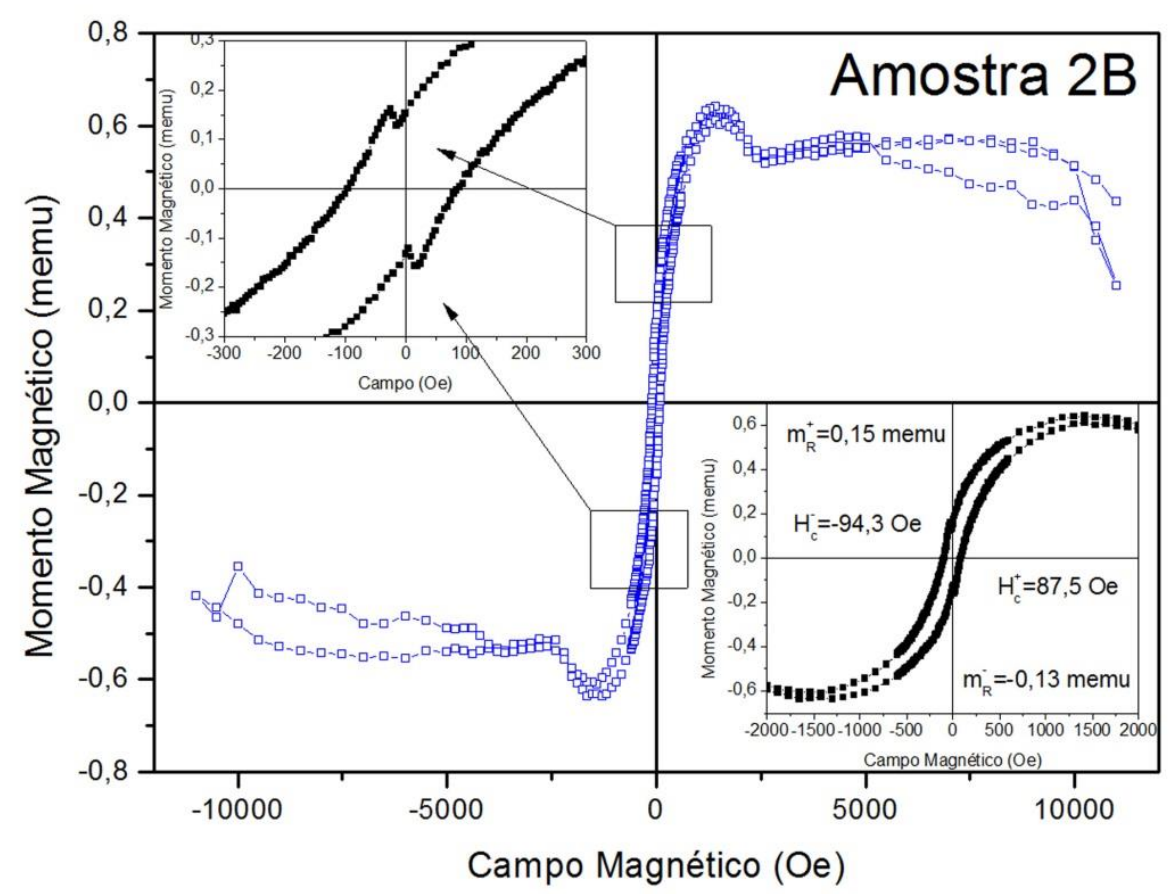

(a)

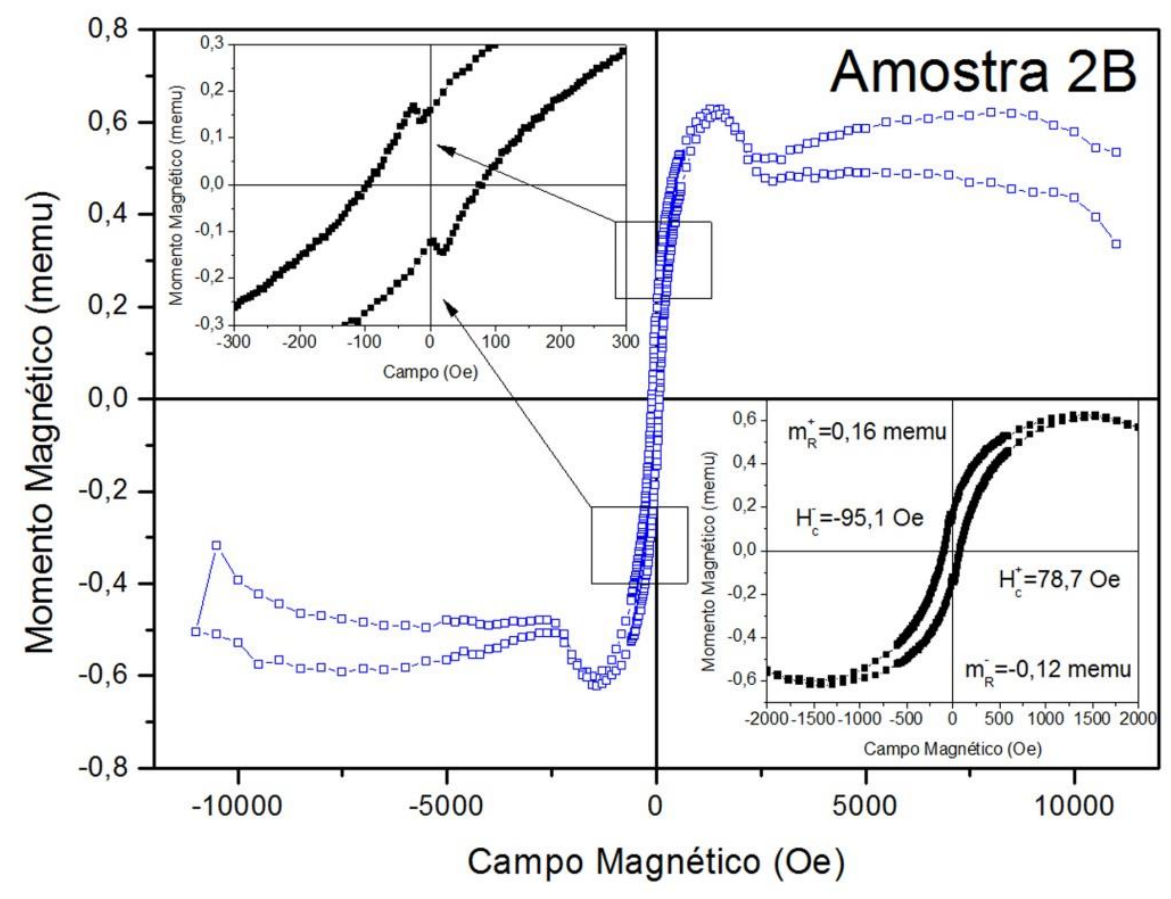

(b)

Figura 4-8. Histereses feitas na fase AFM da amostra 2B. Medidas feitas em 325 K. (a) Amostra virgem e (b) após primeiro ciclo térmico. 
Depois de realizarmos os ciclos térmicos, foram escolhidas as temperaturas onde foram medidos os ciclos de histerese, as quais são mostradas na Tabela 4-3 para as amostras 1B e 2B. Para cada amostra foram escolhidas temperaturas nas regiões onde a amostra se encontra, predominantemente, nas fases AFM e FM, nas temperaturas críticas de transição e no início de cada transição, sendo acrescentadas outras temperaturas próximas às mesmas.

Tabela 4-3. Temperaturas utilizadas para as medidas de momento magnético versus campo das amostras $1 \mathrm{~B}$ e $2 \mathrm{~B}$.

\begin{tabular}{|c|c|}
\hline $1 B$ & 2B \\
\hline \multicolumn{2}{|c|}{ Aquecimento (K) } \\
\hline 80 & 325 \\
\hline 110 & 352 \\
\hline 215 (Início da Transição) & 370 (Início da Transição) \\
\hline 270 & 400 \\
\hline $324\left(T_{A F M}-F M\right)$ & $429\left(T_{\text {AFM }-F M}\right)$ \\
\hline 380 (Fim da Transição) & 440 \\
\hline 400 & 450 (Fim da Transição) \\
\hline 420 & 500 \\
\hline \multicolumn{2}{|c|}{ Resfriamento (K) } \\
\hline 307 (Início da Transição) & 450 \\
\hline 260 & 409 (Início da Transição) \\
\hline $213\left(\mathrm{~T}_{\mathrm{FM}}-\mathrm{AFM}\right)$ & 400 \\
\hline 150 & $383\left(T_{F M}-A F M\right)$ \\
\hline 110 (Fim da Transição) & 365 \\
\hline 80 & 352 (Fim da Transição) \\
\hline--- & 325 \\
\hline
\end{tabular}

As curvas de histereses medidas para a amostra 1B se encontram na Figura 4-9. Observa-se que o momento máximo da amostra cresce até atingir um máximo em $380 \mathrm{~K}$, temperatura de fim da transição de fase AFM $\rightarrow$ FM. Depois, os ciclos medidos em $400 \mathrm{~K}$ e $420 \mathrm{~K}$ mostram uma diminuição do momento magnético máximo, o qual é o comportamento esperado para uma fase FM quando se incrementa a 
temperatura. No resfriamento a amostra apresentou dois ciclos de histerese abertos, em $260 \mathrm{~K}$ e $213 \mathrm{~K}$. Em ambos os casos a magnetização no final do ciclo apresenta valores menores que no começo do ciclo, mostrando que pode existir relaxação de grãos magnéticos que começam na fase FM, mas terminam na fase AFM. Isto é consistente com o fato da amostra se encontrar na região de temperaturas onde uma das fases está metaestável.

Também é observado na Figura 4-9 que os ciclos de histerese em altas temperaturas não apresentam curvas de desmagnetização com degraus, o que é observado nos ciclos de baixa temperatura. Isto reforça a impressão que na região de baixas temperaturas temos a coexistência de duas fases magnéticas.

Na Figura 4-10 são apresentados em (a) os momentos magnéticos remanentes $m_{R}$ em função da temperatura. Para facilitar a comparação entres os momentos remanentes positivos $m_{R}(+)$ e negativos $m_{R}(-)$ os $m_{R}(-)$ são apresentados em módulo. O momento magnético remanente na região de alta temperatura foi aproximadamente de 4 vezes o momento remanente na região de baixas temperaturas. No aquecimento a amostra apresentou um máximo entre $\mathrm{T}_{\mathrm{AFM}}$ - FM e a temperatura de fim de transição, tornando-se aproximadamente constante a partir desta. O comportamento no resfriamento foi similar ao do aquecimento. Na mesma figura, gráfico (b), apresentamos os valores do momento remanente dividido pelo valor de momento máximo $\left(m_{R} / m_{M A X}\right)$ observado nos ciclos de histerese. Os valores de $m_{R} / m_{\operatorname{MAX}}$ acompanham o incremento da temperatura, porém, na região de baixas temperaturas eles são inferiores ou próximos de 0,5, o que indica interações predominantes desmagnetizantes entre os grãos, enquanto que na região de altas temperaturas eles chegam até 0,75 , sugerindo que as interações magnetizantes entre os grãos FM acabam prevalecendo nesta região.

Pode-se ver na Figura 4-11 (a) o comportamento do campo coercivo em função da temperatura. Um aspecto significativo que se observa neste gráfico é que a fase FM presente em baixas temperaturas apresenta uma coercividade quase que uma ordem de magnitude maior que a correspondente a altas temperaturas. Como em baixas temperaturas encontramos, predominantemente, a fase AFM, pode-se inferir que o acoplamento entre a fase FM remanescente nesta região, e a fase AFM dominante, produz um incremento na coercividade, como normalmente observado em sistemas acoplados AFM/FM. 
Finalmente, na Figura 4-11 (b), mostramos o valor do deslocamento (exchange-bias) dos ciclos medidos, tanto no aquecimento quanto no resfriamento. Os valores obtidos são de pequena intensidade, de ambos os sinais, e não aparentam seguir uma tendência definida na amostra. 


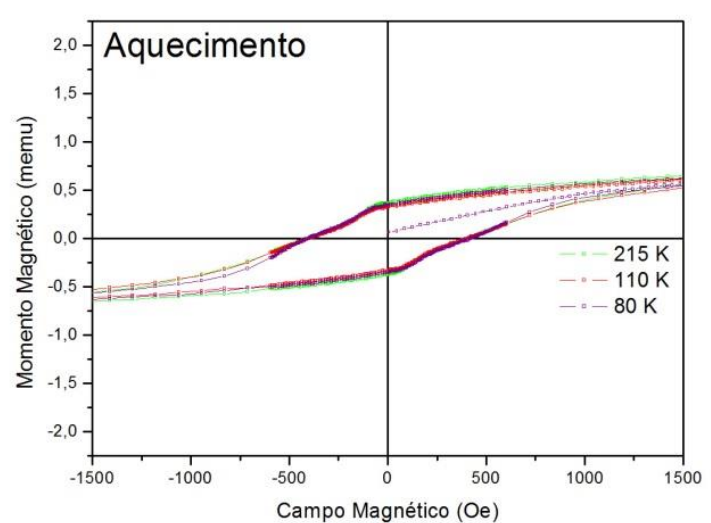

(a)

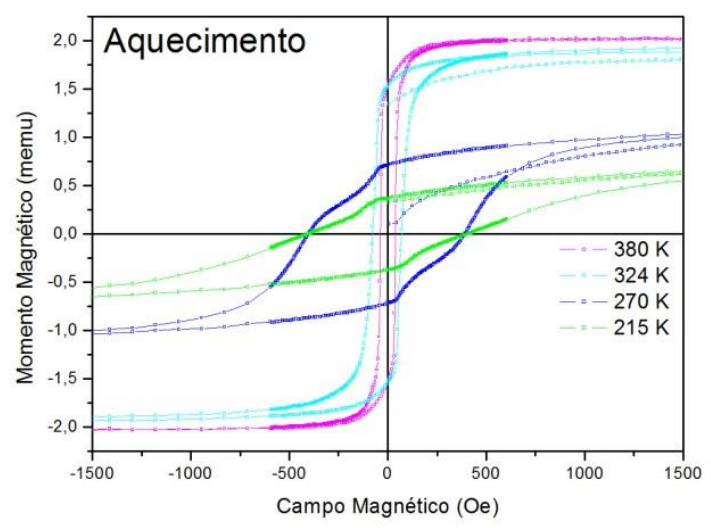

(c)

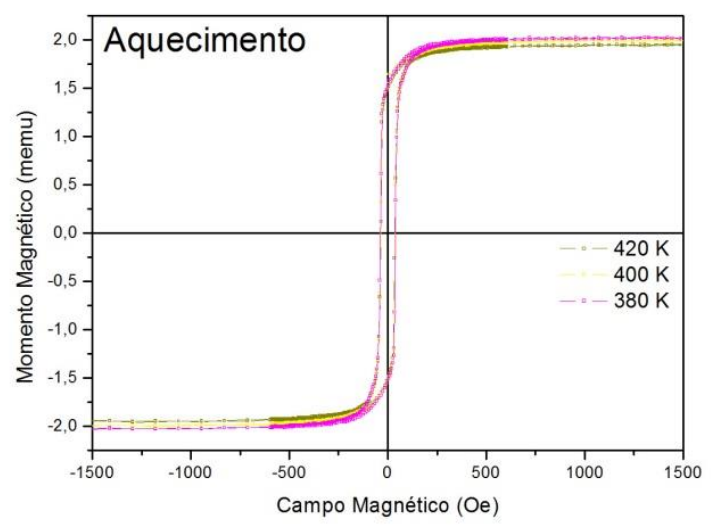

(e)

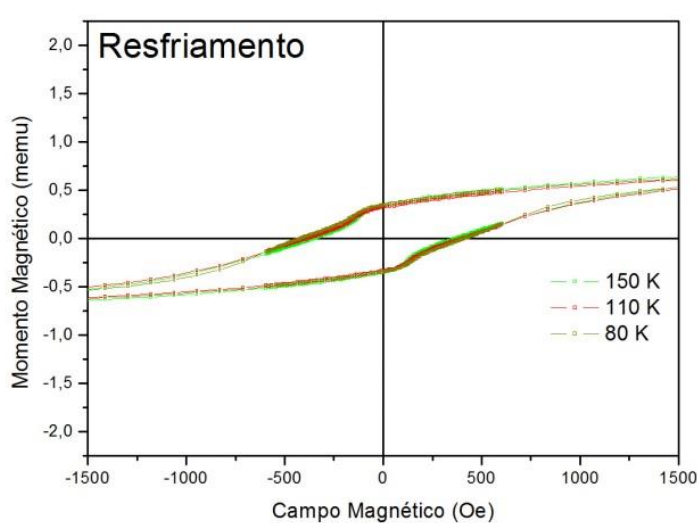

(b)

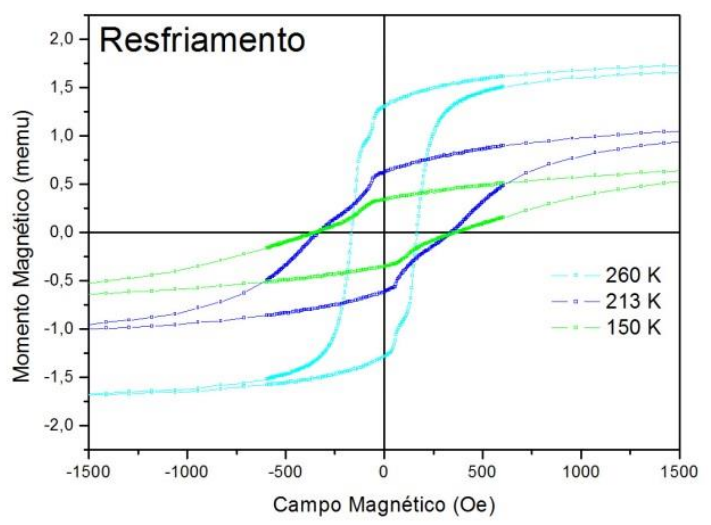

(d)

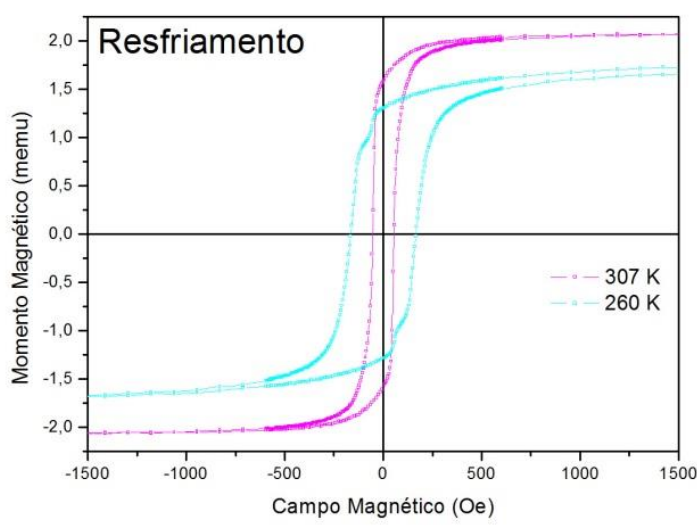

(f)

Figura 4-9. Amostra 1B: Histereses medidas na transição AFM $\rightarrow$ FM (aquecimento) e FM $\rightarrow$ AFM (resfriamento), sendo (a) e (b) baixas temperaturas, (c) e (d) temperaturas de transição e (e) e (f) altas temperaturas. 


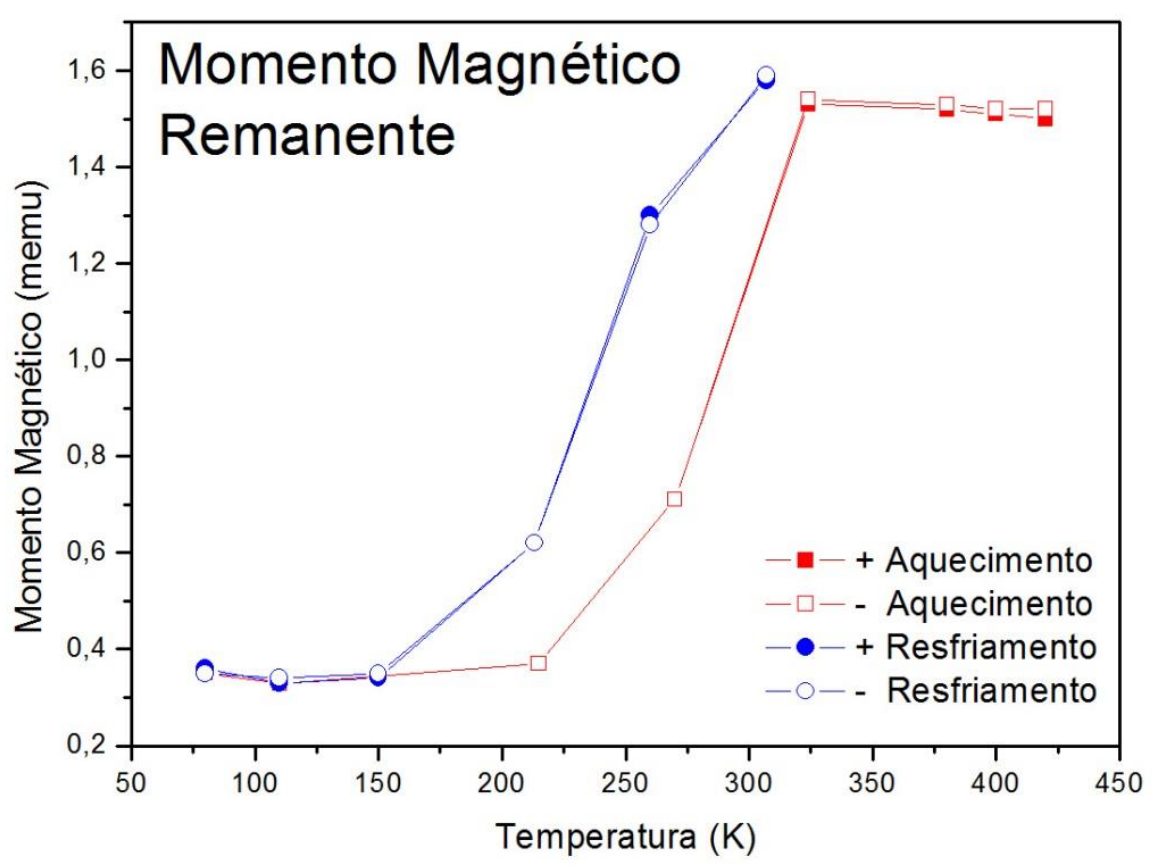

(a)

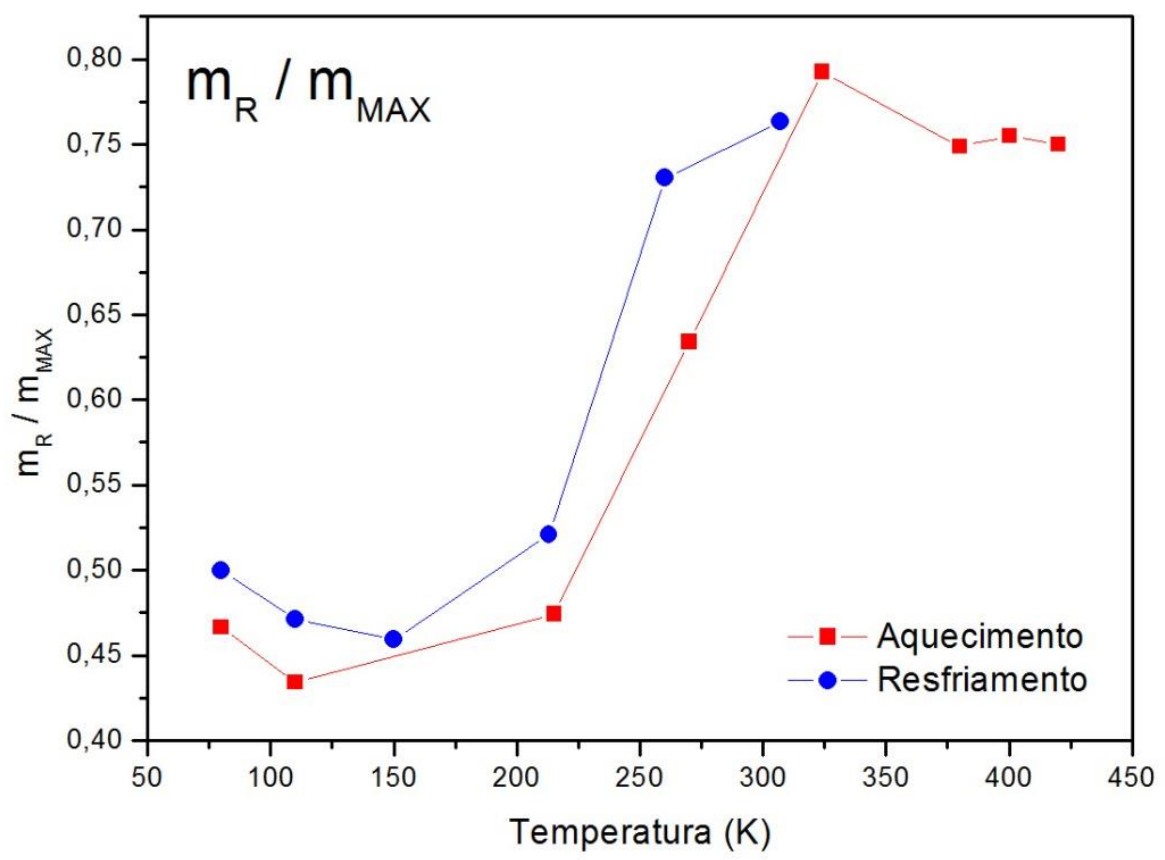

(b)

Figura 4-10. Amostra 1B: (a) Momentos magnéticos remanentes e (b) razão entre o momento magnético remanente e o momento magnético máximo. 


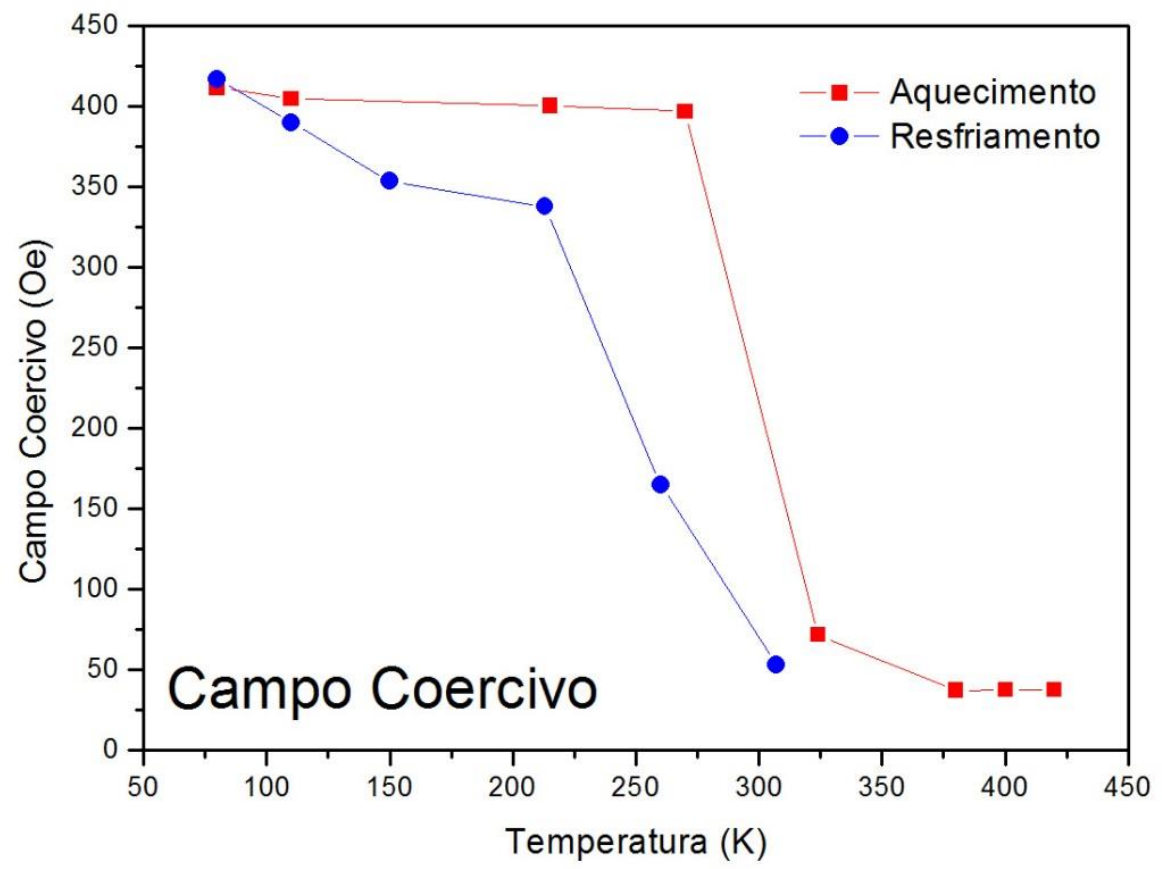

(a)

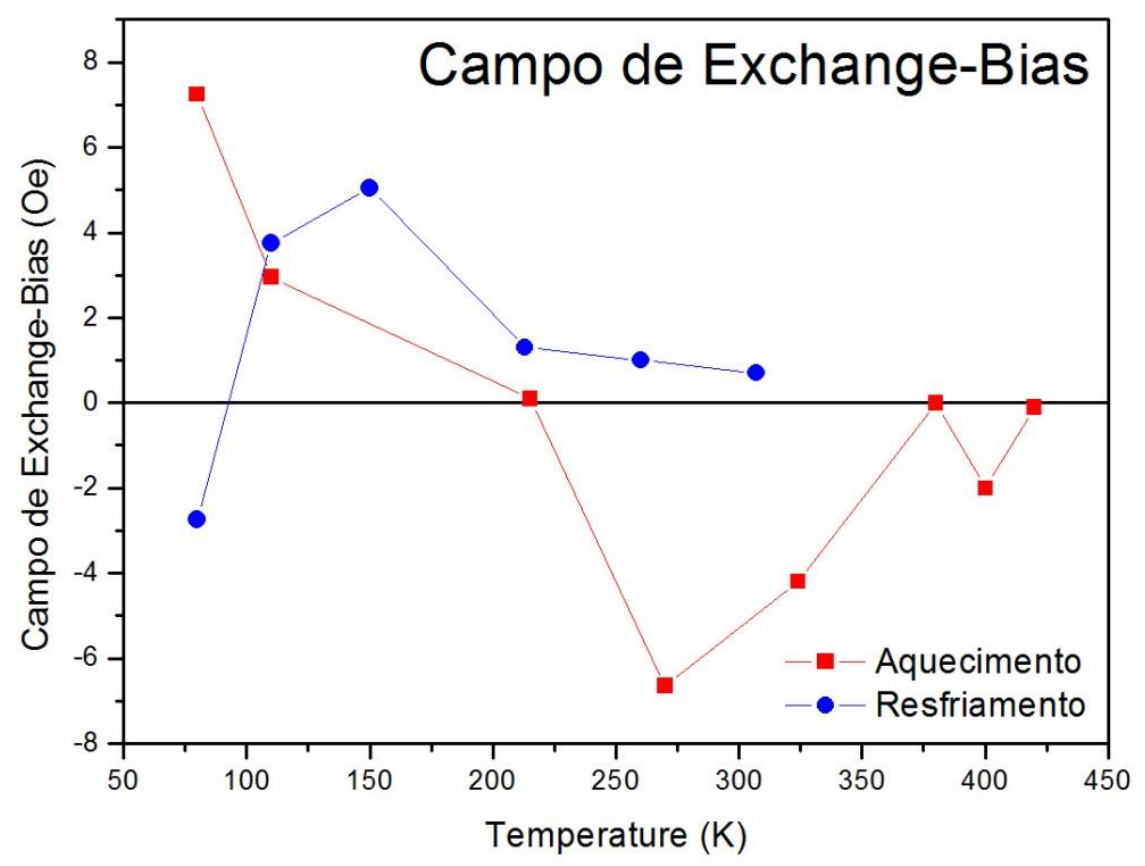

(b)

Figura 4-11. Amostra 1B: (a) Campos coercivos e (b) campos de exchange-bias. 
Na Figura 4-12 são apresentados os ciclos de histerese para a amostra 2B. Da mesma forma que a amostra 1B, o momento magnético máximo se incrementa com o aumento da temperatura, atingindo um máximo em $440 \mathrm{~K}$, temperatura onde termina transição de fase AFM - FM. Posteriormente, o momento máximo mostra uma diminuição com o incremento da temperatura. No resfriamento a amostra apresentou ciclos de histerese abertos em $400 \mathrm{~K}$ e em $383 \mathrm{~K}$, o que sugere instabilidades bastante acentuadas da magnetização do sistema na região de temperaturas de transição, como já foi mencionado anteriormente. Observa-se também, nos ciclos da região de baixas temperaturas, as remagnetizações mencionadas anteriormente (ver Figura 4-8), as quais aparecem nas curvas de desmagnetização para campos pequenos (da ordem de $20 \mathrm{Oe}$ ). Estes picos desaparecem nos ciclos de temperaturas maiores, então eles podem ser atribuídos a algum efeito vinculado à fase AFM, tal como um reordenamento de spin.

O comportamento da magnetização remanente, mostrada na Figura 4-13 (a), é bastante similar àquela mostrada pela amostra 1B. Porém, o comportamento de $m_{R} / m_{M A X}$, Figura 4-13 (b), apesar de também ser similar, apresentou valores distintos, sendo aproximadamente 0,25 em baixas temperaturas e atingindo um máximo de 0,6 em altas temperaturas, o que sugere que as interações desmagnetizantes existentes nesta amostra são mais intensas que as da amostra $1 \mathrm{~B}$.

Na Figura 4-14 (a) vemos uma notável diferença no comportamento da coercividade entre ambas as amostras (1B e 2B): embora a coercividade do sistema na região de baixas temperaturas continua sendo maior que na região de altas temperaturas (neste caso o dobro), o máximo de coercividade se atinge na região de temperaturas de transição. Finalmente, o deslocamento dos ciclos de histerese, mostrados na Figura 4-14 (b), mostra novamente valores pequenos, praticamente nulos na região de altas temperaturas (onde se espera a presença somente de uma fase $F M$ ), e com um máximo de somente 6 Oe na região de baixas temperaturas, onde, aparentemente, temos coexistência de fases AFM e FM. 


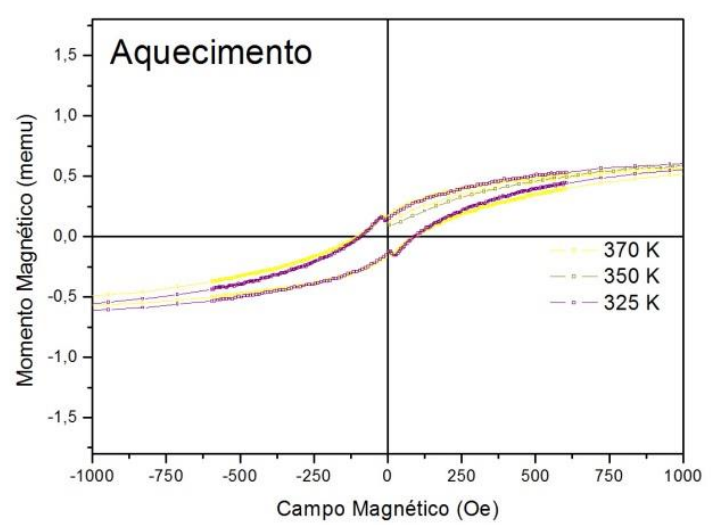

(a)

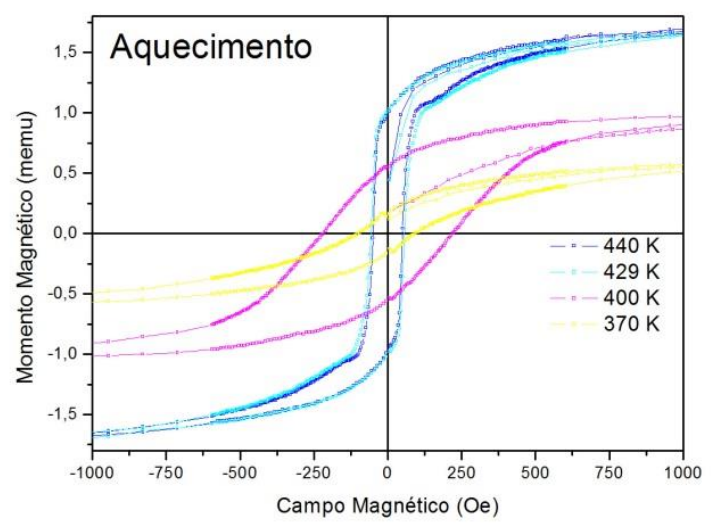

(c)

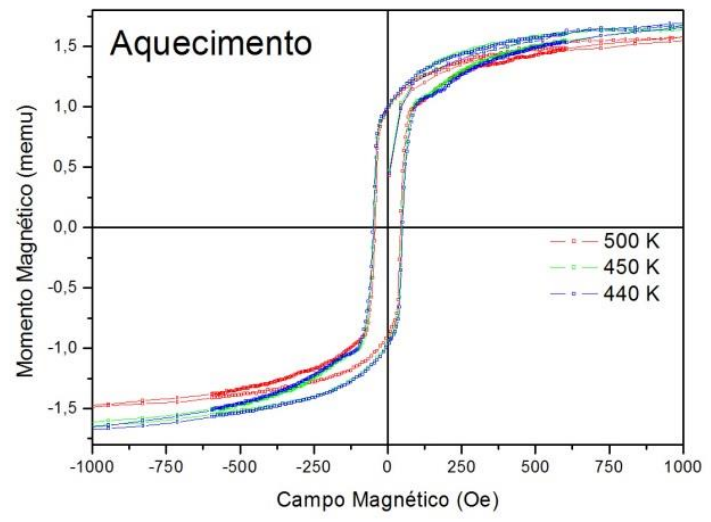

(e)

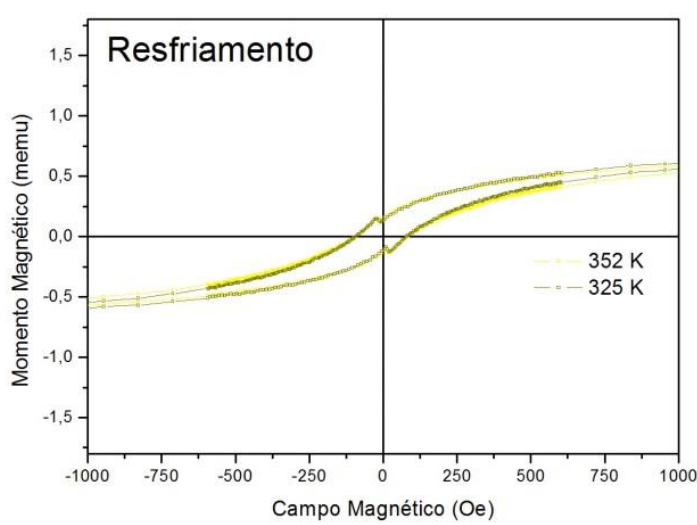

(b)

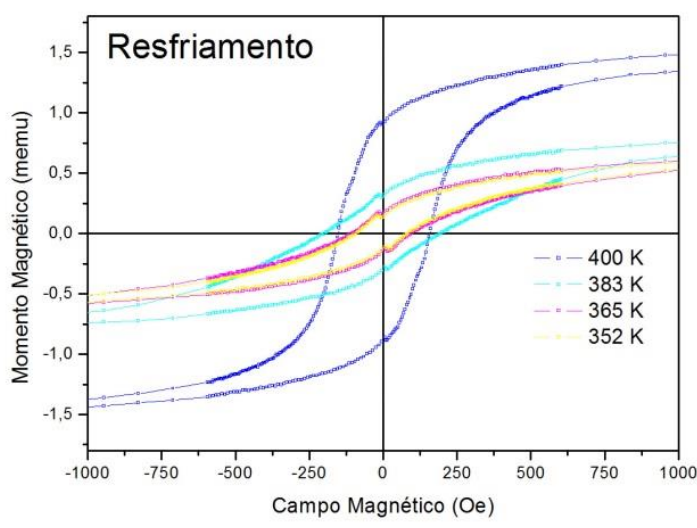

(d)

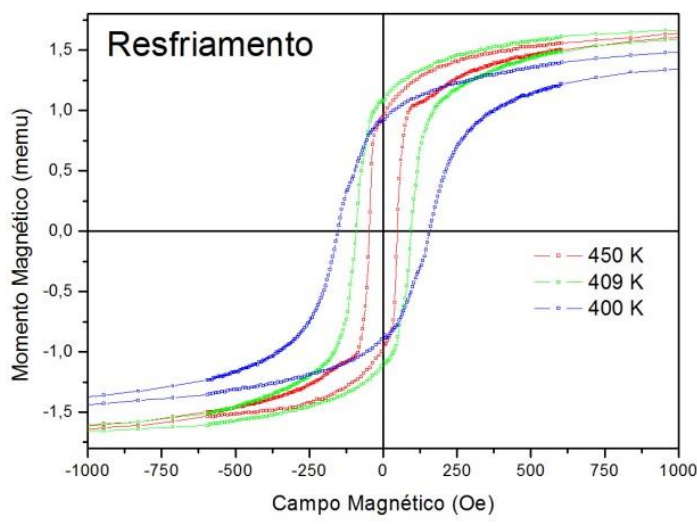

(f)

Figura 4-12. Amostra 2B: Histereses medidas na transição AFM $\rightarrow$ FM (aquecimento) e FM $\rightarrow$ AFM (resfriamento), sendo (a) e (b) baixas temperaturas, (c) e (d) temperaturas de transição e (e) e (f) altas temperaturas. 


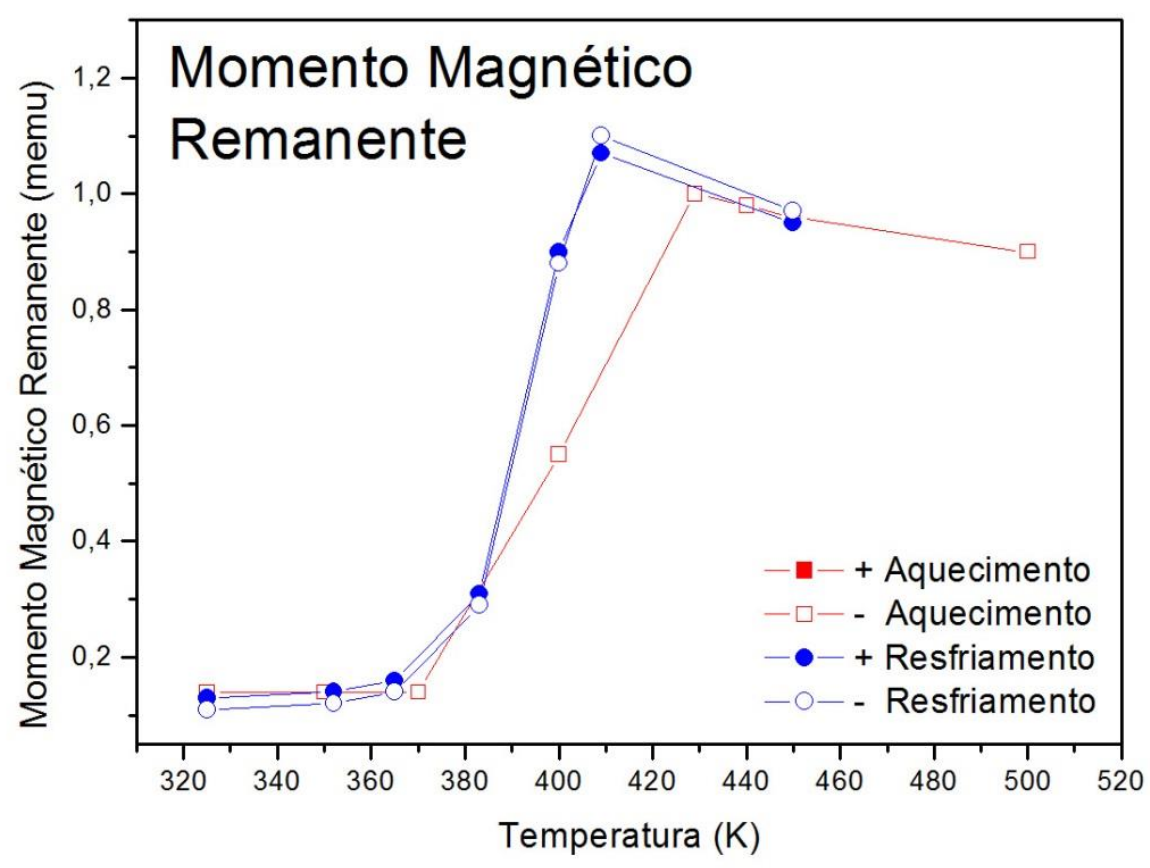

(a)

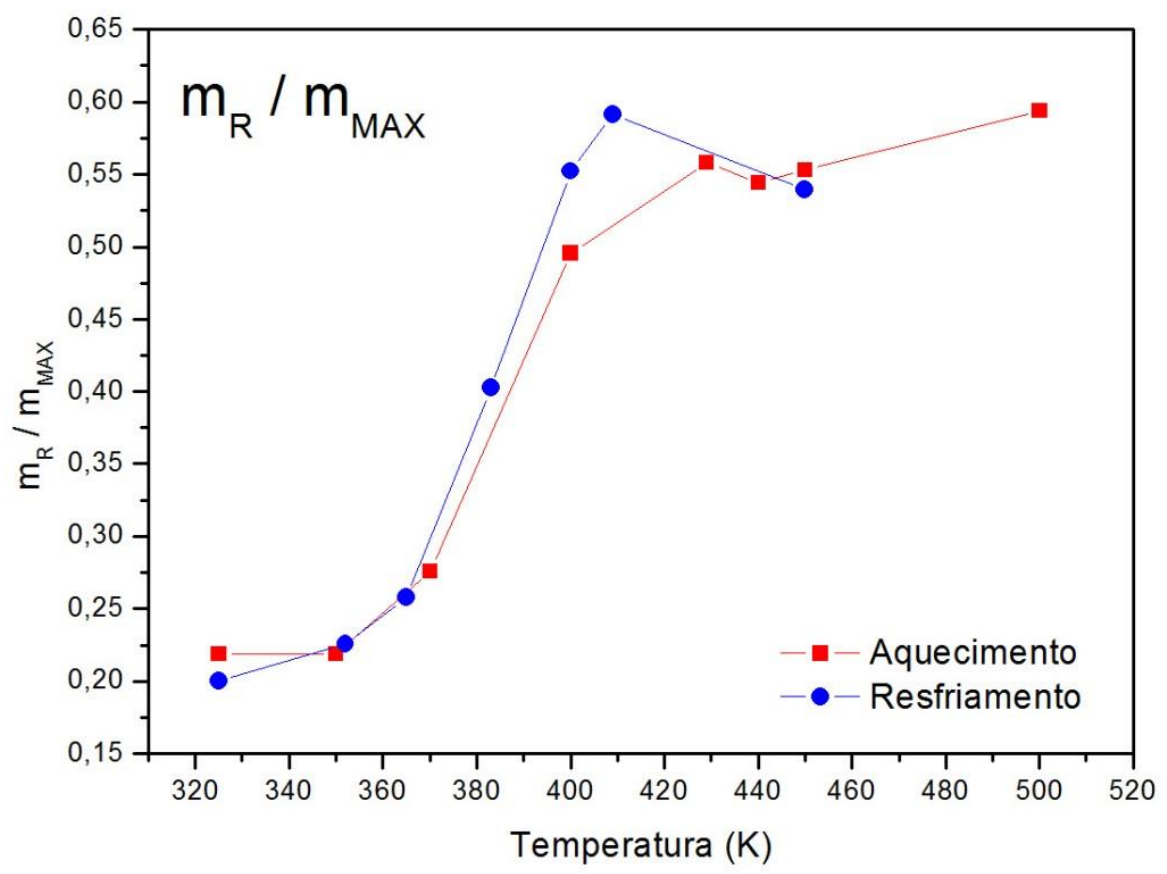

(b)

Figura 4-13. Amostra 2B: (a) Momentos magnéticos remanentes e (b) razão entre o momento magnético remanente e o momento magnético máximo. 


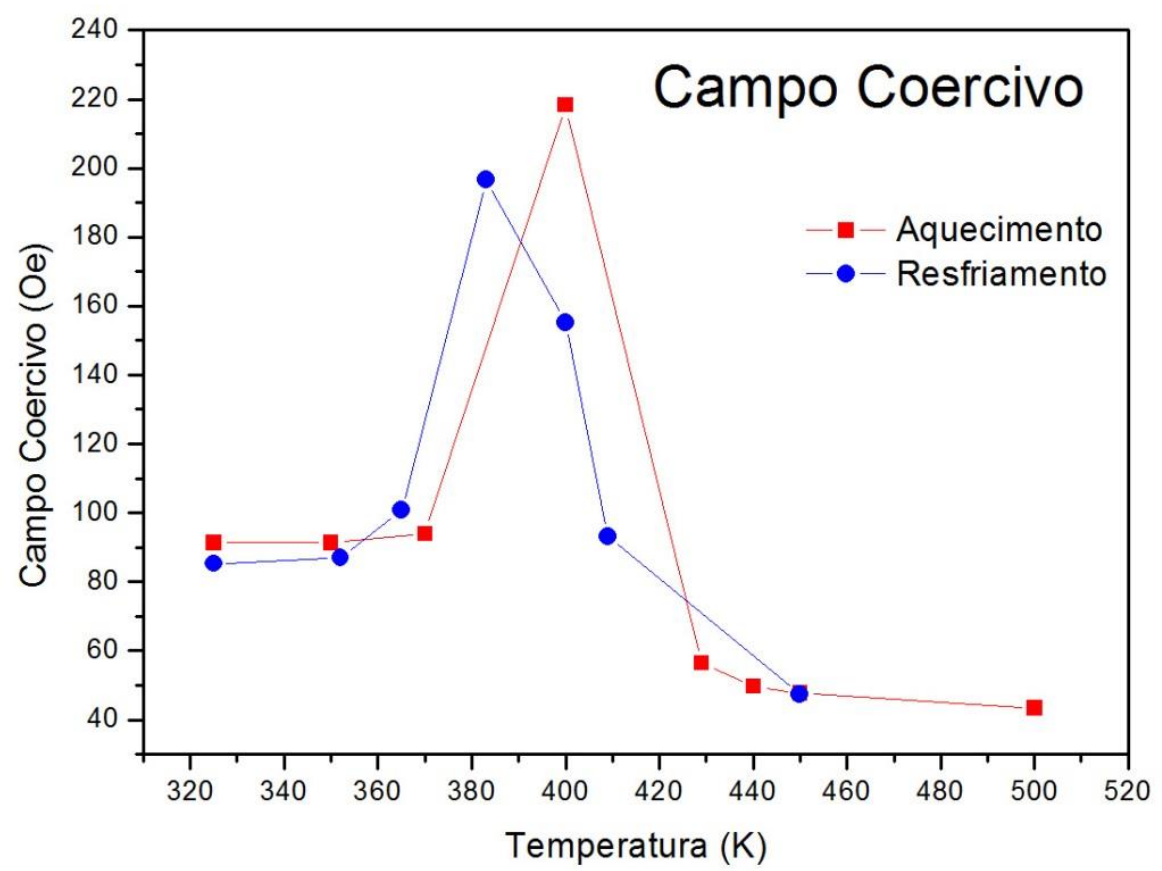

(a)

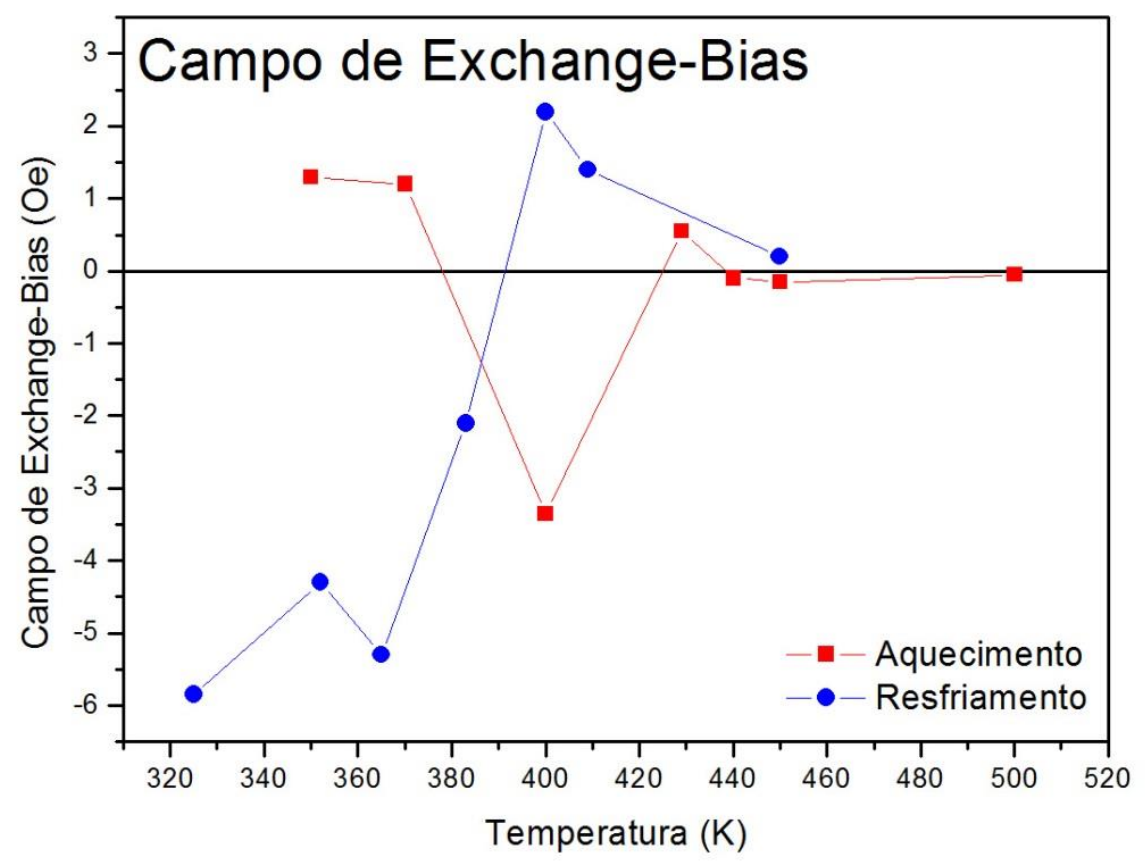

(b)

Figura 4-14. Amostra 2B: (a) Campos coercivos e (b) campos de exchange-bias. 
Vamos agora fazer uma comparação entre os resultados obtidos para as amostras 1B e 2B. Em relação aos momentos magnéticos de saturação e remanente não podemos fazer comparações diretas entre os valores, desta forma vamos analisar os comportamentos com relação à variação de temperatura. Quanto aos momentos magnéticos de saturação ambas as amostras apresentaram comportamentos similares, partindo de um momento baixo, na região de baixas temperaturas, onde predomina a fase AFM, aumentando continuamente durante a transição AFM $\rightarrow$ FM até atingir um máximo na temperatura de fim de transição, iniciando-se, posteriormente, uma diminuição com o aumento da temperatura, o que é normal em um material ferromagnético. Com relação aos momentos magnéticos remanentes o comportamento foi similar para ambas as amostras, porém distinto do momento de saturação, onde os valores de $m_{R}$ se tornam aproximadamente constantes após atingirem um máximo. O momento remanente relativo, $\mathrm{m}_{R} / \mathrm{m}_{\mathrm{MAx}}$, para ambas as amostras, mostrou valores inferiores a 0,5 na região de baixas temperaturas e superiores a 0,5 na zona de altas temperaturas, sendo os valores maiores na amostra $2 \mathrm{~B}$.

Os campos coercivos das amostras 1B e 2B apresentaram comportamentos claramente distintos. Quando as amostras se encontram na região de altas temperaturas, onde a fase FM é predominante, ou única, os campos coercivos são próximos, $\mathrm{H}_{\mathrm{c}}^{1 \mathrm{~B}} \sim 40 \mathrm{Oe} \mathrm{eH}_{\mathrm{c}}^{2 \mathrm{~B}} \sim 50 \mathrm{Oe}$. Porém, o comportamento na região de baixas temperaturas, onde predomina a fase AFM, e nas regiões de transição demonstraram uma forte dependência com relação à produção das amostras. A amostra 1B apresenta um alto valor de coercividade, da ordem dos 400 Oe, provavelmente fruto de um forte acoplamento entre as camadas FM e AFM na região de baixas temperaturas. Já a amostra 2B apresenta coercividade máxima, de uns 200 Oe, somente na região da transição de fase. Provavelmente, isto sugere que a quantidade relativa de fase FM na região de baixas temperaturas é menor na amostra $2 \mathrm{~B}$ que na amostra $1 \mathrm{~B}$. Em relação aos campos de deslocamento, ambas as amostras apresentaram comportamentos distintos, porém não padronizados. Resulta, claro, que os pequenos valores observados (em comparação com a coercividade dos filmes), e o fato que, frequentemente, se observam tanto deslocamentos positivos quanto negativos, coloca o comportamento deste sistema próximo aos sistemas onde a coexistência de fases AFM e FM produzem incrementos na coercividade, mas não deslocamentos do ciclo 
de histerese. Como foi mencionado na introdução, este comportamento foi observado em sistemas $A F M / F M$ onde a $T_{N}$ da fase $A F M$ era maior que a $T_{C}$ da fase $F M$. Em certo sentido, isso tem uma semelhança com o nosso sistema, já que a fase AFM do FeRh é termodinamicamente menos estável que a fase FM.

\subsubsection{Amostras bicamadas}

Vamos agora analisar as amostras 1A e 2A, voltando nossas atenções para as interações entre as camadas de FeRh e Fe. Da mesma forma que para as amostras tipo $B$, a primeira medida realizada nas amostras, ainda virgens, foi um ciclo de histerese na região de baixas temperaturas, sendo a temperatura utilizada para a amostra $1 \mathrm{~A}$ de $80 \mathrm{~K}$ e para a amostra $2 \mathrm{~A}$ de $325 \mathrm{~K}$. Depois de obtidos os ciclos térmicos, nas mesmas condições que foram usadas nas amostras $1 \mathrm{~B}$ e $2 \mathrm{~B}$, novamente os ciclos de histerese foram medidos nas temperaturas mencionadas. O conjunto de ciclos para as amostras 1A e 2A se encontra nas Figura 4-15 e Figura 4-16, respectivamente. Pode-se observar uma diferença importante entre o comportamento da bicamada de FeRh/Fe na amostra $1 \mathrm{~A}$ e a correspondente bicamada na amostra $2 \mathrm{~A}$. $\mathrm{Na}$ primeira amostra (1A), o ciclo de histerese é consistente com o comportamento de uma fase FM simples, havendo um único campo de inversão da magnetização, que se traduz em uma coercividade de 215 Oe para o ciclo inicial, campo que se incrementa até 230 Oe depois de realizado o ciclo térmico (um incremento de aproximadamente 6\%) sem mudanças significativas no momento magnético. Como veremos depois, podemos esperar que exista uma certa quantidade de fase FM presente na camada FeRh em baixa temperatura nas duas amostras e, neste caso, a magnetização dessa componente se encontra bem acoplada com a camada de Fe. Observe-se também a alta relação entre a remanência nestes ciclos e o momento magnético máximo obtido. Na amostra $2 \mathrm{~A}$, por outro lado, o ciclo de histerese é totalmente diferente ao da amostra anterior. A forma do ramo de desmagnetização mostra duas fases se desmagnetizando, e a coercividade global da amostra é de 134 Oe no primeiro ciclo e sobe para 143 Oe depois de realizado o ciclo térmico. Neste caso não parece haver um bom acoplamento entre a camada de 
Fe e a fase FM presente na camada de FeRh. Dada a semelhança entre as camadas de Fe de ambas as amostras, a diferença deve vir da microestrutura da camada de FeRh. 


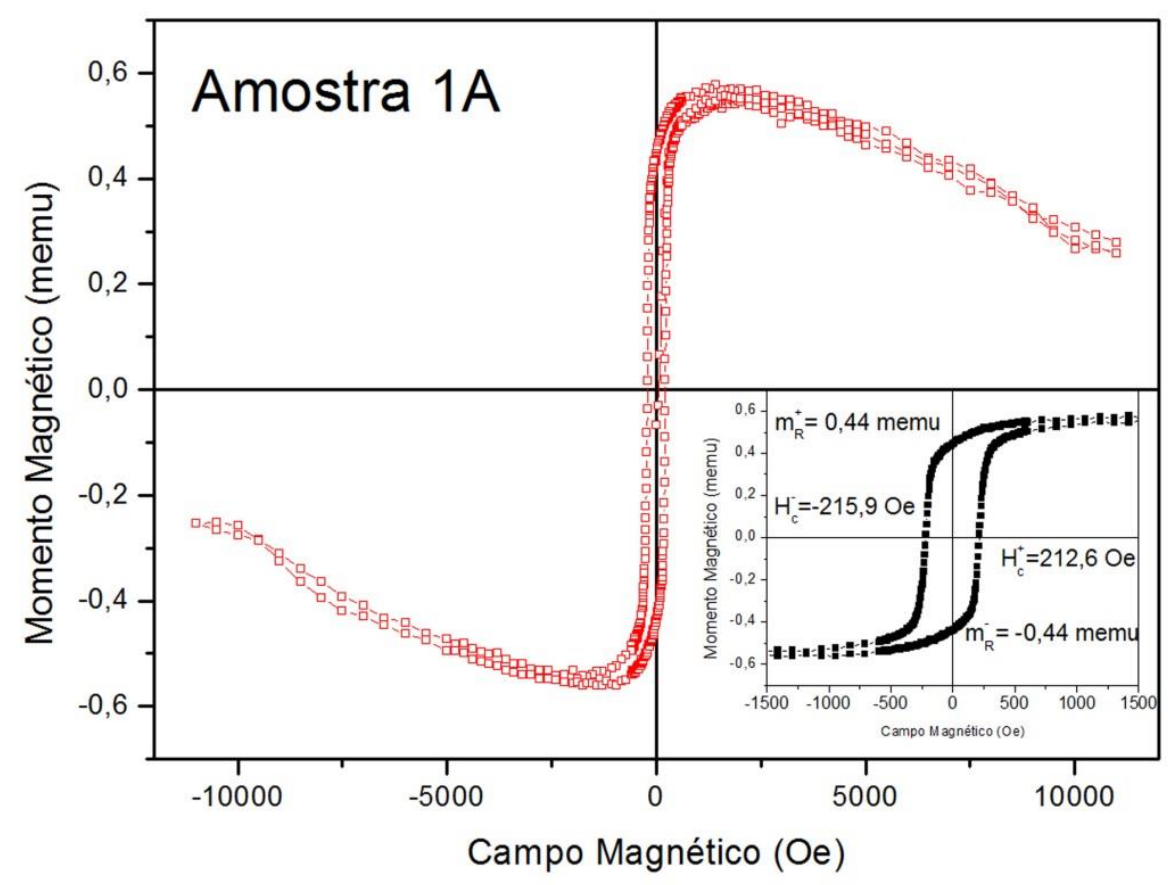

(a)

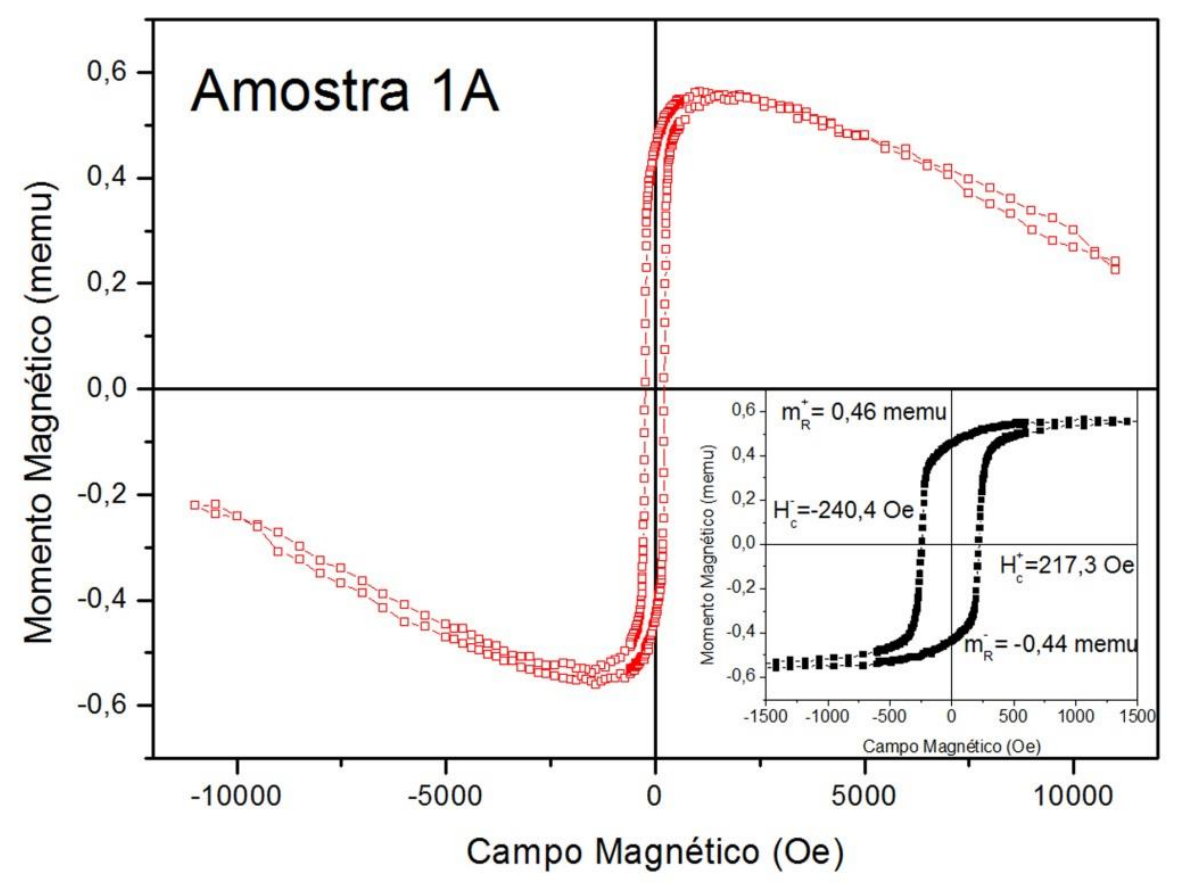

(b)

Figura 4-15. Histereses feitas na fase AFM da amostra 1A. Medidas feitas em 80 K. (a) Amostra virgem e (b) após primeiro ciclo térmico. 


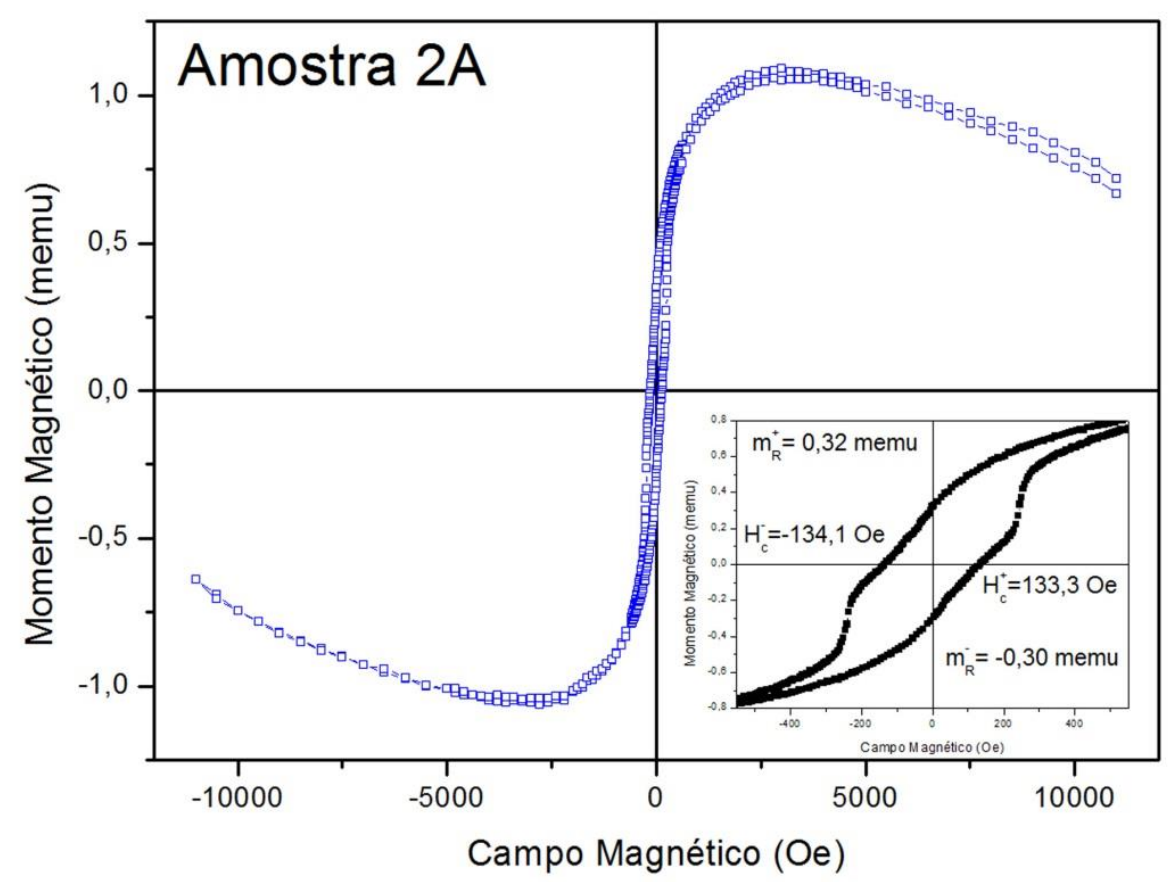

(a)

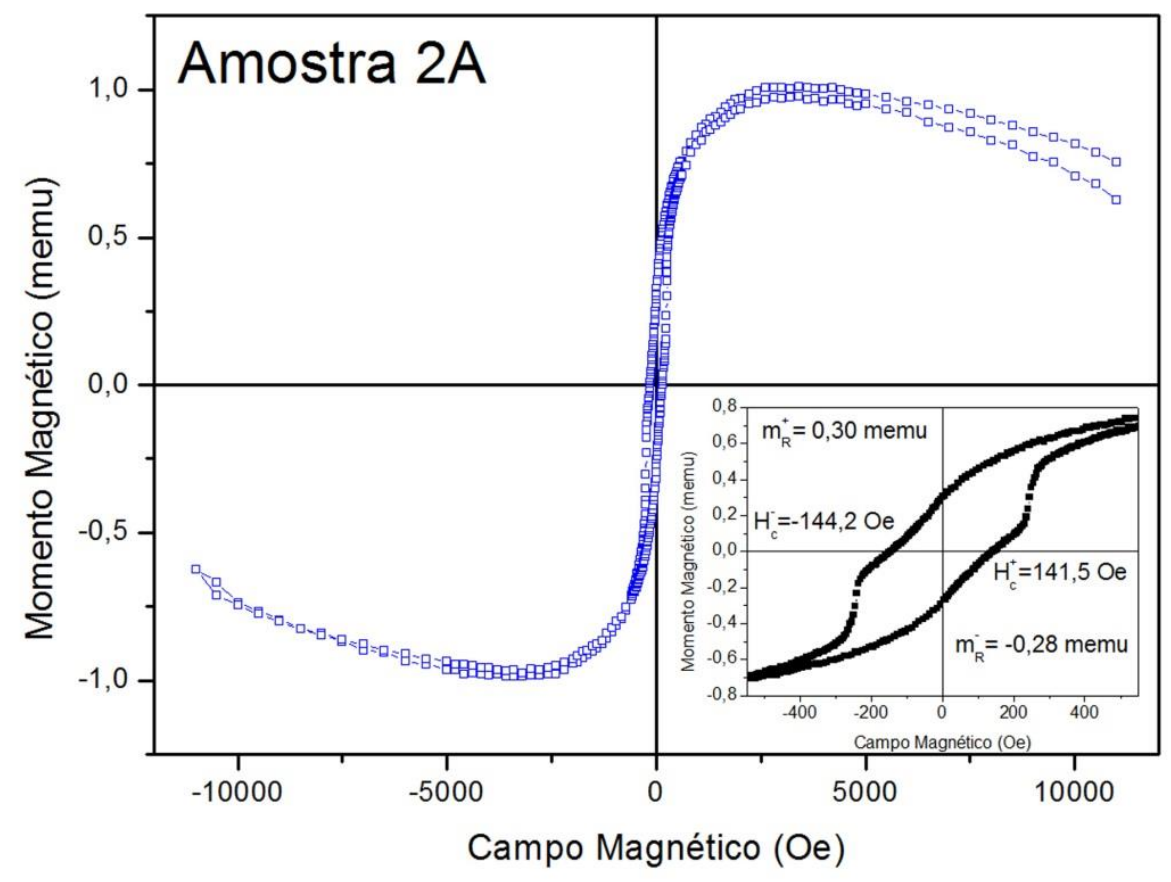

(b)

Figura 4-16. Histereses feitas na fase AFM da amostra 2A. Medidas feitas em 325 K. (a) Amostra virgem e (b) após primeiro ciclo térmico. 
A Figura 4-17 (a) mostra que a transição AFM $\rightarrow$ FM não chegou a se completar na amostra 1A até a temperatura limite que pode ser atingida no criostato (450 K). Depois da aplicação do campo de 11 kOe, o momento magnético aumentou consideravelmente e no resfriamento a amostra apresentou uma magnetização menor que a inicial, o que, provavelmente, se deve à contribuição diamagnética do substrato. Uma falha ocorrida no experimento entre os 200 e $225 \mathrm{~K}$ desligou o campo magnético aplicado e, como se observa na figura, sem a presença do campo o momento magnético da amostra se aproxima do apresentado na condição inicial. Da mesma forma que as amostras $1 \mathrm{~B}$ e $2 \mathrm{~B}$, o momento remanente existente na amostra, após a primeira histerese, favoreceu a orientação do momento magnético.

No ciclo térmico da amostra 2A, Figura 4-17 (b), realizado utilizando o forno, se observa que a transição AFM $\rightarrow$ FM se completou, e que a aplicação do campo de $11 \mathrm{kOe}$, quando se chega em $500 \mathrm{~K}$, somente levou a um pequeno incrementou do momento magnético, o que indica que a magnetização obtida durante o aquecimento estava praticamente no seu valor de saturação. Já durante o resfriamento, se observa que a transição inversa FM $\rightarrow$ AFM também se completa.

Os critérios para a escolha das temperaturas em que foram feitos os ciclos térmicos foram os mesmos que para as amostras $1 \mathrm{~B}$ e $2 \mathrm{~B}$. As temperaturas escolhidas encontram-se na Tabela 4-4.

Na Figura 4-18 encontram-se os ciclos de histerese medidos no aquecimento e no resfriamento para a amostra $1 \mathrm{~A}$. $\mathrm{O}$ momento magnético máximo apresenta um aumento contínuo com o incremento da temperatura a medida que se produz a transição de fase AFM $\rightarrow$ FM, porém não foi possível identificar se chegava-se a um máximo, uma vez que não foi obtida uma transição de fase completa até a máxima temperatura testada. No resfriamento a amostra apresentou dois ciclos de histerese abertos, em 357 e 385 K, sendo estas na mesma região das histereses abertas apresentadas pela amostra 1B, sugerindo que o acoplamento da camada de FeRh com a camada de Fe não alterou, significativamente, a metaestabilidade da fase FM existente nesta região. Em relação à forma da curva de desmagnetização dos ciclos, não se observam degraus nos ciclos da região de altas temperaturas, o que evidencia um bom acoplamento entre a fase FM da camada de FeRh e a camada de Fe. Já na região de temperaturas intermediarias, onde se produzem as transições, se observa um pequeno degrau, o qual desaparece na região de baixas temperaturas. 

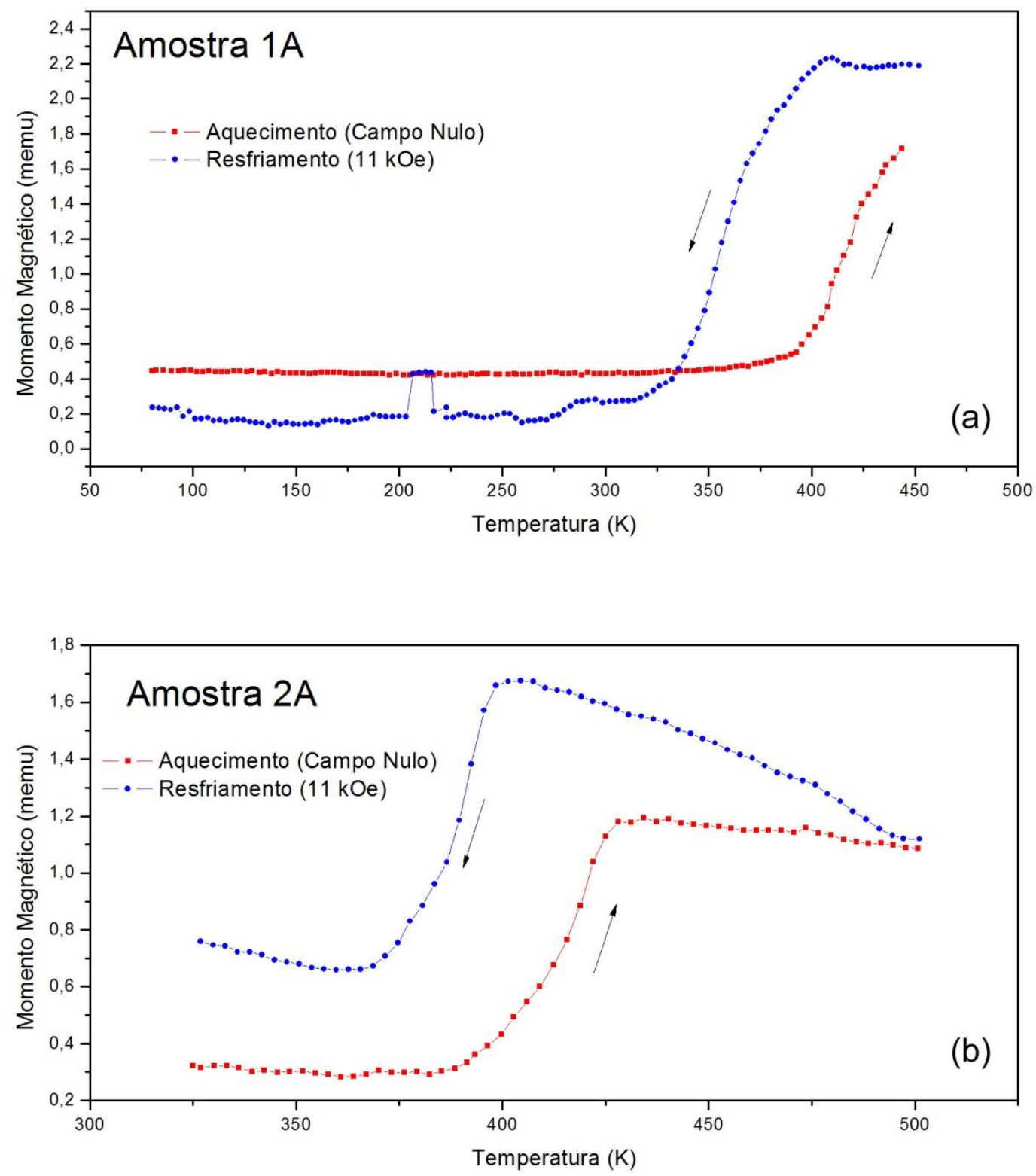

Figura 4-17. Curvas de aquecimento e resfriamento para as amostras (a) $1 \mathrm{~A} \mathrm{e} \mathrm{(b)} 2 \mathrm{~A}$, utilizadas como referência para a escolha das temperaturas a serem feitas as histereses. Aquecimento feito a campo nulo e resfriamento a $11 \mathrm{kOe}$. 
Tabela 4-4. Temperaturas utilizadas para as curvas de momento magnético versus campo das amostras $1 \mathrm{~A}$ e $2 \mathrm{~A}$.

\begin{tabular}{|c|c|}
\hline $1 \mathrm{~A}$ & $2 \mathrm{~A}$ \\
\hline \multicolumn{2}{|c|}{ Aquecimento $(\mathrm{K})$} \\
\hline 80 & 325 \\
\hline 200 & 385 (Início da Transição) \\
\hline 280 & 400 \\
\hline 365 (Início da Transição) & $420\left(T_{A F M}-F M\right)$ \\
\hline 380 & 427 \\
\hline $415\left(T_{A F M}-F M\right)$ & 435 (Fim da Transição) \\
\hline 430 & 500 \\
\hline 450 & --- \\
\hline \multicolumn{2}{|c|}{ Resfriamento $(\mathrm{K})$} \\
\hline 430 & 435 \\
\hline 410 (Início da Transição) & 403 (Início da Transição) \\
\hline 385 & 392 \\
\hline $357\left(\mathrm{~T}_{\mathrm{FM}}-\mathrm{AFM}\right)$ & $382\left(T_{F M}-A F M\right)$ \\
\hline 333 & 372 \\
\hline 310 (Fim da Transição) & 362 (Fim da Transição) \\
\hline 280 & 325 \\
\hline 200 & --- \\
\hline 80 & --- \\
\hline
\end{tabular}

Na Figura 4-19 (a), amostra 1A, é apresentado o comportamento do momento remanente, em função da temperatura, para o aquecimento e o resfriamento, sendo este comportamento similar ao da amostra 1B. Já o comportamento de $m_{R} / m_{M A X}$, Figura 4-19 (b) não apresentou similaridades com essa amostra, nem apresentou um padrão definido com relação a temperatura, mas todos os valores acima de 0,75 e 0,85, aproximadamente, o que revela um predomínio de interações magnetizantes nesta amostra.

$\mathrm{Na}$ Figura 4-20 (a) se mostram as coercividades obtidas. A forma geral do comportamento desta grandeza não difere muito daquela mostrada pela amostra 1B (monocamada de FeRh). Em particular, a coercividade obtida na região de baixas temperaturas é claramente maior que a obtida na região de altas temperaturas. 
Lembremos que a forma dos ciclos de histerese da amostra $1 \mathrm{~A}$ (bicamada FeRh/Fe) sugere um bom acoplamento entre as camadas, porém, a coercividade em baixas temperaturas da bicamada $1 \mathrm{~A}$ (uns $220 \mathrm{Oe}$ ) é bastante menor que a da monocamada 1B (aproximadamente 400 Oe). Esta perda de coercividade pode ser um efeito do acoplamento entre as camadas, já que, por um lado, temos uma camada de FeRh de "alta coercividade" e por outro lado uma camada de Fe de "baixa coercividade", como foi observado nos filmes de Fe preparados a tal fim. Esta coercividade intermediaria costuma ser observada, por exemplo, em bicamadas de sistemas do tipo exchange-spring magnet [50][51].

São apresentados no gráfico (b) da figura mencionada os valores de campo de deslocamento em função da temperatura, para os ciclos medidos. Novamente, os valores são pequenos e podem ser considerados nulos na região de altas temperaturas, onde temos a camada de FeRh, na fase FM, em contato com a camada de Fe. Certamente, não esperamos deslocamentos nesta região de temperaturas. Já na região de baixas temperaturas, e inclusive na região de coexistência de fases, se observam pequenos valores de deslocamentos e em todos os casos negativos. Isto parece refletir um possível acoplamento via exchange-bias entre a camada de FeRh (com fase predominantemente AFM) e a camada de Fe. No entanto, os pequenos valores de campo de exchange-bias obtidos, sugerem que a energia de acoplamento é extremamente baixa. 


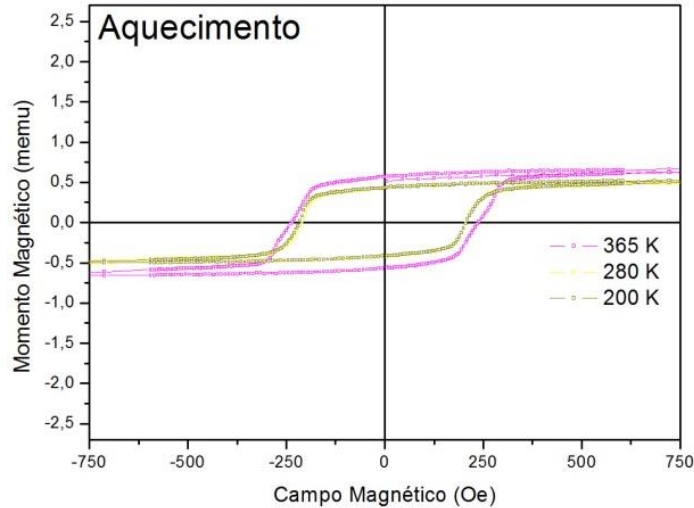

(a)

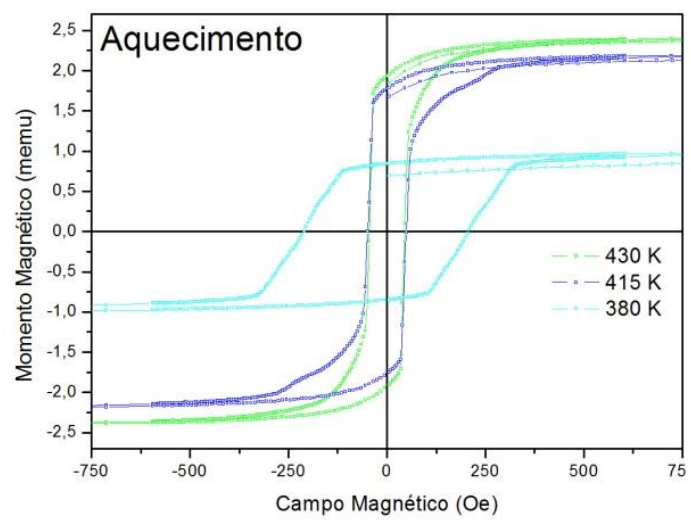

(c)

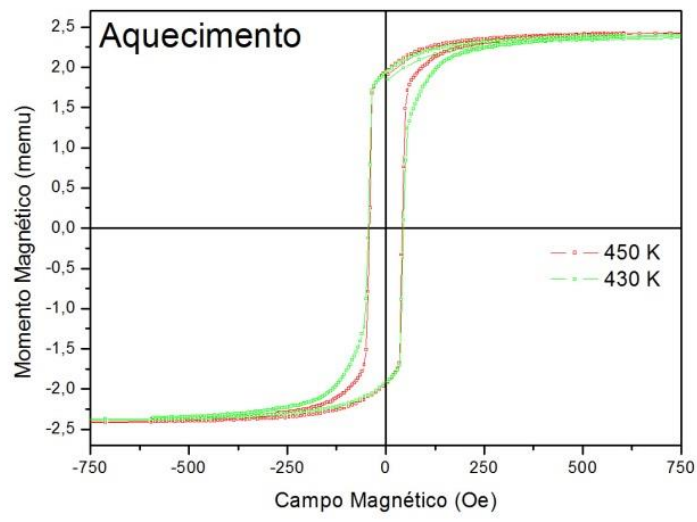

(e)

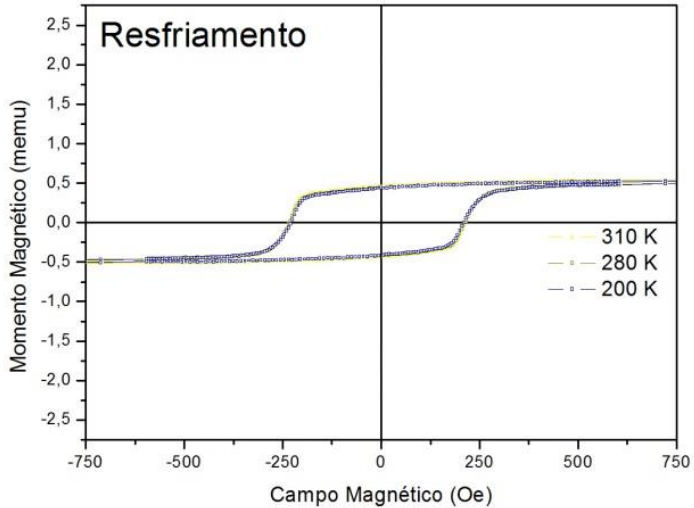

(b)

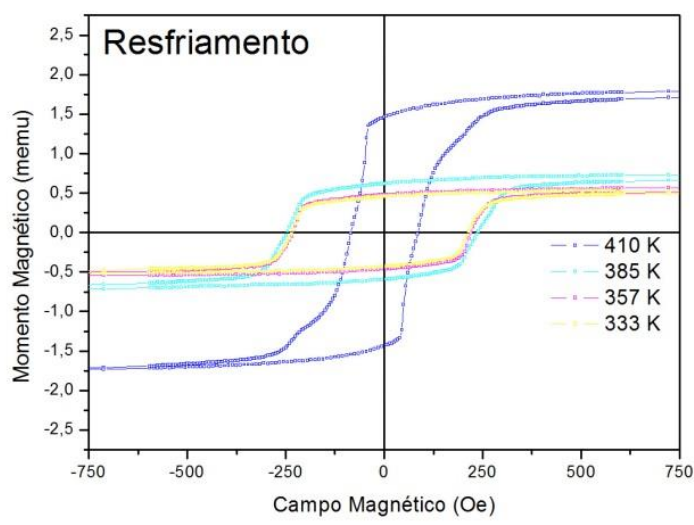

(d)

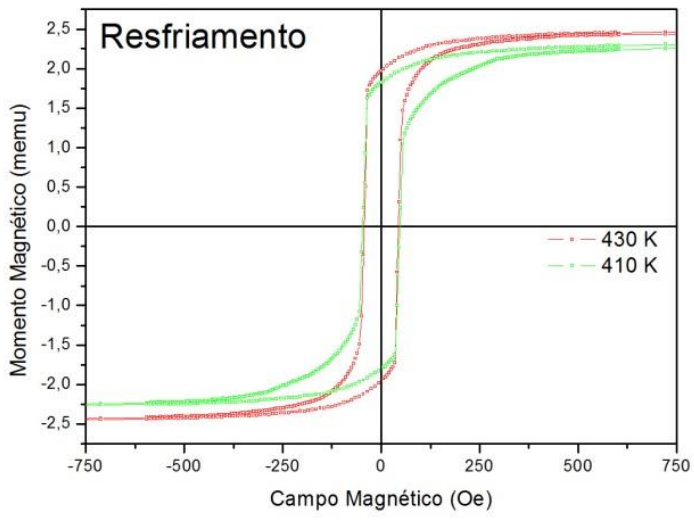

(f)

Figura 4-18. Amostra 1A: Histereses medidas na transição AFM $\rightarrow$ FM (aquecimento) e FM $\rightarrow$ AFM (resfriamento), sendo (a) e (b) baixas temperaturas, (c) e (d) temperaturas de transição e (e) e (f) altas temperaturas. 


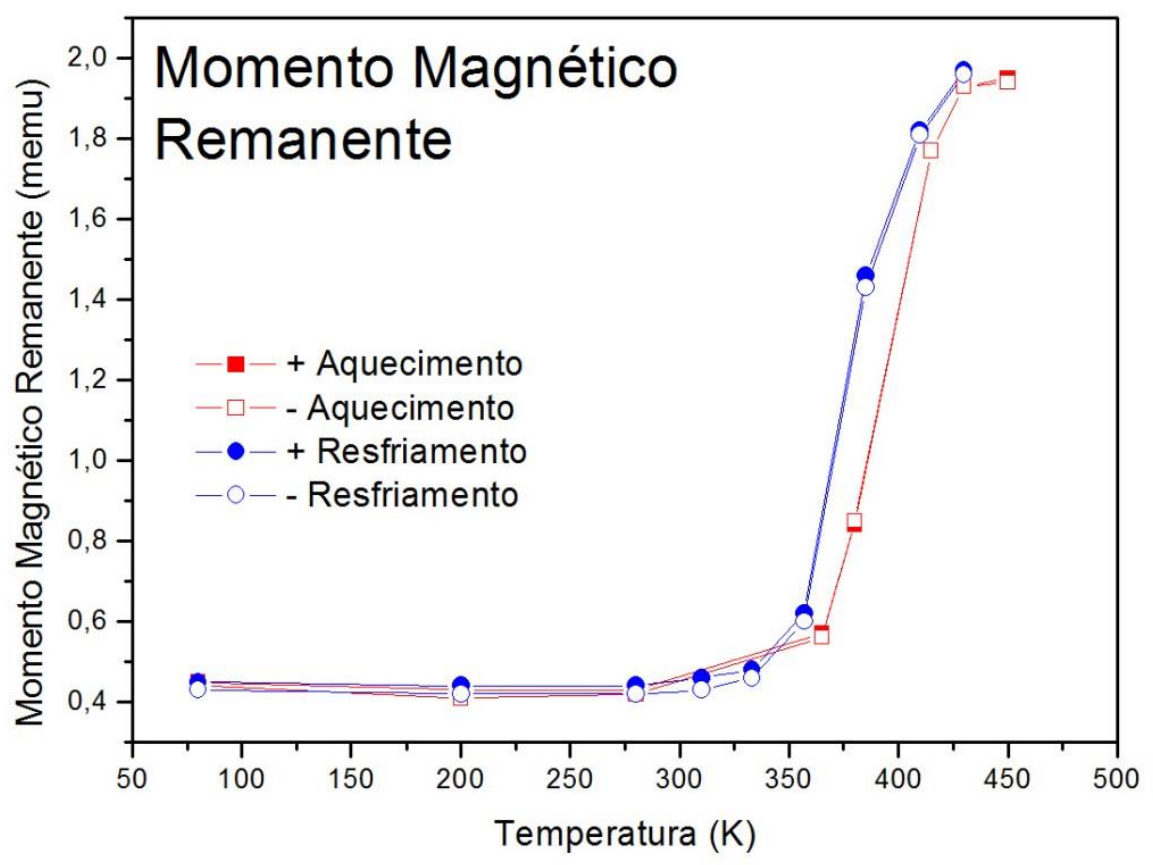

(a)

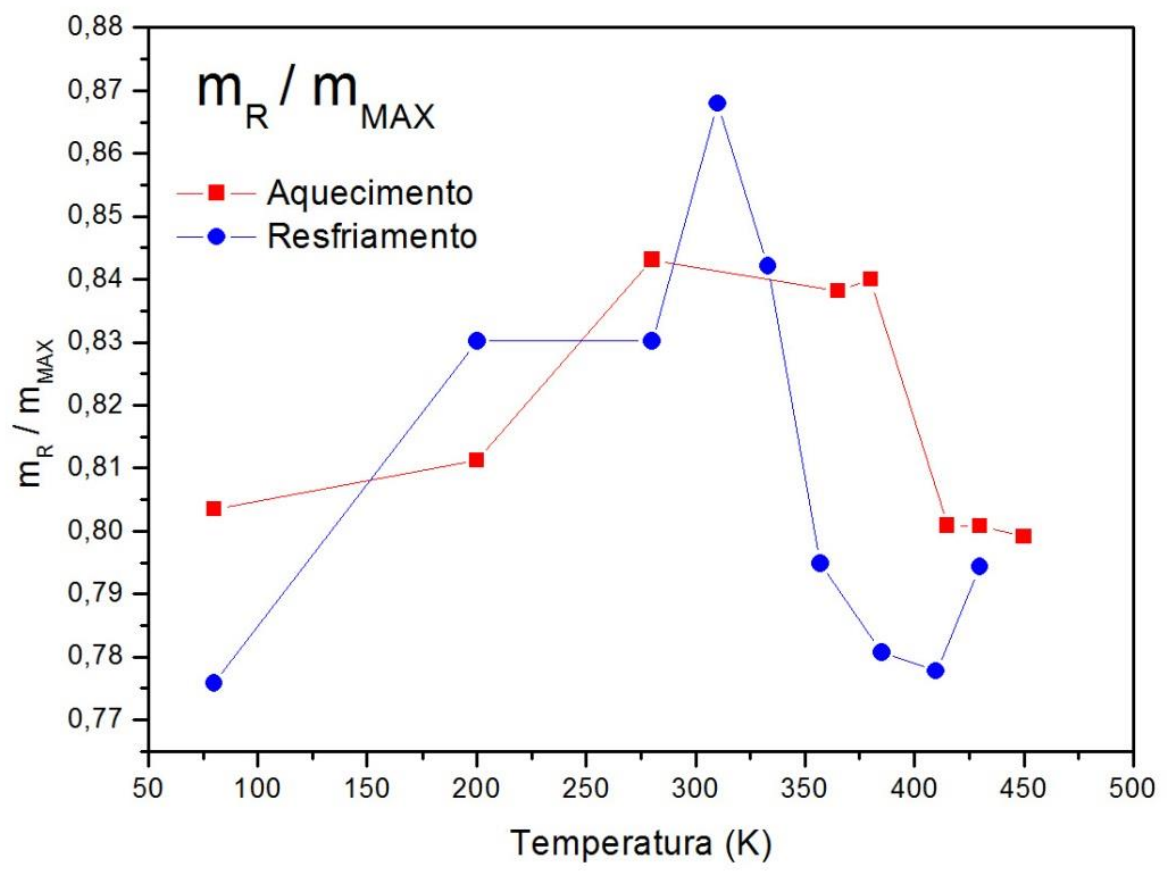

(b)

Figura 4-19. Amostra 1A: (a) Momentos magnéticos remanentes e (b) razão entre o momento magnético remanente e o momento magnético máximo. 


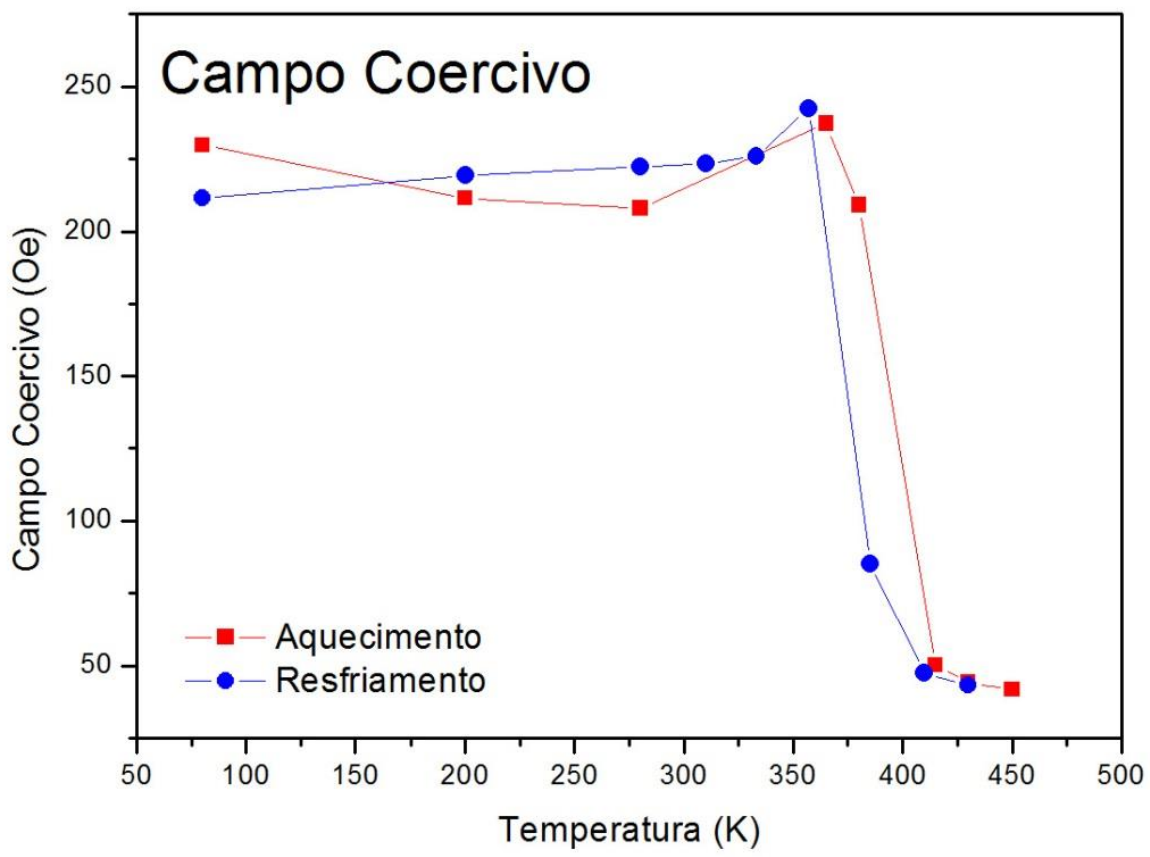

(a)

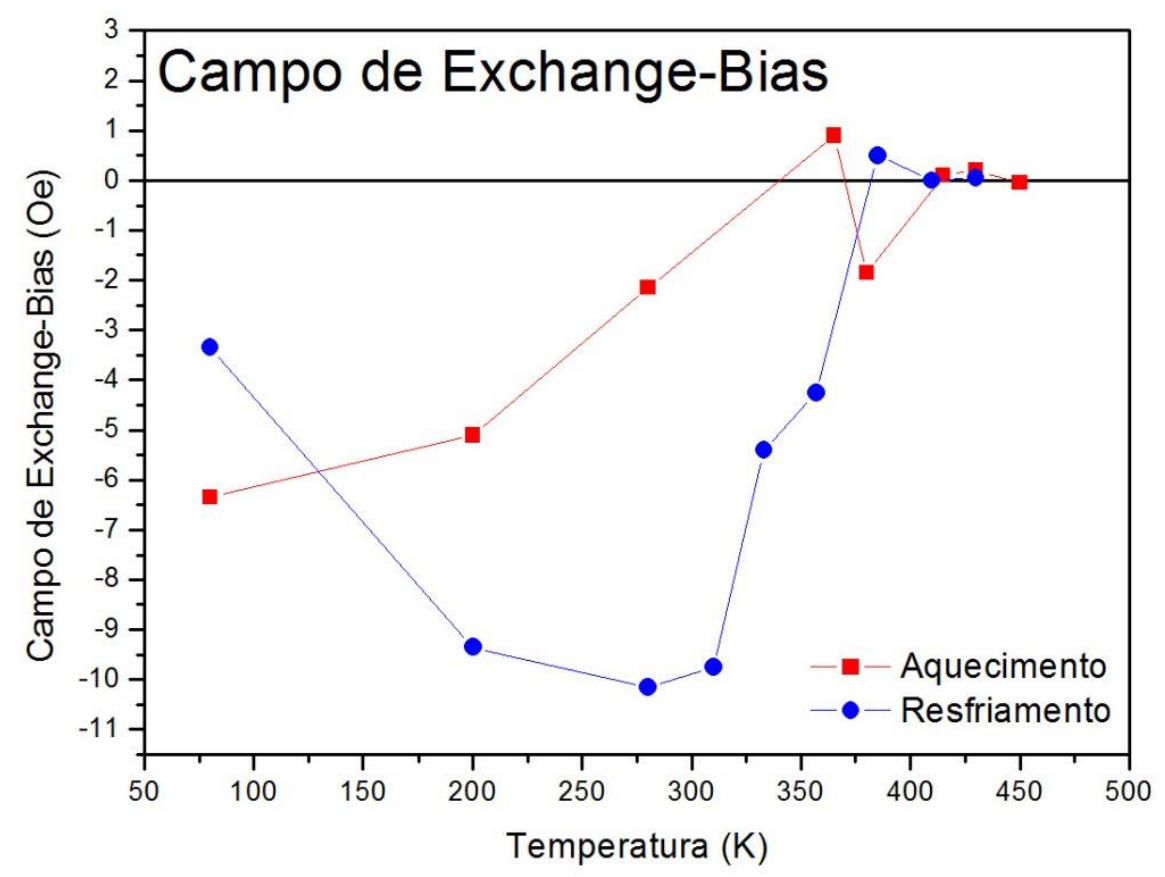

(b)

Figura 4-20. Amostra 1A: (a) Campos coercivos e (b) campos de exchange-bias. 
Na Figura 4-21 encontram-se os ciclos de histerese medidos no aquecimento e no resfriamento para a amostra $2 \mathrm{~A}$. Novamente é observado que o momento magnético máximo se incrementa conforme a temperatura aumenta, já que a quantidade de fase FM na camada de FeRh cresce com a temperatura até que a transição se complete. Depois, o momento magnético máximo diminui com o aumento da temperatura. No resfriamento a amostra apresentou dois ciclos de histerese abertos, em 403 e $392 \mathrm{~K}$, sendo estas na mesma região que as histereses abertas apresentadas pela amostra 2B, sugerindo que o acoplamento da camada de FeRh com a camada de $\mathrm{Fe}$, da mesma forma que para a amostra 1A, não alterou a característica metaestável de fase FM do FeRh existente nesta região. Na região de altas temperaturas, a forma da curva de desmagnetização dos ciclos não mostra nenhum degrau, de maneira que a fase FM da camada AFM está perfeitamente acoplada com a camada de Fe. Já nas temperaturas intermediarias e em baixas temperaturas todos os ciclos mostram desmagnetizações com degraus, o que evidencia um pobre acoplamento entre a camada de FeRh e a camada de Fe. Este comportamento é bem diferente do observado na amostra $1 \mathrm{~A}$, onde existia bom acoplamento em todas as faixas de temperaturas.

O momento magnético remanente, mostrado na Figura 4-22 (a), mostra um comportamento geral similar às outras amostras estudadas, porém com valores relativos menores. O comportamento de $m_{R} / m_{M A X}$, por outro lado, Figura 4-22 (b), foi similar ao da monocamada (amostra 2B) tanto em função da temperatura como pelos valores apresentados, sendo agora aproximadamente 0,3 em baixas temperaturas e 0,65 em temperaturas elevadas. Isto sugere que na região de baixas temperaturas houve predomínio das interações desmagnetizantes entre as camadas, enquanto que para altas temperaturas as interações magnetizantes prevaleceram. Este comportamento foi claramente diferente daquele mostrado pela amostra.

Os campos coercivos da amostra 2A são mostrados na Figura 4-23 (a). O campo coercivo em função da temperatura se comporta de forma similar ao da amostra 2B, onde, no aquecimento, sai de um valor inicial, atinge um máximo e diminui para um valor menor que o valor inicial, sendo este comportamento também observado no resfriamento. Para esta amostra, o valor máximo da coercividade é de aproximadamente 205 Oe, valor muito similar ao obtido para a monocamada (amostra 2B), que foi de 219 Oe. Isto, junto com a forma geral dos ciclos de histerese, su- 
gere que não houve um bom acoplamento magnético entre a camada de FeRh e a camada de Fe nesta amostra, sobre tudo em comparação ao obtido na amostra $1 \mathrm{~A}$.

Finalmente no gráfico (b) da mesma figura, mostramos os valores do campo de deslocamento dos ciclos de histerese em função da temperatura. Nesta amostra, durante o aquecimento, não foram observados deslocamentos significativos. Já no resfriamento a amostra apresentou valores de deslocamentos próximos aos 10 Oe em três temperaturas, sendo todas abaixo de $\mathrm{T}_{\mathrm{FM}}$ - AFM, o que, novamente, sugere a existência de um acoplamento do tipo exchange-bias entre as camadas FeRh (na sua fase AFM) e a camada de Fe, mas com uma intensidade bastante pequena, em comparação a de outros sistemas conhecidos. 


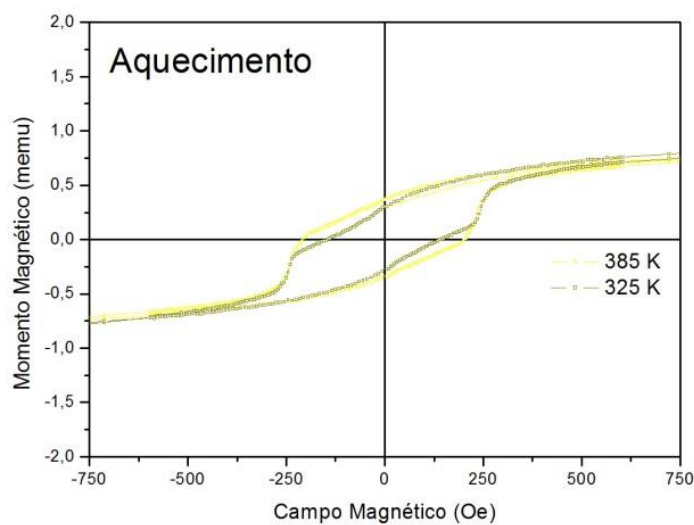

(a)

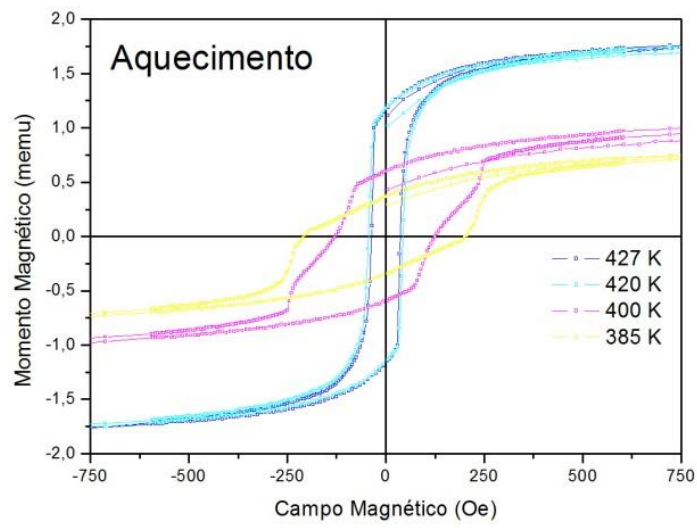

(c)

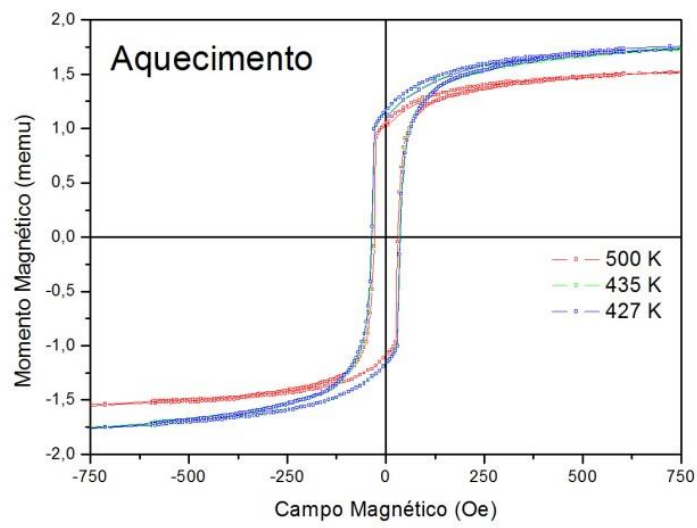

(e)

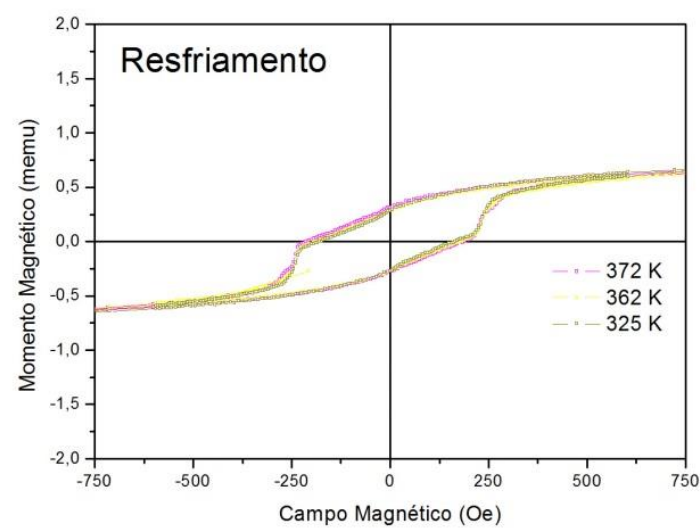

(b)

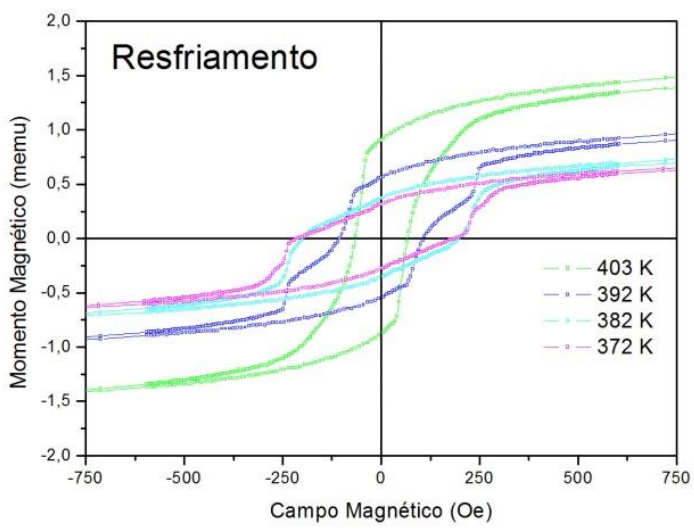

(d)

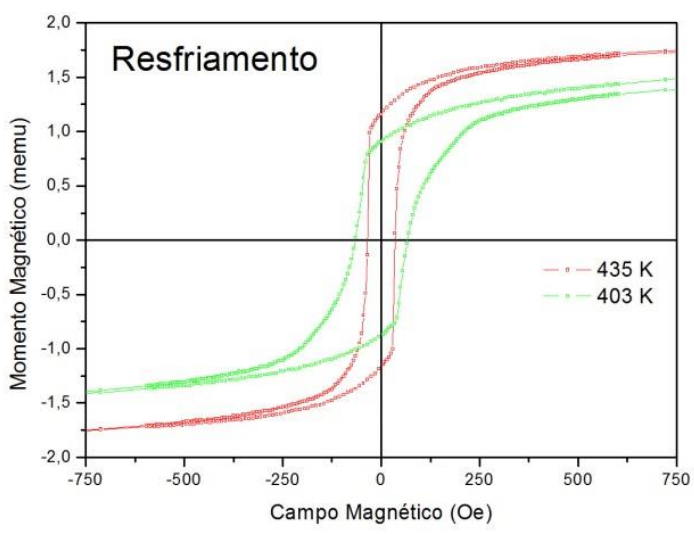

(f)

Figura 4-21. Amostra 2A: Histereses medidas na transição AFM $\rightarrow$ FM (aquecimento) e FM $\rightarrow$ AFM (resfriamento), sendo (a) e (b) baixas temperaturas, (c) e (d) temperaturas de transição e (e) e (f) altas temperaturas. 


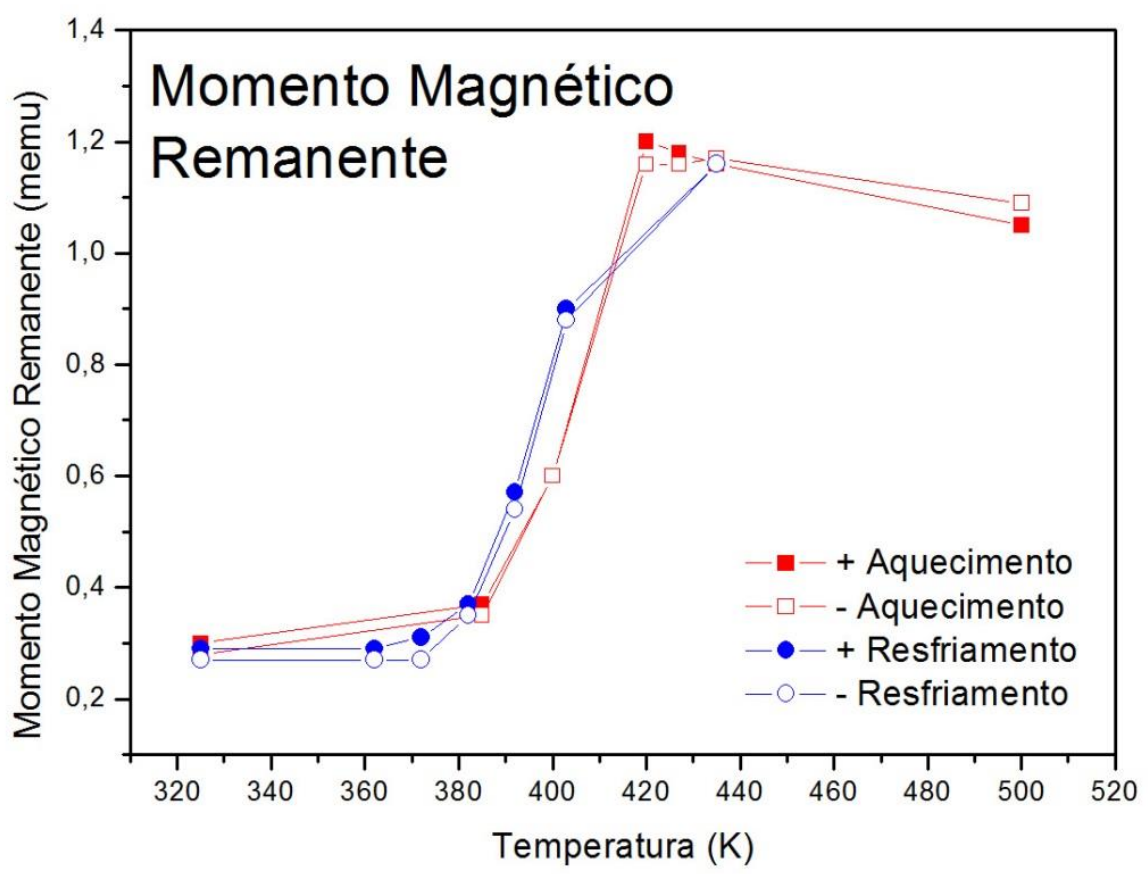

(a)

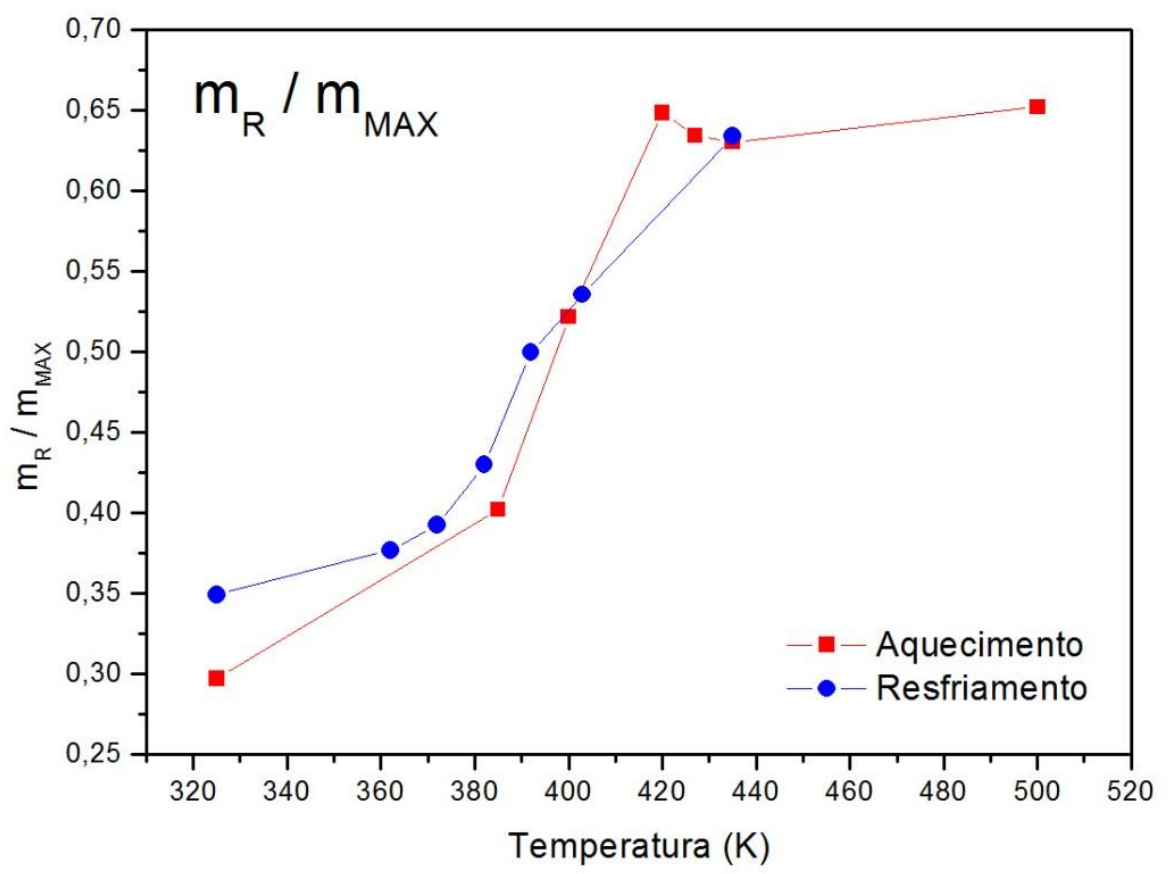

(b)

Figura 4-22. Amostra 2A: (a) Momentos magnéticos remanentes e (b) razão entre o momento magnético remanente e o momento magnético máximo. 


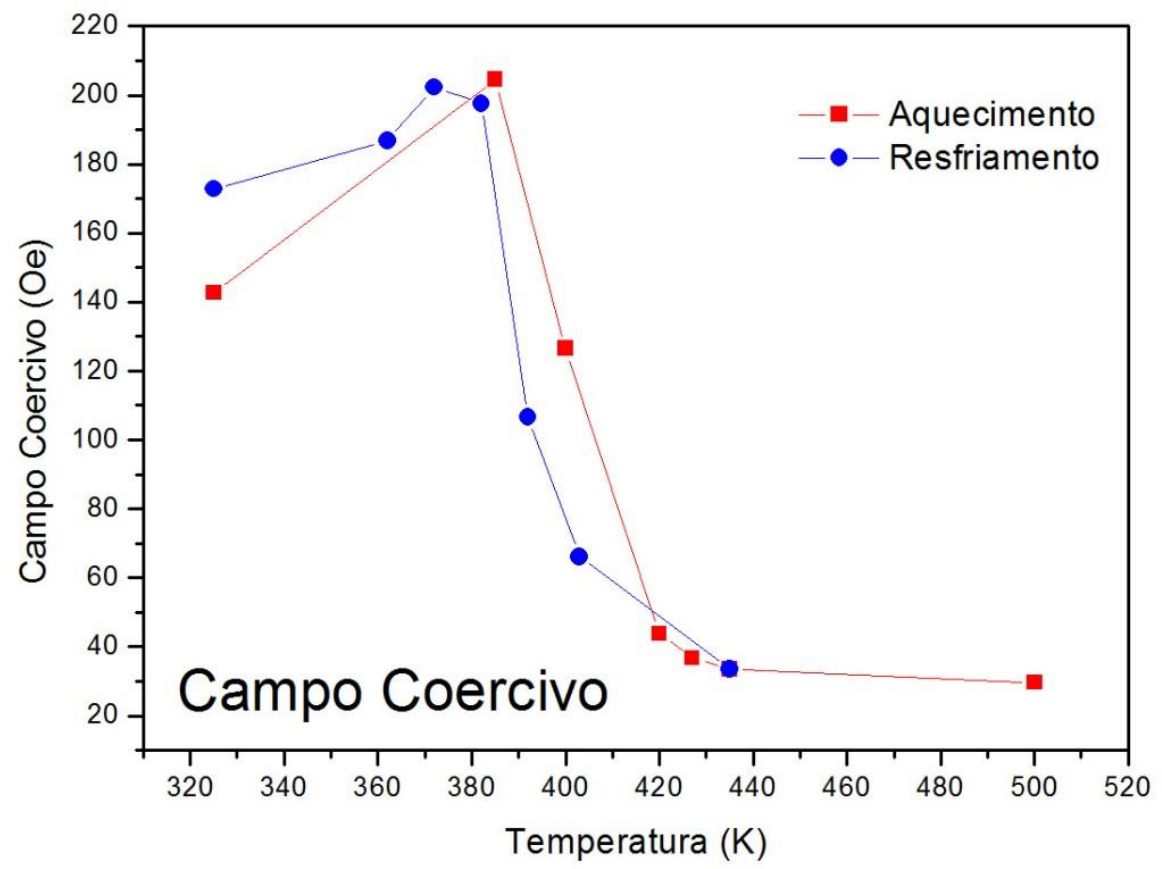

(a)

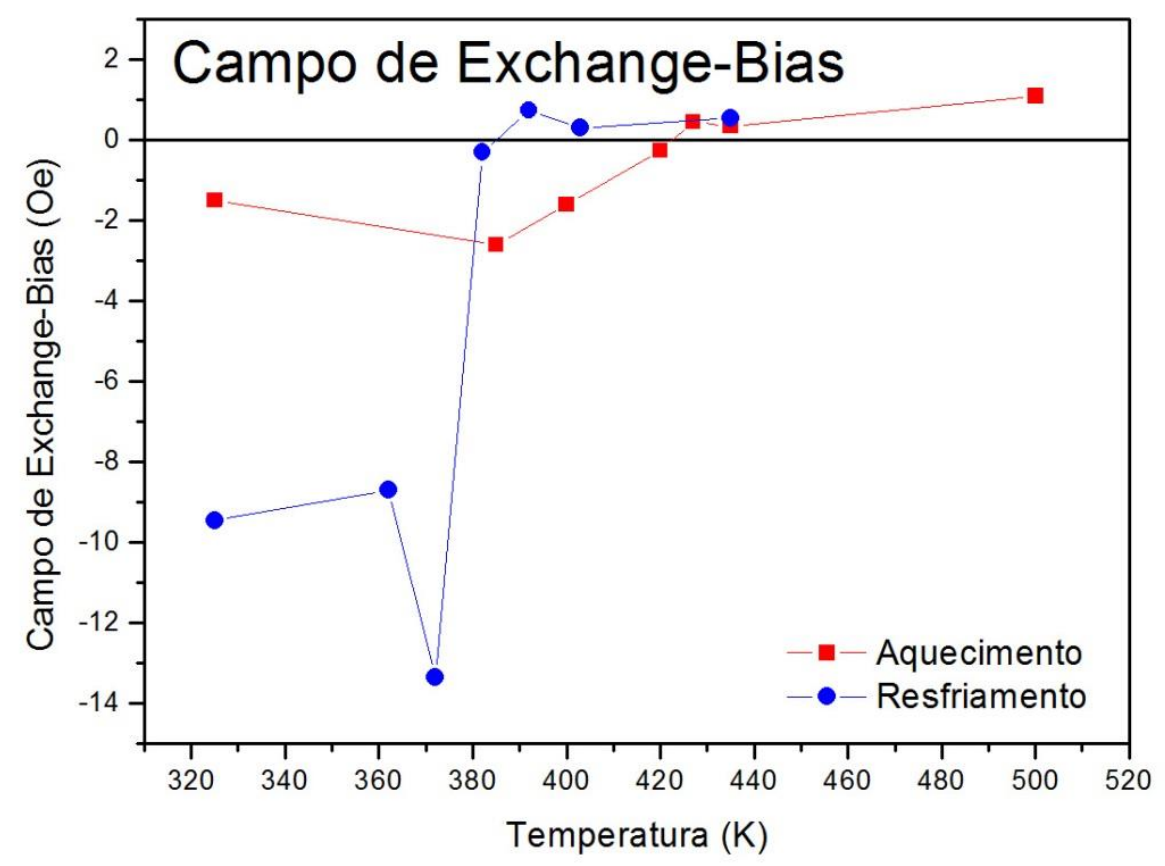

(b)

Figura 4-23. Amostra 2A: (a) Campos coercivos e (b) campos de exchange-bias. 


\subsection{Temperaturas de Curie}

Concluídas as caracterizações magnéticas das amostras, encerramos nosso estudo com novas medidas de momento magnético em função da temperatura, porém com temperaturas mais elevadas com a intenção de obtermos a temperatura de Curie das amostras monocamadas de FeRh.

Para ambas as amostras, 1B e 2B, não aplicamos campo magnético durante a medida, sendo observado uma grande flutuação do momento magnético, principalmente para temperaturas acima da temperatura de Curie. Os resultados obtidos encontram-se na Figura 4-24.

A amostra 1B, como se mostra na Figura 4-24 (a), apresentou um valor de $T_{C}$ de aproximadamente $700 \mathrm{~K}$. Por outro lado, a curva correspondente à amostra $2 \mathrm{~B}$ (Figura 4-24 (b)) mostra, inicialmente, a transição de fase AFM $\rightarrow$ FM, seguida por uma diminuição do momento magnético entre 460 e $625 \mathrm{~K}$, e depois uma abrupta remagnetização quando a amostra se aproxima ao estado crítico, o qual termina em um valor de $T_{C}$ de aproximadamente $660 \mathrm{~K}$. Os valores obtidos para as duas amostras diferem em aproximadamente $40 \mathrm{~K}$, e ambos são diferentes do valor correspondente a uma liga bulk de composição equiatômica, o qual é $T_{C}=675 \mathrm{~K}$. De todas maneiras, é conhecido que pequenas alterações na composição desta liga, acarretam diferentes valores na temperatura de Curie da fase FM. 


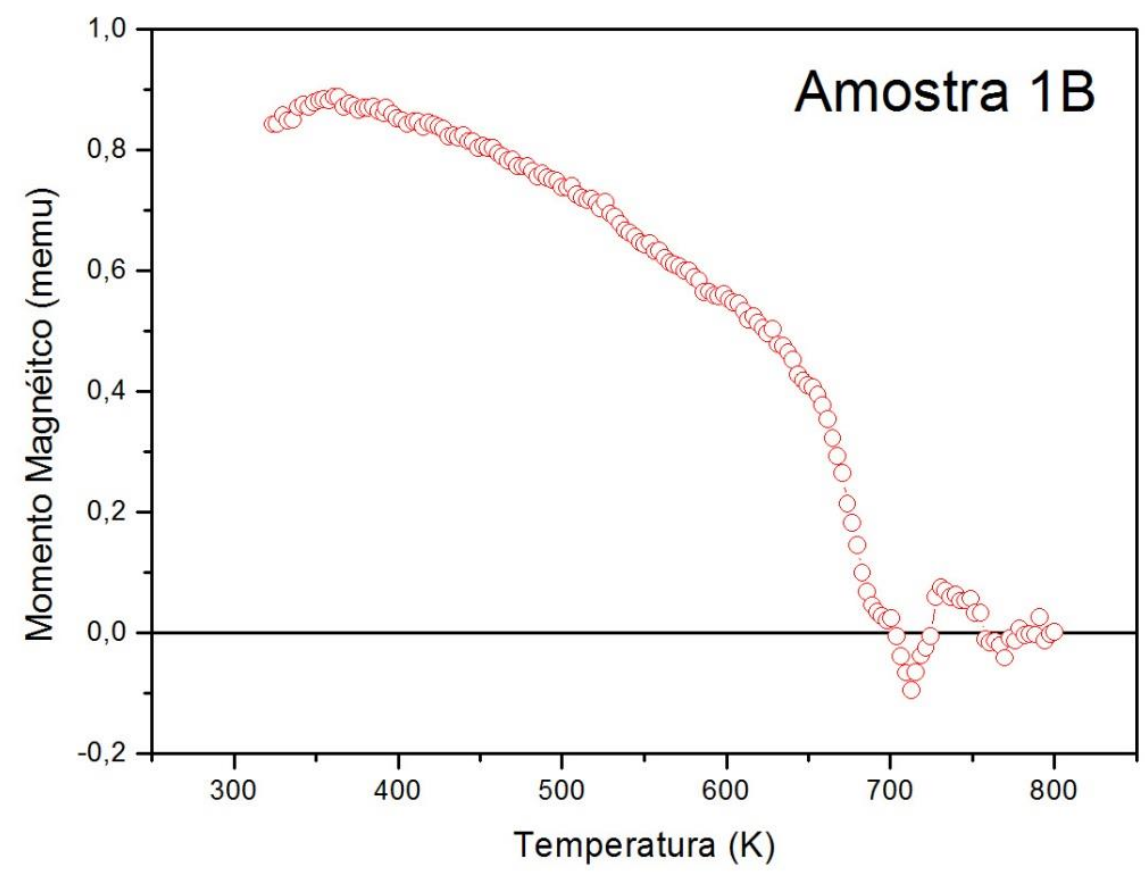

(a)

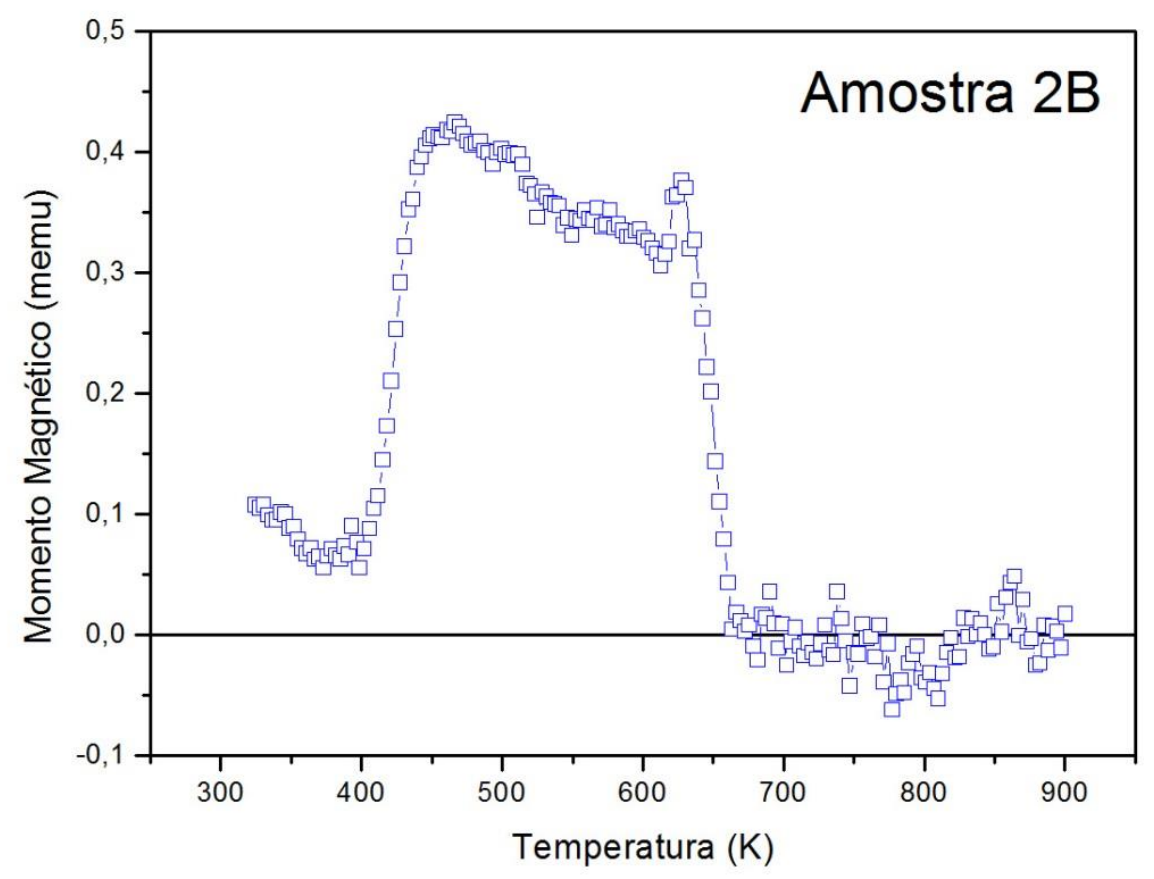

(b)

Figura 4-24. Gráfico de M vs T para a obtenção da Temperatura de Curie das amostra (a) 1B e (b) $2 B$. 


\section{Capítulo 5: Discussões e Conclusões}

Como foi mostrado na seção 1.3, a liga de FeRh apresenta uma transição de fase magnetoestrutural de primeira ordem, onde o material passa de um estado antiferromagnético para um estado ferromagnético, com uma temperatura crítica de transição próxima da temperatura ambiente. Esta temperatura é fortemente dependentes de fatores externos, em particular do campo magnético aplicado, e de fatores estruturais, como composição da liga de FeRh e dimensionalidade da amostra (amostra massiva, filmes, nanopartículas, etc.), sendo também dependente do método de produção.

Em nosso trabalho foram produzidos dois grupos de filmes finos, sendo utilizado para cada grupo um valor diferente de temperatura de deposição e de tratamento térmico, com a intensão de obter diferenças estruturais nas amostras e estudar as consequências destas diferenças nos comportamentos magnéticos delas. Em cada grupo, foram produzidas monocamadas de FeRh e bicamadas FeRh/Fe, com o intuito de estudar também o possível acoplamento entre ambas as camadas e os efeitos da transição de fase do FeRh nesse acoplamento. As amostras do grupo 1 foram depositadas com o substrato na temperatura de $798 \mathrm{~K}$, enquanto que para as amostras do grupo 2 a temperatura do substrato foi de $913 \mathrm{~K}$.

Com relação à composição da camada de FeRh foi obtida, para todas as amostras, uma composição próxima a equiatômica (ver Tabela 3-1). Também foram obtidas condições similares de espessura para todas as camadas dos filmes.

As diferentes técnicas de raios $X$ utilizadas mostraram que haviam pequenas diferenças estruturais entre os grupos. Os parâmetros de rede calculados, usando a varredura $\theta-2 \theta$ (ver Tabela 3-2) foram compatíveis entre todas as amostras, sendo $\sim 7 \%$ maiores que o valor correspondente ao material bulk de composição equiatômica. A partir desta mesma varredura também foram calculados os diâmetros médios de grão para os picos de espalhamento referentes ao plano (001), onde todas as amostras apresentaram diâmetros bastante similares entre elas (ver Tabela 3-3), com os valores em torno de $30 \mathrm{~nm}$. Podia-se esperar que a maior temperatura do substrato, maior fosse o tamanho de grão, mas aparentemente o efeito das tensões existentes entre filme e substrato, ao relaxar durante o resfriamento, compensaram 0 
efeito do tratamento térmico. Prosseguindo com as medidas de raios $X$, foram feitas medidas de varredura em $\phi$, onde foi observado em todas as amostras epitaxia entre a camada de FeRh e o substrato, sendo a célula unitária do FeRh rotacionada em 45ํ com relação à célula unitária do $\mathrm{MgO}$ (ver Figura 3-7). Concluímos estas caracterizações com as medidas tipo rocking curves, feitas para as amostras $1 \mathrm{~A}$ e $2 \mathrm{~A}$ nos planos (002) da camada de FeRh, onde obteve-se que a amostra $2 \mathrm{~A}$ possui uma melhor orientação de grãos comparado a amostra 1A, sendo isto relacionado ao tratamento térmico feito após a deposição do filme.

Desta forma, podemos concluir que as diferenças estruturais entre as amostras do grupo 1 e do grupo 2 se encontram na melhor distribuição de grãos obtida para as amostras do segundo grupo, ou seja, para as amostras que foram depositadas em uma temperatura mais elevada.

Passamos, posteriormente, a analisar as propriedades magnéticas das amostras, dando ênfase nas transições de fase. Desta forma as primeiras medidas a serem feitas foram as curvas ZFC - FC, onde analisamos as temperaturas críticas de transição, largura da transição e largura dos ciclos térmicos. Estas curvas foram feitas com campo de 100 Oe e 10 kOe aplicado, sendo verificado que a aplicação de campos mais intensos leva a uma diminuição das temperaturas críticas de transição. Foi observado também que o ciclo térmico correspondente a amostra 1B foi consideravelmente mais largo que o correspondente a amostra $2 \mathrm{~B}$. Isto sugere que na região de baixas temperaturas a amostra 1B pode apresentar quantidades relativas de fase FM metaestável maiores do que na amostra $2 \mathrm{~B}$.

Continuamos os estudos com medidas de ciclos de histerese realizados em diversas temperaturas, tanto nas regiões extremas onde é esperada a presença de uma fase dominante, quanto nas regiões de temperaturas onde acontecem as transições.

A amostra 1B, monocamada de FeRh depositada a $798 \mathrm{~K}$ sobre MgO (001), mostrou ciclos de histerese e coercividade altas ( 400 Oe) na região de baixas temperaturas, compatível com a presença de uma fase FM minoritária, porém com coercividade melhorada pela presença da fase AFM majoritária. Alguns desses ciclos (Figura 4-11) mostraram pequenos deslocamentos, mas sem um padrão definido, quando estudados em função da temperatura. Na região de altas temperaturas, depois da transição AFM $\rightarrow \mathrm{FM}$, a coercividade diminui até uns $40 \mathrm{Oe}$. Na amostra 2B, 
monocamada de FeRh depositada a $913 \mathrm{~K}$ sobre MgO (001), a análise dos ciclos de histerese (Figura 4-14) mostrou uma amostra menos coerciva na região de baixas temperaturas (campos coercivos da ordem de 90 Oe), porém com coercividades similares às da amostra 1B em altas temperaturas. Neste caso, foi observado um pico de coercividade, de uns 200 Oe, na região de temperaturas de transição. Novamente, não se verificaram deslocamentos apreciáveis dos ciclos de histerese nesta amostra. Da análise comparativa entre as amostras 1B e 2B, podemos deduzir que nas regiões de temperaturas onde há marcada coexistência de fases AFM e FM da liga FeRh, a coercividade do sistema é incrementada, um fato compatível com um acoplamento via exchange entre momentos magnéticos vizinhos de grãos com ordenamentos magnéticos diferentes. A magnetização remanente relativa mostrou valores menores que 0,5 na região de baixas temperaturas, e maiores do que 0,5 na zona de altas temperaturas, no entanto na amostra $1 \mathrm{~B}$ os valores de $m_{R} / m_{M A X}$ foram substancialmente maiores do que na amostra $2 \mathrm{~B}$, o que sugere que nesta última amostra as interações desmagnetizantes foram mais significativas do que na obtida a menor temperatura de deposição.

Em relação às bicamadas $\mathrm{FeRh} / \mathrm{Fe}$, houve também significativas diferenças no comportamento magnético entre a amostra depositada a $798 \mathrm{~K}(1 \mathrm{~A})$ e a depositada a $913 \mathrm{~K}(2 \mathrm{~A})$. A primeira delas mostrou ciclos de histerese compatíveis com um bom acoplamento magnético entre as camadas: curvas sem degraus na região de desmagnetização e com altos valores da magnetização remanente relativa. A coercividade desta bicamada, na zona de baixas temperaturas ficou em 200 Oe, aproximadamente, um valor intermediário entre o correspondente à monocamada de FeRh e a do filme de Fe. Como há evidência que nesta zona de baixa temperatura ainda existe uma componente FM minoritária na camada de FeRh (pelo observado na amostra 1B), em contato com a fase majoritária AFM, então a coercividade obtida e a forma do ciclo de histerese sugerem um comportamento do tipo exchange-spring na bicamada. Na zona de alta temperatura, por outro lado, os ciclos continuaram a mostrar bom acoplamento entre a camada de FeRh (que já se encontra predominantemente no estado FM) e a camada de Fe, mas a coercividade da bicamada diminuiu até uns $40 \mathrm{Oe}$, valor que coincide com o obtido na correspondente monocamada. Em relação ao campo de deslocamento dos ciclos de histerese, foi verificado que ele apresentou valores pequenos e negativos (de até uns -11 Oe), na região de tempe- 
raturas de transição, e para baixas temperaturas, reforçando a ideia de existir um possível acoplamento do tipo de exchange-bias entre a fase AFM do FeRh e a camada de Fe. Finalmente, a análise dos resultados obtidos na bicamada $2 \mathrm{~A}$ leva a pensar que para esta amostra não houve um bom acoplamento entre a camada de FeRh e a camada de Fe, já que a forma dos ciclos de histerese na região de baixas temperaturas mostrou dois degraus, e ainda os valores de remanência relativa foram bastante baixos. Para esta amostra, a coercividade mostrou um pico na região de temperaturas de transição, embora na região de baixas temperaturas a coercividade, de uns $160 \mathrm{Oe}$, foi maior que a correspondente à monocamada (90 Oe).

A modo de síntese das conclusões alcançadas neste trabalho segue abaixo um quadro mostrando os principais resultados obtidos das análises estruturais e magnéticas de forma resumida e comparativa.

\section{Caracterização Estrutural}

- Para ambas temperaturas de deposição foi obtido o crescimento epitaxial do filme de FeRh

- A temperatura de deposição mais elevada proporcionou uma melhor distribuição dos grãos cristalinos

\section{Caracterização Magnética}

Baixa temperatura de deposição

- Temperaturas críticas próximas da temperatura ambiente

- Extensas faixas de transição

- Forte acoplamento com a camada FM
Alta temperatura de deposição

- Temperaturas críticas acima da temperatura ambiente

- Pequenas faixas de transição

- Fraco acoplamento com a camada FM 


\subsection{Perspectivas}

Devido aos interessantes resultados magnéticos apresentados pelos dois grupos de amostras e a observação de estruturas cristalográficas muito similares, a continuação deste trabalho deverá envolver tanto novas medidas magnéticas como novas análises morfológicas. Particularmente, estamos interessados em obter imagens por microscopia eletrônica de transmissão das amostras usadas neste estudo, visando relacionar os distintos comportamentos magnéticos, obtidos pelas diferentes temperaturas de deposição, com a formação cristalina.

Pretendemos estender o nosso estudo sobre as interações magnéticas destes sistemas utilizando a metodologia FORC (First Order Reversal Curves), buscando uma melhor compreensão da coexistência de fases observada na liga de FeRh.

Também pretendemos estender nosso trabalho fazendo medidas de magnetorresistência, tanto nas monocamadas quanto nas bicamadas, e mudando o tipo de substrato utilizado, com o intuito de pesquisar a aplicabilidade de filmes de FeRh como possíveis sensores de campo. 


\section{Referências Bibliográficas}

[1] Fr. Heusler, W. Starck, E. Haupt, Verh DPG, 220 (1903)

[2] T. Graf, C. Felser, S. S. P. Parkin, Prog. in Solid State Chem., 39, 1 (2011)

[3] S. B. Roy, J. Phys.: Condens. Matter 25, 183201 (2013)

[4] T. Mukherjee, S. Michalski, R. Skomski, D. J. Sellmyer e Ch. Binek, Phys. Rev. B, 83, 214413 (2011)

[5] W. H. Meiklejohn e C. P. Bean, Phys. Rev., 102, 1413 (1956)

[6] J. Nogués e I. K. Schuller, J. Magn. Magn. Mater., 192, 203 (1999)

[7] J. Nogués, J. Sort, V. Langlais, V. Skumryev, S. Suriñach, J. S. Muñoz e M. D. Baró, Physics Reports, 422, 65 (2005)

[8] M. Getzlaff, Fundamentals of Magnetism, Ed. Springer (2008)

[9] W. H. Meiklejohn e C. P. Bean, Phys. Rev., 105, 904 (1957)

[10] D. Mauri, H. C. Siegmann, P. S. Bagus e E. Kay, J. Appl. Phys., 62, 3047 (1987)

[11] K. D. Sossmeier, D. Schafer, A. P. O. Bastos, J. E. Schmidt e J. Geshev, J. Appl. Phys., 112, 013904 (2012)

[12] R. Cichelero, A. Harres, K. D. Sossmeier, J. E. Schmidt e J. Geshev, J. Phys.: Condens. Matter, 25, 426001 (2013)

[13] M. Fallot, Ann. Phys., 10, 291 (1938)

[14] M. Fallot, R. Horcart, Rev. Sci., 77, 498 (1939)

[15] G. Shirane, C. W. Chen, P. A. Flinn e R. Nathans, Phys. Rev., 131, 183 (1963)

[16] L.J. Swartzendruber, Bulletin of Alloy Phase Diagrams Vol. 5 No. 5, 456 (1984)

[17] J. Balun, L. Eleno e J. Inden, Intermetallics 15, 1237 (2007)

[18] F. de Bergevin e L. Muldawer, Compt. Rend. 252, 1347 (1961) 
[19] J. S. Kouvel, J. Appl. Phys., 37, 1257 (1966)

[20] Y. Ohtani e I. Hatakeyama, J. Magn. Magn. Mater., 131, 339 (1994)

[21] J. M. Lommel, J. Appl. Phys., 37, 1483 (1966)

[22] J. S. Kouvel e C. C. Hartelious, J. Appl. Phys., 33, 1343 (1962)

[23] Y. Ohtani e I. Hatakeyama, J. Appl. Phys., 74, 3328 (1993)

[24] S. Maat, J.-U. Thiele e E. E. Fullerton, Phys. Rev. B, 72, 214432 (2005)

[25] Y. Ding, D.A. Arena, J. Dvorak, M. Ali, C.J. Kinane, C.H. Marrows, B.J. Hickey e L.H. Lewis, J. Appl. Phys., 103, 07B515 (2008)

[26] H. Y.Y. Ko, S. Inoue, N.T. Nam e T. Suzuki, IEEE Trans. Mag., 44, 2780 (2008)

[27] V. Kuncser, R. Nicula, U. Ponkratz, A. Jianu, M. Stir, E. Burkel e G. Filoti, J. Alloys Comp., 386, 8 (2005)

[28] H.Y.Y. Ko e T. Suzuki, J. Appl. Phys., 101, 09J103 (2007)

[29] Z. Jia, J. W. Harrell e R. D. K. Misra, Appl. Phys. Lett., 93, 022504 (2008)

[30] S. Inoue, N. N. Phuoc, J. Cao, N. T. Nam, H. Y. Y. Ko e T. Suzuki, J. Appl. Phys., 103, 07B312 (2008)

[31] J. Cao, N. T. Nam, S. Inoue, H. Y. Y. Ko, N. N. Phouc e T. Suzuki, J. Appl. Phys., 103, 07F501 (2008)

[32] M. Loving, F. Jimenez-Villacorta, B. Kaeswurm, D. A. Arena, C. H. Marrows e L. H. Lewis, J. Phys. D: Appl. Phys., 46, 162002 (2013)

[33] G. Shirane, R. Nathans e C. W. Chen, Phys. Rev., 134, A1547 (1964)

[34] T. Kawagoe, Y. Suzuki, M. Nývlt, J. Franta e N. Hosoito, Surface Science, 493, 721-730 (2001)

[35] R. E. Rottmayer, S. Batra, D. Buechel, W. A. Challener, J. Hohlfeld, Y. Kubota, L. Li, B. Lu, C. Mihalcea, K. Mountfield, K. Pelhos, C. Peng, T. Rausch, M. A. Seigler, D. Weller e X. Yang, IEEE Trans. Mag., 42, 2417 (2006)

[36] M. Sharma, H. M. Aarbogh, J. -U. Thiele, S. Maat, E. E. Fullerton e C. Leighton, J. Appl. Phys., 109,083913 (2011) 
[37] P.J. Kelly e R.D. Arnell, Vacuum 56, 159 - 172 (2000)

[38] Disponível em: <http://www2.if.usp.br/ lamfi/Hist.htm>. Acesso em Junho/2014

[39] M. H. Tabacniks, Análise de Filmes Finos por PIXE e RBS. Disponível em $<$ http://www2.if.usp.br/ lamfi/pixe\&rbs.pdf>. Acesso em Junho/2014

[40] B. D. Cullity, Elements of X-Ray Diffraction, Addison-Wesley Publishing Company (1956)

[41] U. Holzwarth e N. Gibson, Nature Nanothecnology, Vol. 6, 534 (2011)

[42] J. E. Mattson, Eric E. Fullerton, C. H. Sowers, e S. D. Bader, J. Vac. Sci. Technol. A 13(2), 276 (1995).

[43] S. Foner, Rev. Sci. Instrum. 27, 548 (1956)

[44] H. Kumar, M. C. A. Fantini e D. R. Cornejo, IEEE Trans. on Magn., 49, 4506 (2013)

[45] Disponível em: < http://home.rzg.mpg.de/ mam/>. Acesso em Junho/2014

[46] Disponível em: < http://www.genplot.com/>. Acesso em Junho/2014

[47] S. Inoue, H. Y. Y. Ko e T. Suzuki, IEEE Trans. on Magn., 44, 2875 (2008)

[48] M. Manekar, M. K. Chattopadhyay e S. B. Roy, J. Phys.: Condens. Matter, 23, 086001 (2011)

[49] H. Kumar, Relatório FAPESP, processo oํ 2010/18590 (2013) - Não publicado.

[50] E. E. Fullerton, J. S. Jiang, M. Grimsditch, C. H. Sowers e S. D. Bader, Phisical Review B, 58, 12193 (1997)

[51] J.-U. Thiele, S. Maat e E. E. Fullerton, Appl. Phys. Lett., 82, 2859 (2003) 